\title{
Choosing Urban Elements: \\ Interdisciplinary Participation in the \\ Preston Street Reconstruction Project
}

\author{
by \\ Maria Gabriela Sanches \\ A thesis submitted to \\ the Faculty of Graduate and Postdoctoral Affairs \\ in partial fulfillment of the requirements for the degree of \\ Master of Design \\ in \\ Industrial Design
}

Carleton University

Ottawa, Ontario

C 2011, Maria Gabriela Sanches 
Library and Archives

Canada

Published Heritage

Branch

395 Wellington Street

Ottawa ON K1A ON4

Canada
Bibliothèque et

Archives Canada

Direction du

Patrimoine de l'édition

395 , rue Wellington

Ottawa ON K1A ON4

Canada
Your file Votre référence

ISBN: 978-0-494-87850-7

Our file Notre référence

ISBN: 978-0-494-87850-7

\section{NOTICE:}

The author has granted a nonexclusive license allowing Library and Archives Canada to reproduce, publish, archive, preserve, conserve, communicate to the public by telecommunication or on the Internet, loan, distrbute and sell theses worldwide, for commercial or noncommercial purposes, in microform, paper, electronic and/or any other formats.

The author retains copyright ownership and moral rights in this thesis. Neither the thesis nor substantial extracts from it may be printed or otherwise reproduced without the author's permission.
AVIS:

L'auteur a accordé une licence non exclusive permettant à la Bibliothèque et Archives Canada de reproduire, publier, archiver, sauvegarder, conserver, transmettre au public par télécommunication ou par l'Internet, prêter, distribuer et vendre des thèses partout dans le monde, à des fins commerciales ou autres, sur support microforme, papier, électronique et/ou autres formats.

L'auteur conserve la propriété du droit d'auteur et des droits moraux qui protege cette thèse. $\mathrm{Ni}$ la thèse ni des extraits substantiels de celle-ci ne doivent être imprimés ou autrement reproduits sans son autorisation.
In compliance with the Canadian Privacy Act some supporting forms may have been removed from this thesis.

While these forms may be included in the document page count, their removal does not represent any loss of content from the thesis.
Conformément à la loi canadienne sur la protection de la vie privée, quelques formulaires secondaires ont été enlevés de cette thèse.

Bien que ces formulaires aient inclus dans la pagination, il n'y aura aucun contenu manquant. 


\begin{abstract}
This research presents a case study of the choice of urban elements in the Preston Street rehabilitation process. In order to investigate how participatory design methods can enhance the development of urban elements and what roles industrial designers can assume in this sort of project, three research methods were utilized: interviews with stakeholders, surveys with the general public and archival research. Noticing that industrial designers were not among the stakeholders in the process, the researcher explored ways to support their involvement in design discussions in connection with elements in urban spaces. Final considerations suggest that designers can contribute to the development of urban elements including public art, the facilitation of interdisciplinary design development groups, the research of the users' needs, and the creation of policies concerning design activity in Ottawa. Such recommendations are regarded as strategies to foster the creation and selection of urban elements through participatory design methods.
\end{abstract}

Keywords: design of urban elements, interdisciplinary design development, public design participation, public art, street furniture 


\section{ACKNOWLEDGEMENTS}

First of all, I would like to thank Professor Lois Frankel for her complete support, incentive and availability. I really appreciate the time she took to read my work, edit it, and help me connect the ideas until they made sense as a whole. Thanks to Professor Benjamin Gianni, who pushed me to assume new challenges and obtain the best results possible. Thanks also to Professor Brian Given for unveiling to me a new world of anthropological symbols. My gratitude goes as well to the program graduate administrator Valerie Daley for solving all sorts of bureaucratic problems and making this research possible.

Thanks to all participants in the interviews and surveys for dedicating their time to this study. I deeply admire their efforts to improve the urban life and, above all, their love for urban spaces.

I could not omit my appreciation to my family, my mother, and my sisters for encouraging me and cheering me on even from a distance. Always motivating me from closer were also my fellow MDES students. Thank you, guys!

Finally, thanks to Lucas Lacerda with whom I had endless discussions about this thesis. He is a true partner in all aspects of my life. 


\section{TABLE OF CONTENTS}

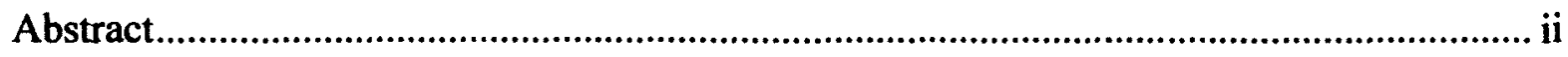

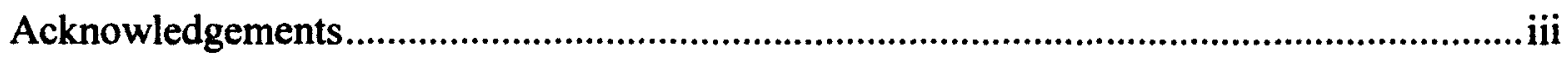

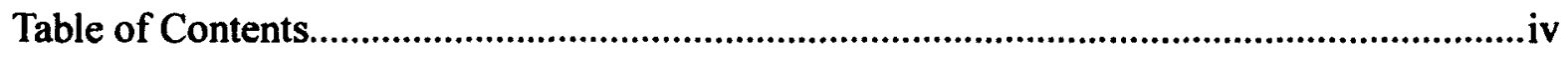

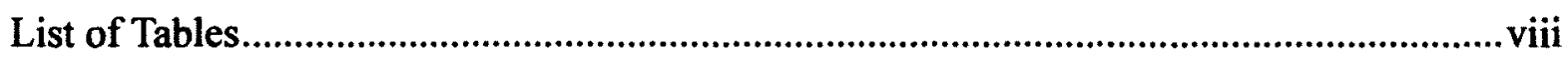

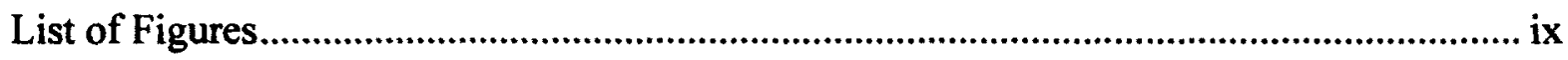

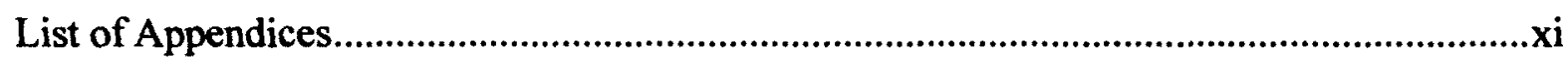

\section{CHAPTER}

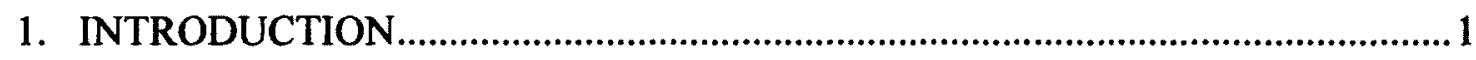

1.1 Preston Street Rehabilitation.............................................................................

1.1.1 Postcards from the Piazzas..................................................................... 2

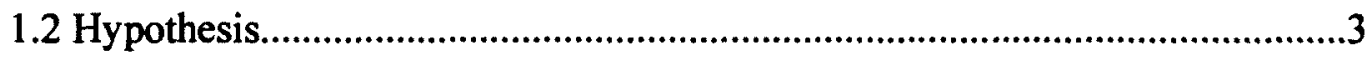

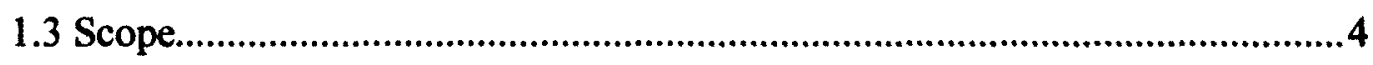

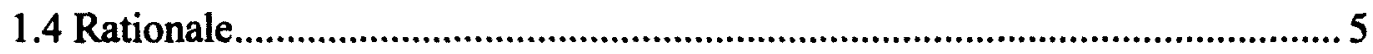

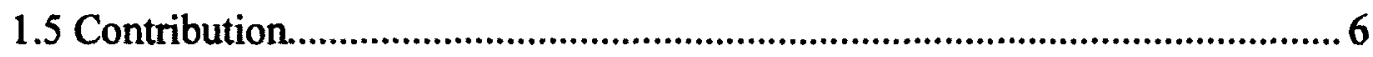

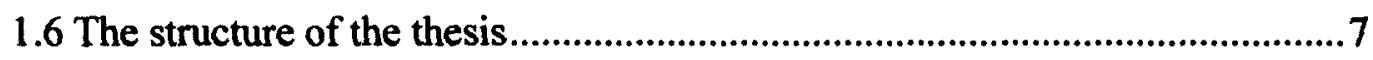

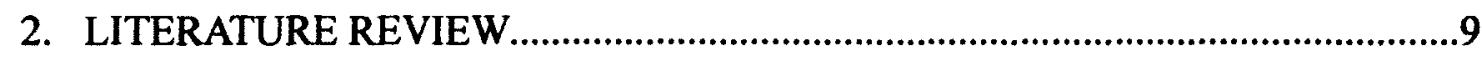

2.1 The success of urban spaces.............................................................................11

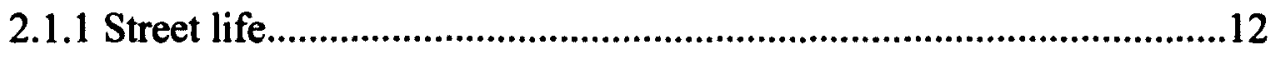

2.2 The urban experience.................................................................................... 13 
2.2.1 Symbolic meanings in the built environment..................................... 13

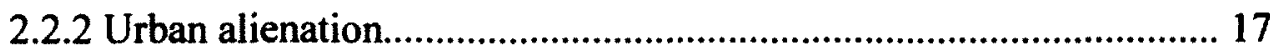

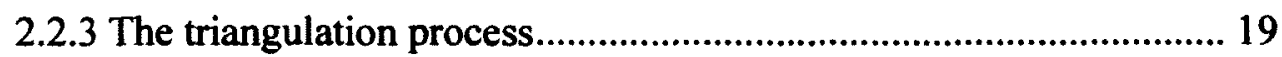

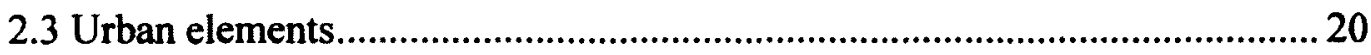

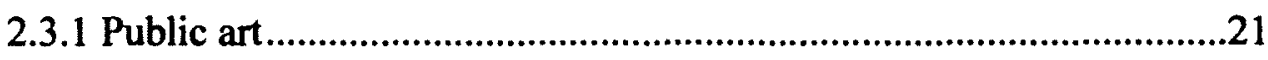

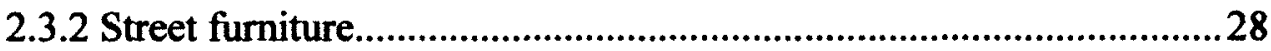

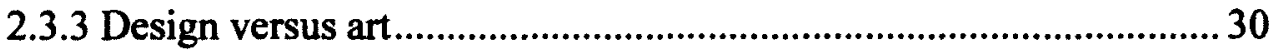

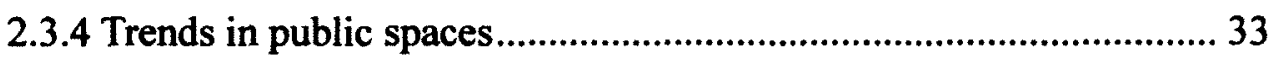

2.4 Participatory design research processes............................................................37

2.4.1 Public, community and design participation.......................................40

2.4.2 An interdisciplinary activity .............................................................42

2.4.3 Evaluating the performance of designed environments......................43

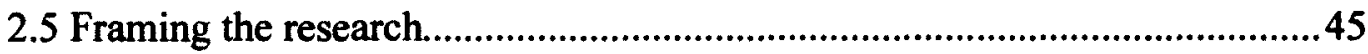

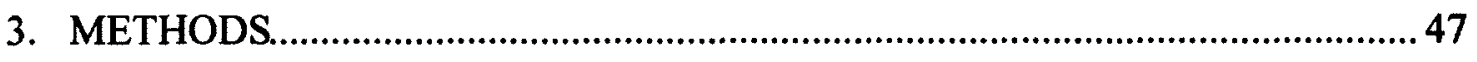

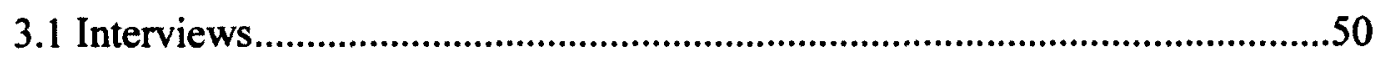

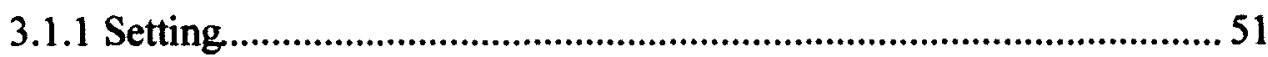

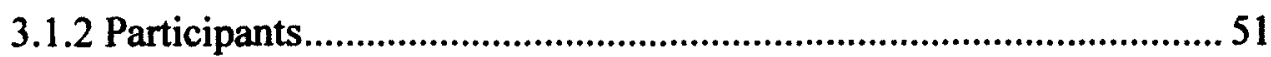

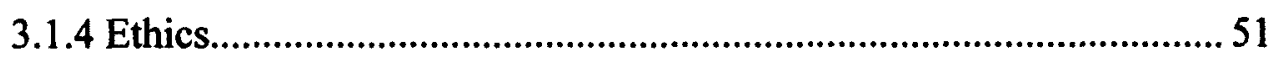

3.1.5 Data collection procedures.............................................................. 52

3.1.6 Data analysis..................................................................................53

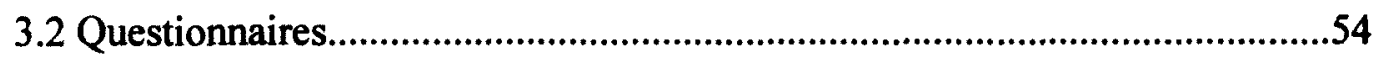

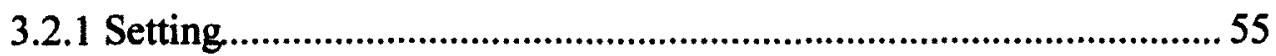

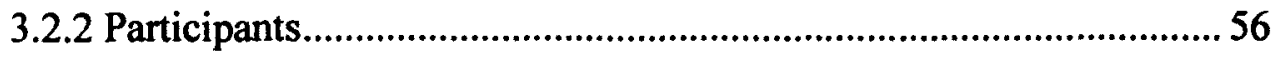




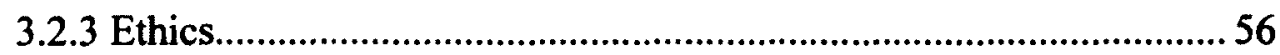

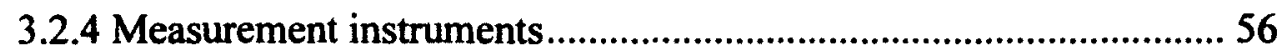

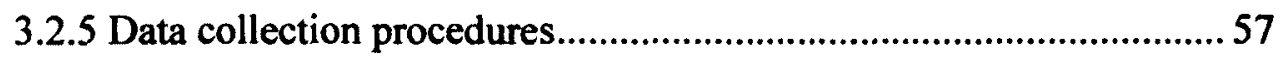

3.2.6 Data analysis ..................................................................................59

3.3 Archival research........................................................................................59

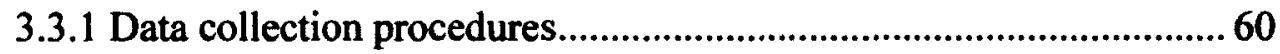

3.3.2 Data analysis ...............................................................................61

4. RESULTS.

4.1. Overview of the results..................................................................................64

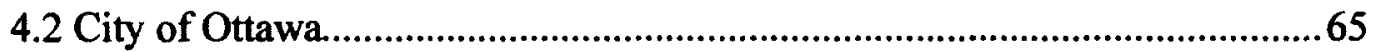

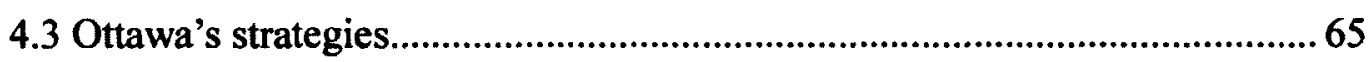

4.3.1 Public Art Program and the Percent for Art policy .............................65

4.3.2 Integrated Street Furniture Program.....................................................67

4.4 Preston Street rehabilitation................................................................................68

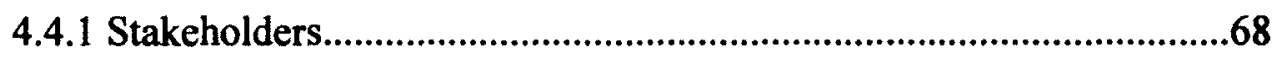

4.4.2 Possible roles for designers............................................................. 71

4.4.3 The community-based art process...................................................... 72

4.5 The general public's perspective....................................................................... 74

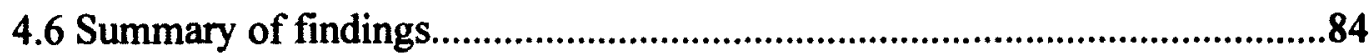

5. DISCUSSION

5.1 The system of meanings associated to participatory processes..............86

5.2 Increasing user participation................................................................ 90

5.3 Including industrial designers.............................................................. 92 
5.4 Additional roles for industrial designers.....................................96

5.5 Bringing industrial design to urban spaces...................................97

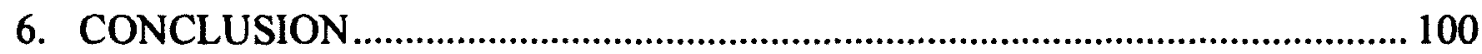

6.1 Research questions.............................................................. 100

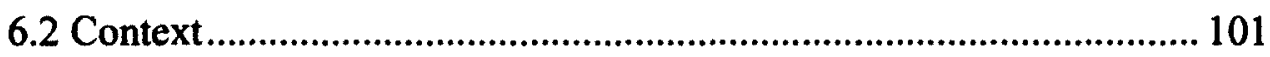

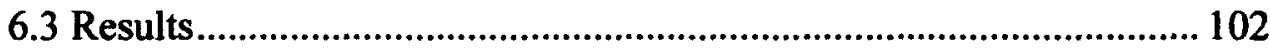

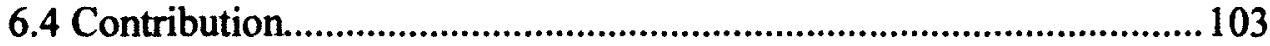

6.5 Possible directions for future research.........................................105

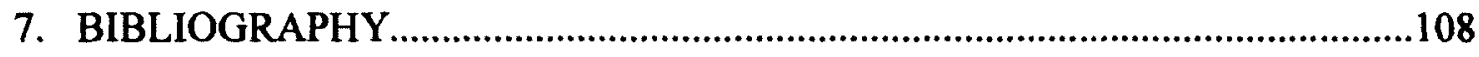

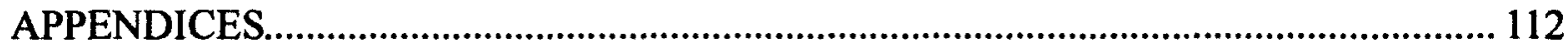




\section{LIST OF TABLES}

Table

Page

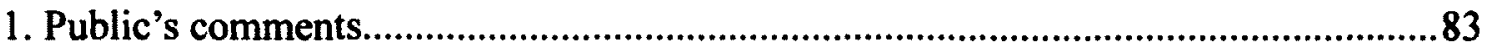




\section{LIST OF FIGURES}

Figure

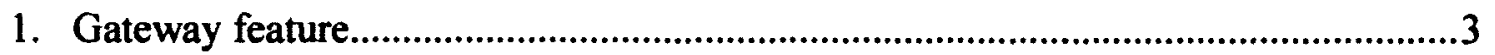

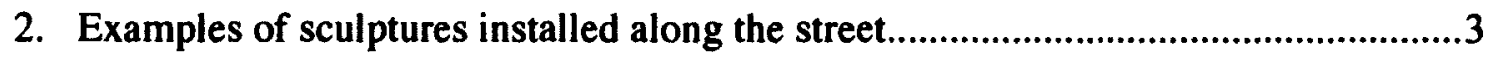

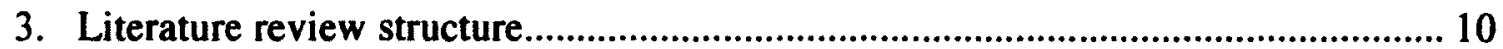

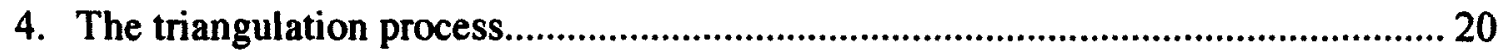

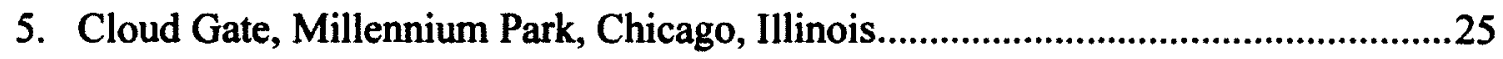

6. Crown Fountain, Millennium Park, Chicago, Illinois........................................ 27

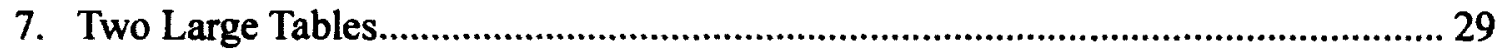

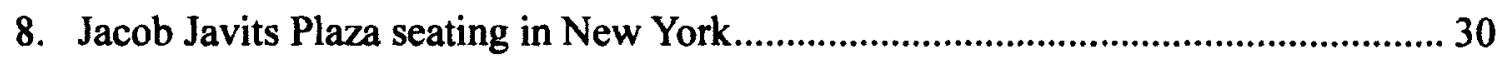

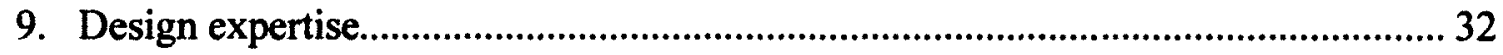

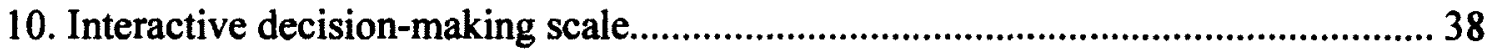

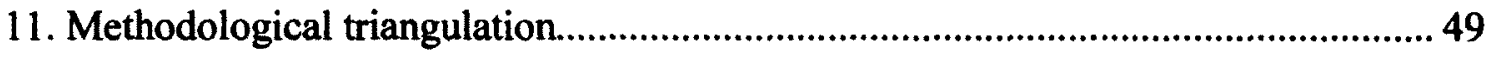

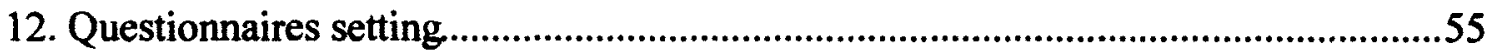

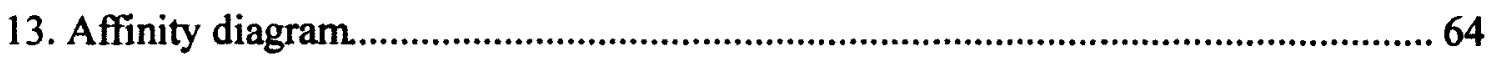

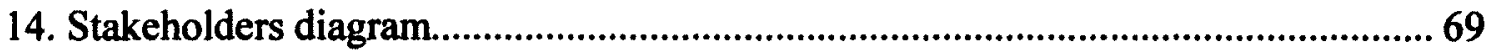

15. Participants' relation to Preston Street............................................................. 74

16. Time spent per week in Preston Street's public outdoor spaces.............................75

17. Activities performed in Preston Street's outdoor spaces....................................76

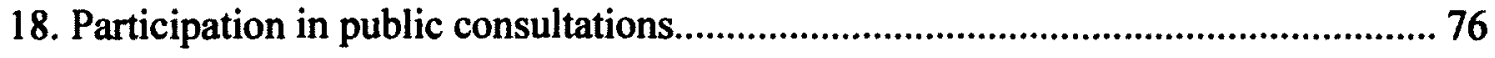

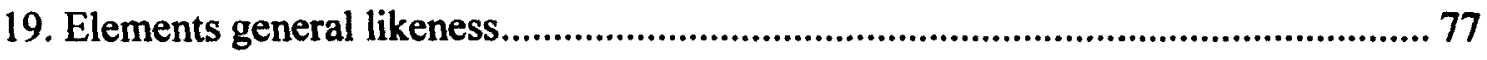




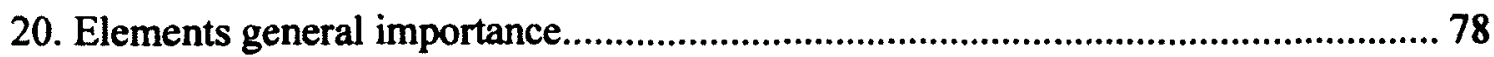

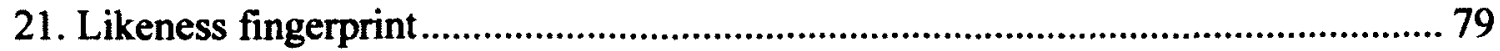

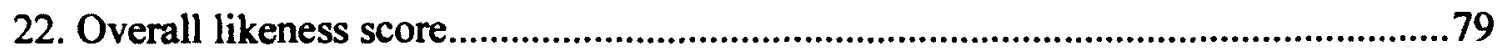

23. Beauty scale

24. Pleasure scale

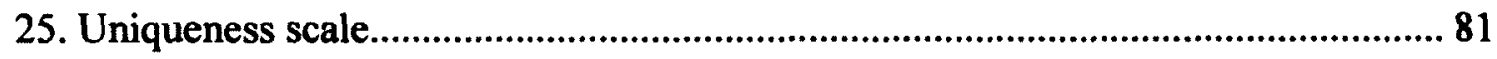

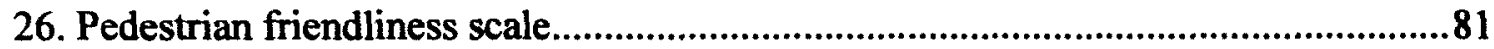

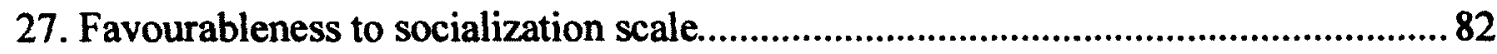

28. Industrial design as a midpoint between art and design.............................................94

29. Similarities between requirements for public art and design.................................... 95 


\section{LIST OF APPENDICES}

Appendix A Postcards from the Piazzas brochure..................................................................115

Appendix B Interact and Include paper........................................................................120

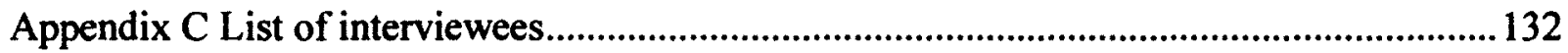

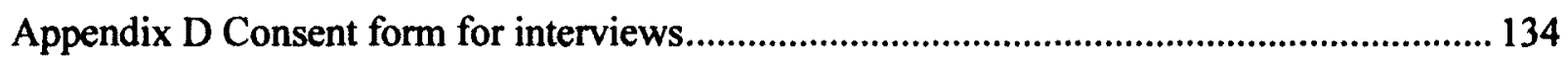

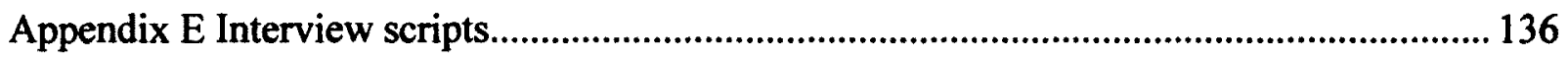

Appendix F Participants' perceptions of the process................................................................ 149

Appendix G Consent form for surveys....................................................................... 152

Appendix H Overall likeness score and likeness fingerprint formula.....................................155

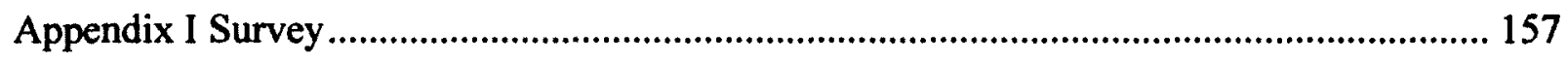

Appendix J List of archival research documents............................................................... 160

Appendix K Comparisons between residents, visitors and employees.................................... 162 


\section{CHAPTER 1}

\section{INTRODUCTION}

This case study analyzes the Preston Street rehabilitation process. Preston Street, or the Corso Italia, is the site of Ottawa's historic Italian neighbourhood (City of Ottawa, n.d.a). The street was subjected to a recent reconstruction action that would improve its sewage and water draining systems as well as enhance its streetscape features. The investigation examined the interdisciplinary participatory process of selection and development of the urban elements which were installed in this public space. The idea was to understand how decisions were made and what roles, if any, industrial designers would assume in this context.

\subsection{Preston Street Rehabilitation}

Preston Street is an arterial road in the city's west end (City of Ottawa, n.d.d.). Marked by a noteworthy landmark archway at its southern entrance, it connects Dow's Lake and the LeBreton Flats area. In recent years, in attempting to satisfy the community's demands, the city identified the need to improve several aspects of the street including the area's water and sewer systems to prevent basement flooding (City of Ottawa, n.d.e).

The rehabilitation project involved infrastructure, landscaping, and public art components as well as engineers, landscape architects and artists. It was expected to fulfill specific requirements defined by the City of Ottawa (City of Ottawa, n.d.e). First, the existing water mains and street's sanitary and storm sewers were replaced. In addition, the road surface was 
replaced. This comprised the construction of new curbs and the widening of the sidewalks.

Finally, a streetscaping study previously conducted was implemented.

By the end of 2010, the construction work was mostly completed (City of Ottawa, n.d.e). Minor deficiencies should be executed in the 2011 construction season. Still in the same year, a new gateway feature is expected to be installed at the intersection of Gladstone and Preston.

\subsubsection{Postcards from the Piazzas}

A significant portion of the rehabilitation process was attributed to public art. Since Ottawa's Public Art Program has established a Percent for Art policy, "one percent of funds for municipal development projects is set aside in order to beautify spaces and make art accessible to everyone" (City of Ottawa, 2010a).

'Postcards from the Piazzas', a set of sculptures created by the artist cj fleury, was selected from among other proposals to complement the Preston Street's streetscaping project. In total, 15 sculptures were installed along the street. The pieces were supposed to be human scaled so that people could "meet the art just as they might meet someone face to face" (Dawson, 2010). The concept refers to postcards and letters which can establish a connection between the 'old country' and Ottawa's Little Italy (Dawson, 2010).

A pair of artefacts at Primrose Street function as a gateway to the street (Figure 1) and other pieces consisting of granite columns with cast elements on the top (Figure 2) are placed at intervals along the streescape. Each element of the latter group alludes to a different Italian theme, being inspired by specific piazzas in various regions of Italy (Dawson, 2010). The input of the local community in a collaborative process distinguished this project from other public art 
installations in the city. For more information regarding 'Postcards from the Piazzas', consult Appendix A.

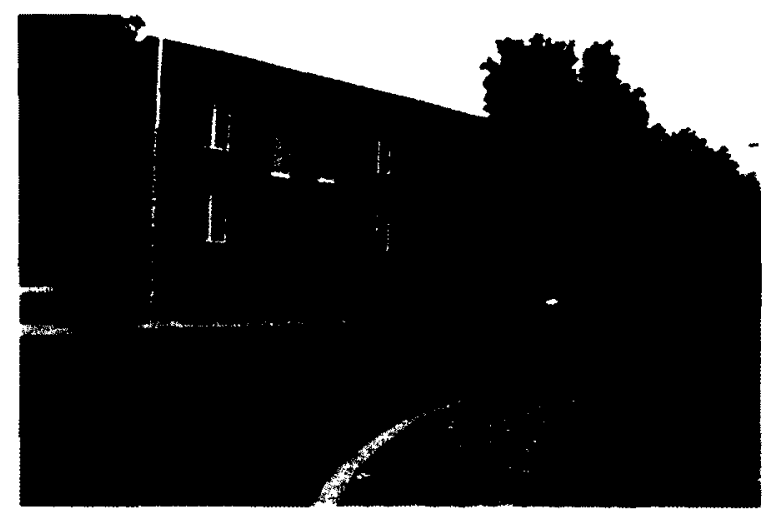

Figure 1. Gateway feature
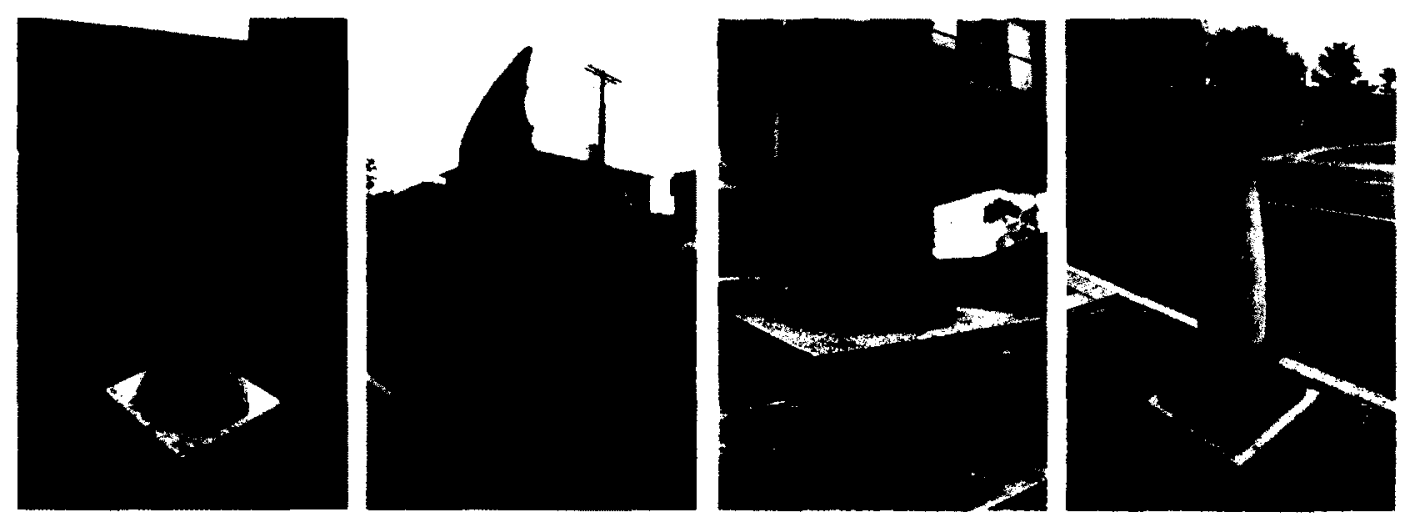

Figure 2. Examples of sculptures installed along the street

\subsection{Hypothesis}

There seems to be an increasing awareness in the design literature about the importance of public participation in projects for spaces which significantly affect citizens' lives. However, professionals who are involved in actual participatory processes in the area of industrial design experience barriers on a daily basis as noted by researchers (Sanders \& Stappers, 2008; Sanders 
\& Simons, 2009; Sleeswijk Visser, 2009). This study intended to explore through a case study how interdisciplinary participatory processes may foster the development and selection of urban elements, that is, the artefacts that are placed in urban spaces. Furthermore, it aimed to explore the roles which industrial design would assume in this context.

Observing that no industrial designer was involved in the development of the Preston Street project and assuming that their interdisciplinary knowledge could contribute to many aspects of the process, the researcher slightly changed the focus of the investigation. It seemed more appropriate to question how to include designers and improve the interdisciplinary process. Also, it became important to analyze ways to achieve more user participation and acquire results that would be as meaningful to the population as to the stakeholders.

\subsection{Scope}

The scope of this investigation embraces participatory processes which focus on public urban spaces and, especially, on the urban elements. Such projects are usually interdisciplinary, which requires that the researcher look at other discipline's perspectives on the topic in order to identify the space that industrial design could occupy. Accordingly, design research, urban planning, anthropology, and art theories were the source of criteria for the analysis.

The study did not intend, however, to invade such disciplines' spaces by developing new theories of urban spaces, semiotics or public art. It simply aimed to understand public participation and public spaces through diverse lenses and, then, focus on aspects where industrial design can enhance public life. That said, the research represents the analysis of such processes from an industrial designer's point of view. It seems appropriate to clarify 
straightaway that the terms design and designer in this thesis will therefore represent the referred instance of design activity, except when indicated.

\subsection{Rationale}

Public spaces are acquiring crucial importance nowadays. The reduction of the average size of the household and the changes in the work place, where jobs are more and more repetitious and mechanized (Gehl, 1989: 12,14) are some of the reasons why urban areas assume at present new functions, becoming places for socialization, recreation, and leisure. This might be seen as an opportunity for cities to offer opportunities for significant experiences outside the home and the work place (Gehl, 1989: 14). City streets and plazas, the small urban spaces, deserve special attention in this context. They are the 'stages' where everyday life happens, and, for this reason, they should be always available (Gehl, 1989: 17) and prepared to fulfill the population's needs.

Urban elements, artefacts which are placed in these spaces, are therefore fundamental in the study. Being either pieces of urban furniture or artwork, they are capable of strongly influencing the way people experience spaces (Main \& Hannah, 2010: 4). The literature dedicated to such artefacts is to some extent limited. On the one hand, cities are interested in branding themselves and offering pleasurable memorable spaces for city dwellers and tourists. On the other hand, urban elements, especially pieces of street furniture are in many instances regarded with some indifference by many researchers, planners and even users. According to Siu, "there is a lack of serious and in-depth studies on public design, in particular regarding the areas related to local needs and lifestyles" (Siu, 2009: 87). This is another reason for developing 
studies which can demonstrate their importance while expanding the body of knowledge connected with the topic.

\subsection{Contribution}

The study was intended to benefit all stakeholders in the process. Urban planners, engineers, landscape architects, politicians, artists, industrial designers, and members of the community might be interested in having access to an informed outsider's perspective. The understanding of the overall system may clarify aspects that can be improved for the next projects. By means of this study, the lessons learned by the people involved might reach other professionals who can apply the knowledge generated by this specific experience in other related circumstances.

By introducing this multifaceted approach, the research intended to suggest recommendations to enhance interdisciplinary collaboration. Furthermore, from a design researcher's point of view, the analysis attempted to point to new directions that industrial designers can follow. With the purpose of contributing to creating public spaces capable of providing pleasurable urban experiences, they might be involved in the planning and the decision making processes.

The study will possibly draw researchers' and professionals' attention to elements which offer the potential to foster people's experiences in public spaces. In fact, the investigation aimed to emphasize the importance of the design of the urban elements in contributing to the way users perceive the urban environment. 


\subsection{The structure of the thesis}

In this first chapter, the project which is the object of the case study is presented. The hypothesis and the scope of the research are also defined. The participatory approach is described as an essential element of the analysis which aims to grasp how everyday users are involved in the decisions regarding an actual public project. Moreover, the rationale for such a scrutiny as well as the contribution that it could offer to the design field are revealed.

The second chapter is a literature review, which provides the theoretical framework for the analysis. Theories about design research, urban planning, and social sciences are discussed as possible structures to support the analysis of the case study. Symbolic meanings in the built environment and public art cases provide contextual awareness that contributes to a better understanding of the topic. In addition, post-occupancy evaluation, inclusivity and the triangulation process in public spaces emerge as possible criteria to assess the rehabilitation project.

The methods employed in the research are uncovered in the third chapter. With the purpose of supporting the precise development of the study each measurement instrument is described in detail. In fact, both qualitative and quantitative methods were utilized. Interviews, surveys and archival research are discussed in terms of setting, sampling, data collection procedures and data analysis. Together, the three processes promoted a necessary methodological triangulation, which provided the researcher with a more global view of the problem. Needless to say, they were based on the theoretical background gathered from the diverse disciplines previously mentioned. 
Findings are presented in the fourth chapter. Data collected were organized according to categories which evolved in the data analysis process. The chapter provides a general perspective of the City of Ottawa context as well as its strategies and policies connected with public art and design. Furthermore, the Preston Street rehabilitation process was scrutinized. An extensive list of stakeholders involved in the project was disclosed. Their opinions about design and the roles designers may assume were also included. The participatory art method explored by the artist cj fleury was also explored. Lastly, the general public's perceptions of the results of the reconstruction were analyzed.

In the fifth chapter, the discussion generated by the results is revealed. In an effort to answer the research questions, the researcher integrated the theoretical framework consolidated in the literature review with the facts and evidence collected in the investigation process. The idea was to formulate possible answers or at least a dialogue concerning the main inquiries identified by the study. Recommendations for future design practice and research were also developed.

Finally, conclusions of this extensive analysis are drawn in the last chapter. The most important points of the research were emphasized in this section. The researcher reflects on the findings and contributions of the study. Overall, the chapter functions as a summary of the study which highlights the lessons learned during the investigation process. 


\section{CHAPTER 2}

\section{LITERATURE REVIEW}

The following sections comprise the fields of knowledge from which the research questions evolved. The main arguments gathered from diverse disciplines were summarized and condensed under four leading topics: the success of urban spaces; the urban experience; urban elements; and design research processes.

Urban spaces figure as the context of the present research. It makes sense thus to start with a general discussion regarding how such areas have been regarded by scholars and how their views have developed through time. The theories presented in this section draw from urban planning, urban design, and architecture. Such disciplines have extensively discussed why some urban spaces are considered successful whereas others remain abandoned or underused.

The way people react to spaces is also strongly relevant to research which is concerned with the experience urban elements may provide. This is what the second section of this chapter explores. By observing the symbolic meanings the city elements may acquire along with topics such as urban alienation and interaction in public spaces, the study intends to make sense of how the general public perceive urban spaces and what factors influence their experience. This section incorporates concepts developed by anthropologists, urban planners and architects, and design researchers.

The artefacts which occupy urban spaces are discussed in the third portion of the chapter. They are the ultimate tools designers can utilize to transform urban spaces. This section debates public art and the public's reaction to some specific artworks, the role of the industrial designer 
in such a context, street furniture, and trends in urban spaces. It incorporates art history and design principles.

The next section touches on the design research methods which have been used to study the urban realm. Public participation emerges as a movement which is not recent but continues to be discussed in view of the difficulty professionals face when applying its principles to actual projects. The section reviews the different stages of participation and finishes with postoccupancy evaluation, which might be regarded as a phase of the participatory process as well. The method which originated from collaborations between architecture and environmental psychology was developed to assess the performance of buildings after their completion. It is particularly appropriate for this study which addresses a project recently undertaken and with no post-evaluation in any dimension.

The last section summarizes the theoretical framework presented in the chapter in research questions which could be answered by the study. By analyzing the literature related to the research topic, the researcher formulates the inquiries which would guide the data gathering process. Figure 3 graphically represents the literature review structure.

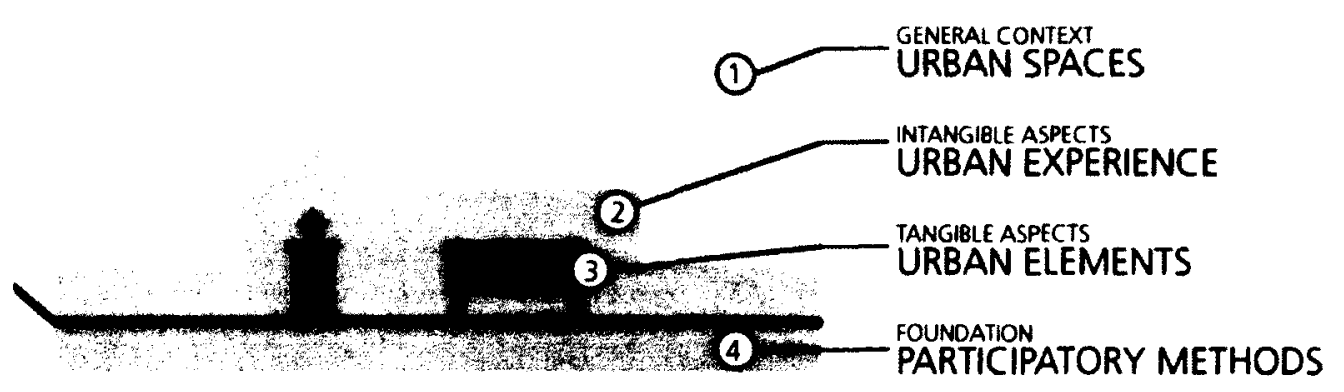

Figure 3. Literature review structure 


\subsection{The success of urban spaces}

Urban public spaces should be utilized, occupied and enjoyed by the whole population. Every city dweller has the right to appropriate these areas, explore their attributes and also take responsibility for them. It is not rare, nonetheless, to encounter misused and even abandoned streets, plazas, and squares in most of the major cities in the world (Gehl, 2003; Trancik, 1986; Whyte, 1988).

The success of urban spaces has been attributed to many different factors. Both Whyte $(1980,1988)$ and Jacobs (1962) agree that people attract people. The question would, thus, be how to attract people? Vegetation, water, and nature in general are often noted with pleasure (Hildebrand, 1999; Lynch, 1960; Whyte, 1980) as well as the sun (Whyte, 1980, 1988). Food availability is also very important, but sitting space is a prerequisite (Whyte, 1980). In fact, Jacobs (1962) believes that what turns streets into popular and interesting places is the diversity, which is achieved when districts serve more than one primary function such as work, commerce, leisure or residence, and feature short blocks with buildings of varied age and condition. This diversity would probably increase a city's imageability, "that quality in a physical object which gives it a high probability of evoking a strong image in any given observer" (Lynch, 1960: 9). According to Lynch (1960: 5), a distinctive and legible environment is capable of heightening "the potential depth and intensity of human experience."

Urban spaces are the scenario of the study. Given that supporting the success of these spaces is one of the goals of the investigation, it is crucial to understand the factors that influence the prosperity of public areas. Even though Whyte (1980) emphasizes the importance of sitting spaces, little attention is attributed to the design of such elements. At the same time, the 
remaining authors rarely connect urban objects to the quality of the experience that spaces can offer.

\subsubsection{Street life}

At present, much of the attention on urban spaces has been turned to streets and squares. These small public spaces may be seen as "the urban parks of this century - much needed amenities which ought to be generally available" (Gehl, 1989: 17). Jacobs (1962: 29) believes that "streets and their sidewalks, the main public places of a city, are its most vital organs". Whyte (1988: 101) adds that even though people normally assume that children play in the streets for lack of playgrounds, they play in the streets "because they like to".

In this sense, streets become more than a space for cars. They assume the role of providing opportunities for socialization and leisure, personal and collective satisfaction. Changes in the size of the households and in the work place mean that "social and creative opportunities offered outside the home and work place are gaining increased importance" (Gehl, 1989: 14). It is in the small spaces of the city that people share "goods, talents and opinions" (Gehl, 1989: 15). Furthermore, city streets and squares function as "a public forum for a very wide range of direct communication and cultural exchange, and as a meeting place and exchange point for the people of the city" (Gehl, 1989:15). Even though these remarks date from 1989 , more recent studies indicate that streets are still extremely important for the conduct of everyday life (Friedmann, 1999). They point to the rise of a street-level culture and scene which allow people to have an authentic experience of a space (Florida, 2002). 
The object of the case study conducted in this research is indeed a street. The Preston Street project aimed to improve the quality of the space and offer better opportunities for the development of public life. However, it might be easier to provide excellent spaces for socialization in squares which generally are created to support only this kind of use. In the case of streets, nevertheless, it may be fundamental to reflect on how limited spaces such as sidewalks can assume so many functions, simultaneously accommodating underground structures as well as pieces of street furniture, infrastructure elements, and sometimes artwork. Here lies a challenge for landscape architects, industrial designers, engineers and artists.

\subsection{The urban experience}

The urban experience is abstract and intangible; nevertheless, it deserves to be discussed with the same attention as a space's concrete attributes. The immaterial aspects of public spaces, such as the meanings they acquire, urban inclusion, and urban alienation, are treated in the present section.

\subsubsection{Symbolic meanings in the built environment}

The city of everyday life is composed of diverse places with "multiple meanings with which we invest the built environment" (Friedmann, 1999: 5). The meaning that an environment acquires through time is "an important dimension of urban quality" (Francis, 1987: 94).

Symbolic approaches interpret the built environment as an expression of culturally shared mental structures and process (Lawrence \& Low, 1990: 466). Symbolic anthropology theorists believe that built forms are capable of describing and explaining relevant aspects of a people's culture. 
The built environment may, for instance, assume a communicative role of expressing meanings between groups or reaffirming a system of pre-established meanings and values.

Anthropological concern with the built environment is at least as old as the first formalization of theories of cultural evolution during the 19th century (Lawrence \& Low, 1990). The concept of the built environment involves products of human building activity, from building types such as dwellings, temples or meeting houses to open areas such as a compound, a plaza, or a street. It may also comprise landmarks or sites.

Urban spaces have been explored as settings for symbolic studies by many researchers. In fact, they are an excellent source of symbols and cultural representations. Walter Benjamin, for instance, examined the concept of urban allegories in which "each object represented may have a host of competing possible meanings" (Gilloch, 1996: 135).

This research has focused mostly on the structuralist view, "the most consistently developed theoretical approach in the symbolic analysis of the built form" (Lawrence \& Low, 1990: 467), represented by Barthes' semiology. The decision to employ this approach was based on the relevant body of knowledge regarding urban spaces the referred author developed. More recent interpretations of the urban environment are also presented in this subsection. They illustrate a contemporary view of the topic.

\section{a. Cities as semiotic systems}

A declared "amateur of cities" (Barthes, 1967: 413), Barthes included the urban space in his semiological analysis. To him (Barthes, 1967), cities are privileged semiotic systems. He argues that urban spaces abound with emptiness waiting to be filled. In this context, signifiers 
may be defined as objects which can embed a signification. And who is responsible for attributing meaning to these elements? The answer is the population, common people who speak to the city "simply by inhabiting it, by traversing it, by looking at it" (Barthes, 1967: 415). They are the users of the space and are actively involved in meaning attribution processes even if they are not aware of it. In the perspective of its inhabitants, then, the city may be thought of as a dense, complex, and often contradictory web of meanings that, however difficult to disentangle, are yet essential to the good life (Friedmann, 1999: 4).

With the example of the Eiffel Tower, Barthes suggests that people habitually attribute significations to urban elements, regardless of the planner's intentions (Barthes, 1979). Whilst [Gustave] Eiffel regarded his tower "in the form of a serious object, rational, useful" (Barthes, 1979), people interpreted it "in the form of a great baroque dream which quite naturally touches on the borders of the irrational" (Barthes, 1979).

However, the meanings which are attributed to the elements in urban spaces are not definitive since the urban context is resistant to fixed significations (Barthes, 1967). "People are living now in a continuously changing world" (Siu, 2009: 85), and the changes in the cities can also influence the signification of its elements.

Considering that people ascribe significations to the urban spaces and elements, it may be important to consider the possibility of involving them in the planning process. This way, planners and designers might be able to understand how users will receive the proposed changes. Different from the case of the Eiffel Tower, in this case an agreement regarding the meaning of the project might be reached. The study intends to grasp the significations that the multiple stakeholders attribute to different components of the street reconstruction. 


\section{b. Extraordinary Vienna}

Another excellent example of cultural symbols embedded in urban spaces was studied by Rotenberg (1996). His analysis of Viennese gardens constitutes a significant interpretation of the diverse meanings urban elements may acquire. According to him, the green spaces in this city have become "a medium through which their designers or gardeners express identification with the project, and through it, with the metropolis as a whole" (Rotenberg, 1996: 82). The urban landscape, including each park, tree-lined street, palace garden, and domestic lawn, communicates and represents the relationship between the citizens and the metropolitan project.

The extraordinary landscapes analyzed by Rotenberg (1996: 88) epitomize and replicate "the social structure of the city as it evolved historically and spatially". Whereas gardens of order suggest that the society should be arranged in a an orderly fashion, gardens of liberty advocate free development. Gardens of domesticity replicate the tension between the individual and the society while gardens of refuge reinforce the sense of community and cooperation with reciprocal exchanges of home grown ingredients. Gardens of pleasure present free-flowing planting growth but with a certain geometry on the ground plan derived of the French curve. Gardens of reform simplify the pleasure ground aesthetics, with grassy lawns inviting the public to exercise and enjoy the fresh air and gardens of renewal are symbols of health and vigour, resulting from a voluntary recreational activity. Finally, gardens of discovery have meditative qualities and typify a balanced human/garden community.

The metropolitan project is interpreted ideologically through the landscape (Rotenberg, 1996: 99). To Rotenberg, green areas in Vienna represent the antagonism between order and liberty as well as public and private according to the political movements that were in power at 
the time when they were built. The city residents share this system of metaphors because they are introduced to it as children when visiting the referred spaces. In adulthood, they assume their citizenship by identifying themselves with their own strategic predilections, which are normally expressed as aesthetic preferences. Those who have the opportunity to garden can manifest their identity by reproducing the practices of public spaces in their private spaces.

This example reveals how important it is to city dwellers to be familiar with the significations embedded in the urban environment. Although in this case the meanings were imposed in an arbitrary way, they were progressively apprehended by the population as political and social movements evolved. This might offer some insight to the urban planners and designers who wish to undertake abrupt changes in urban spaces. In some way, this may cause a disconnection between city users and the spaces they used to know and comprehend. Again, it is possible to wonder whether participation in the projects may enable the public to become familiar with the modifications intended for the areas.

\subsubsection{Urban alienation}

Urban alienation is another example of 'invisible' and 'intangible' phenomena that might be ignored by a quick glance at public urban spaces. However, when the public is not involved in the discussions regarding public spaces, there is a lack of attachment between them and the urban elements. King, Ferrari, Conley and Latimer (1989) claim that when people who are the most affected by the changes are not integrated in the planning process, they are likely to become alienated. 
Alienated people do not feel that the public space also belongs to them. Likewise, they do not feel related to the urban elements. Friedmann (1999:4) agrees that bringing the population into all phases of the planning process might represent "a social process of urban change that will minimize the alienation of small urban spaces and the tearing apart of the web of meanings that any city is for its inhabitants."

Co-creation and participatory design might be an efficient tool to counter urban exclusion and alienation. Besides possessing a social value that "provides a real opportunity for significant change" (Sanders \& Simons, 2009: 1), user participation enables designers to increase "their empathy for the users" (Keates \& Clarkson, 2003: 176). When designers understand the users' needs well, they may be capable of developing more inclusive products. The user, in his/her turn, becomes "a design's true producer, who actualizes the design by filling in its gaps or indeterminacies of meaning" (Siu, 2003: 66).

This research is interested in the relationship between city users and the urban elements. Rather than promoting urban alienation, projects for urban spaces should embrace the population, including every city dweller in a pleasurable experience. Although many researchers, defend participatory design as a way to foster urban inclusion, it might be important to understand through actual projects how accurate this notion is. Very often, the real situation is that not every user participates in the development process. It might be interesting to question thus whether the involvement of just a parcel of the population is enough to enhance the general public's recognition of the urban space and its elements. 


\subsubsection{The triangulation process}

Interactions with urban elements and connections between city dwellers may also promote inclusivity and transform the urban experience, which as defended by Burns (2000) has been atrophying lately in many public spaces. Interpersonal relationships are being replaced with "the packaged messages of a commodified culture of spectacle and merchandising" (Burns, 2000: 74). Instead of being spectators, it might be beneficial to people to assume an active position building their own experiences by interacting with the artefacts that occupy public spaces as well as with other people.

According to Whyte (1980), triangulation is "the process by which some external stimulus provides a linkage between people and prompts strangers to talk to each other as though they were not" (Whyte, 1980: 94). The author argues that street characters make the city environment friendlier. He cites the example of an individual who voluntarily directs the traffic in midtown New York. His performance is capable of drawing members of the crowd together and stimulating conversation among them.

In similar fashion, physical objects or even sights might stimulate connections between people (Figure 4). Sculpture can have strong social effects (Whyte, 1980: 96). An analysis of the Chase Manhattan plaza before and after the installation of 'Four Trees" by Dubuffet concluded that it has had a positive impact on pedestrian activity (Whyte, 1980). People were attracted to the sculpture and interacted with it, standing under it or beside it, touching it, or talking about it. The same effect was observed at the Federal Plaza in Chicago where the huge Alexander Calder's stabile was placed (Whyte, 1980). 
Such linkages may evoke the feeling in people that they are connected to the city to the point that it becomes an important aspect of their lives. At this point, they might understand that they are part of a group, which consists of all the city dwellers and whose responsibility is to take care of the urban environment so that everyone can benefit from it.

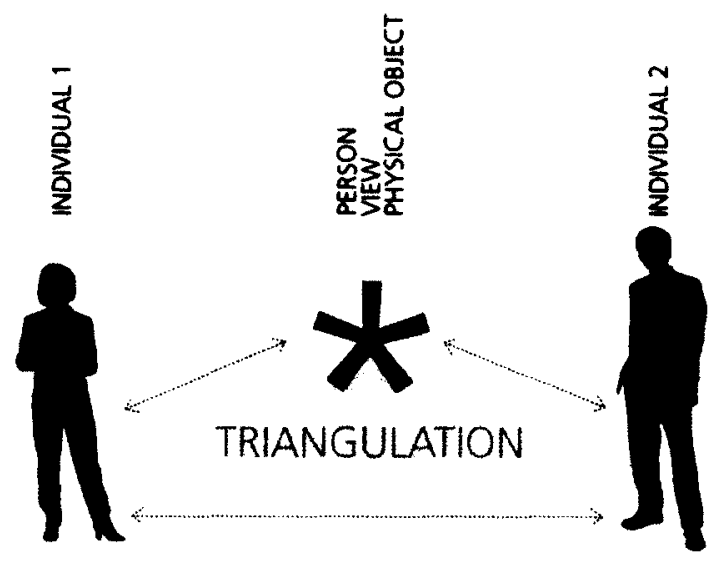

Figure 4. The triangulation process

A question that such analyses may raise is whether there are special characteristics to the pieces studied which transformed them into attractive objects. It is possible that not every performance, view or physical object is capable of invoking people's interest. In this sense, when observing urban artefacts it might be interesting to evaluate how users react to different materials, textures, shapes, colours, and sizes of elements. Empiric studies regarding such topics may contribute to a better understanding of the phenomenon.

\subsection{Urban elements}

Special features such as fountains and sculptures can definitely have an impact on the success of a space (Main \& Hannah, 2010:4) and promote triangulation between individuals 
(Whyte, 1980). Both artefacts may be classified as urban elements, or "objects which are used and which are integrated in the urban landscape" (Creus, 1996: 6). They provide industrial designers with opportunities to directly participate in shaping urban spaces.

Since the project which is the object of the present case study involves pieces of public art and street furniture, the discussion embracing these subjects becomes fundamental. This section examines the history of public art in urban spaces, instances of successful and unsuccessful artworks in public areas, the differences between design and art, and the functions that street furniture elements might assume.

\subsubsection{Public art}

In the late 80s, public art reached a "boom" (Senie \& Webster, 1989: 287), impelled by percent-for-art programs as well as competitions, symposia and discussions involving local and international artists. At the same time that art invaded streets and plazas, academics debated the phenomenon. A substantive body of literature on the relationship between art and public space has emerged across a broad spectrum of methodologies and professions (Lee, 1998: 80). Architects, art historians, urban theorists have explored such themes through diverse ideological approaches.

With the great rush to provide art in open spaces, surprisingly little empirical work has documented how public art is perceived and valued by the public (Francis, 1987: 47). The general public, who might have a totally different reaction than the ordinary art audience, are unquestionably important in this context. They no longer figure as a "passive onlooker[s] but as participant[s], actively implicated in the constitution of the work of art" (Hein, 1996: 3). Given 
the variety of forms public art takes today, the question remains as to what is perceived by a nonmuseum-going audience - one that is largely uninformed about art issues yet is potentially powerful and politically enfranchised (Senie \& Webster, 1989: 288).

Considering that the city of Ottawa has a percent for art policy and intends to make public art accessible to the population, it might be vital to understand how the population perceives the artworks that have been implanted on the streets and how they impact public life. Empirical research where people are asked about their perspective on the sculptures might be a starting point for an evaluation process regarding both art and the current policy.

\section{a. Richard Serra's Tilted Arc}

An example of a controversial piece of public art is Richard Serra's Tilted Arc, which was developed for a public plaza in downtown Manhattan in 1979 and removed five years later "after intense public outcry" (Levine, 2002: 51). He aimed to build a work that would draw attention to the way that people moved through the space, and, to this end, he planned a long, curving wall made out of red Cor-Ten steel to bisect the area (Levine, 2002: 52).

Serra turned "a functional space into an art form that worked against it" (Holman, 1997: 129). Plaza users could no longer cross the plaza (Holman, 1997: 129) and alleged that Serra's wall obstructed the use of the open space (Kelly, 1996: 15). In truth, Serra regarded the Federal Plaza as a space which was represented more by "aesthetic than by public issues" (Kelly, 1996: 17). Furthermore, his work did not encourage different readings. On the contrary, it allowed just one which he "forced the viewer to choose" (Holman, 1997: 129). 
The vital debate here would be whether the involvement of the public in the process of development of the piece of public art would reduce the negative reactions that the artwork provoked in people. Anyway, proposing an artefact that hinders the circulation of passersby in a public space is definitely audacious! One might reflect on the functions that art can assume in varied contexts. Should it divide spaces, impeding the flow of pedestrians or should it aggregate people and assume a more contemplative function? Should it be an object of self expression or should it be agreeable to a public who different from a museum circumstance did not choose to appreciate the artworks of a specific artist?

\section{b. The Veteran's War Memorial in Washington, D.C.}

The Vietnam Veteran War Memorial designed by Maya Lin also suffered public objections. Some veterans and members of the public argued that it was "non-representative and unheroic, and thus would remind citizens more of individual death and national defeat than of the war's mission" (Kelly, 1996: 15). These critics preferred a more traditional war memorial promoting patriotism (Kelly, 1996: 15).

The Veterans Memorial was unveiled in 1982 and, since then, has received enormous support from the audience (Kelly, 1996: 15, 16). It has become one of the most visited monuments in Washington. Eventually, despite the criticism she faced, the artist was capable of successfully invoking personal experiences of the Vietnam War in people by means of her public artwork. The names of the war victims in the order of death, the v-shape, and the polished granite that allows the visitor to see himself reflected in the names "dramatize the primary 
operation of the memorial, which is to symbolize the Vietnam War before the public so that the public can decipher its message and move on" (Friedman, 1995: 66).

Although this case had an ending different than Serra's Arc, in both instances "a small group of people selected a work of art and, in effect, decided in the name of the public what its art should be" (Kelly, 1996: 16). Boards of artworld judges selected the winning proposals from among other submissions that were also produced by artworld figures (Hein, 1996: 2). Lin, however, was the most successful in working with people and the space (Kelly, 1996: 19). Rather than being combative she managed to provide a space where memories could breathe "without her or anyone else pretending to reach a consensus on the war (Kelly, 1996: 20). Whereas in the case of Tilted Arc the participation of the public in the choice of the artwork could have avoided the installation of a piece that would some years later be removed; public opinion could have prevented the existence of this popular monument. It is therefore essential that public art programs find a midpoint between public participation and expert consultation, or proposing and imposing. In any case, the success of an artwork depends on how people connect with it. One might affirm that Lin was successful in attaching symbolic meanings to her memorial which were accepted and shared by the public as opposed to Serra, who offered a blank wall that meant nothing to the population.

\section{c. Anish Kapoor's Cloud Gate}

British artist Anish Kapoor's 'Cloud Gate', aka 'The Bean', reflects the images of the city and the hordes of visitors it draws to the AT \& T Plaza in Chicago's Millennium Park (Main \& Hannah, 2010: 5) (Figure 5). The 168 steel plates comprising the sculpture's skin weigh 
between a half and a full ton each (Matthews, 2010: 11). One can hardly appreciate such "art object or engineering marvel" (Matthews, 2010: 11) without wondering how it was done.

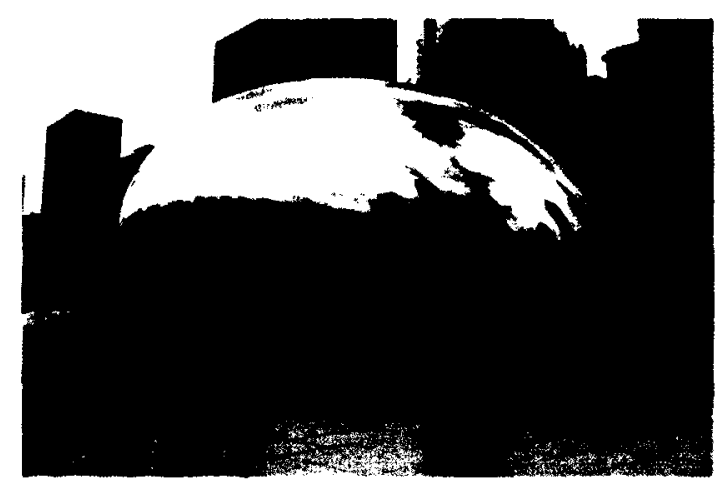

Figure 5. Cloud Gate, Millennium Park, Chicago, Illinois

The kidney bean-shaped piece sits alone in the centre of the space (Matthews, 2010: 12). The size is the first thing one notices about it (Matthews, 2010: 13). Cloud gate is enormous, imposing, and architectural in scale (Matthews, 2010: 13). But the possibility of moving under "the object's bulk of as if through a portal" (Matthews, 2010: 13) brings the experience provided by it to another level of connection between user and object. One's sense of standing on the level plane of the plaza is inverted as one peers into the omphalos (Matthews, 2010:13) or, in other words, its cave-like space.

This is probably one of the most famous pieces of public art in the world. The image of The Bean has become one of the symbols of the city of Chicago and has been reproduced in numerous photographs and videos. Apart from its size, the Cloud Gate is memorable because it invites the public to have a different experience of the space. Through the reflection in the mirror 
or even walking under its hump people become part of the piece. The experience is never the same since the landscape and the individuals are always changing.

When abstract sculpture went public, the public, in turn, gained the ability to amass information about it as a category and thus formulate emotional responses to a new species of art in the environment (Matthews, 2010: 15). As well as abstract sculptures, Cloud Gate may represent anything the observer is capable of envisioning: a bean, a kidney shape, a portal, a reflection of the city landscape. Objects which have a fixed or predetermined meaning might not allow the audience to interpret them in different ways. Should, then, sculptures in public spaces privilege abstract or ambiguous shapes instead of more literal ones? Also, to what extent do the size and the materials of the piece influence people's reactions to it? The success of Cloud Gates reinforces the debate.

\section{d. Crown Fountain, Millennium Park, Chicago}

Also at Millennium Park, the fountain created by the Spanish artist Jaume Plensa in collaboration with the Chicago-based architects Krueck + Sexton is an example of a piece of art that was made for the population's enjoyment. The Crown Fountain consists of two 50-foot tall glass towers which project images of the humankind separated by a long shallow pool (Main \& Hannah, 2010: 19). It was opened on July 16, 2004 and is considered an extremely successful public attraction. It represents an excellent example of the association of compelling art with inspired site furniture (Main \& Hannah, 2010: 19).

The wooden benches located beside the pool support the activities which happen in the pool area. While the pool becomes an 'stage', the benches are the space where the audience stays 
looking at what is happening in the 'stage' like in a theatre (Main \& Hannah, 2010: 20). Even though many people in the city did not agree with the fountain concept that seemed too technological and intellectual, the response after the unveiling was extraordinarily positive (Main \& Hannah, 2010: 22). The Crown Fountain became a recreational space for children. The artist's comments summarize the population's response and the experience the artwork provides.

They were afraid that it was something more for the museum than for the street. But when we unveiled the project, there was an extraordinary response. Kids really saved it - they just went boom. And 1 remember the parents were a little disappointed with me that day because all the kids were completely wet. The next day they did the same thing, but they brought towels. And everybody was happy. So probably the most intellectual piece I did became the most physical one. People use the space as an experience (as cited in Main \& Hannah, 2010: 22).

The benches complete the experience creating an instance of Whyte's triangulation (1980) (Main \& Hannah, 2010: 22) (Figure 6). The piece supports human interaction as people sit on the benches and turn to others laughing, and commenting on children's activities.
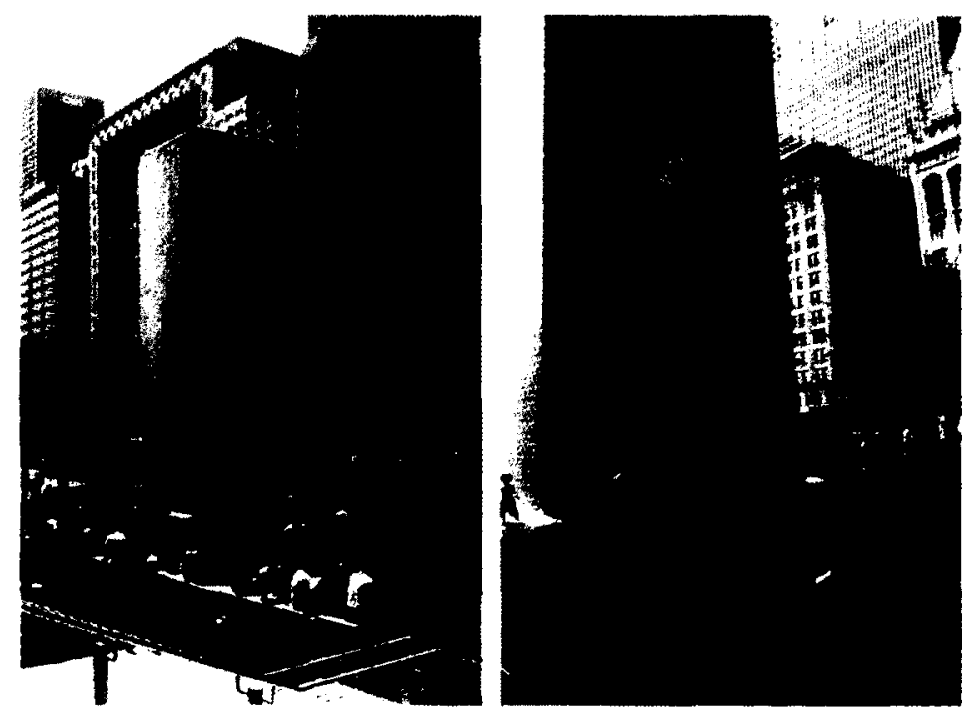

Figure 6. Crown Fountain, Millennium Park, Chicago, Illinois 
This is an example of public art that was genuinely made for the public. Observing what happens in the space, one might realize that the actual attraction in this artwork is the public. Indeed, people occupy the centre of the space or the 'stage', which is exactly the opposite of what happens with traditional sculptures in the urban realm. In general, the piece of art is the focus of the attention and the audience stays around it in contemplative postures. In this case, the glass towers which gush water as well as the benches become a backdrop that encourages users to act. This may prefigure a trend in urban spaces where the experience that artefacts can provide is becoming more important than the actual objects. Instead of having only a contemplative relationship with art, the public may now be expecting more active and dynamic participation in their experience of public artworks.

\subsubsection{Street furniture}

The street furniture category includes benches, chairs, streetlights, flower boxes, bus shelters, bicycle racks, and litter bins, among others. By creating these products, industrial designers are capable of helping shape the urban environment.

Even though designers currently create multiple products for the urban environment, it was only recently that these professionals have started to take responsibility for issues related to the city (Kries, 2006). According to Kries (2006), design received a great impetus in the postwar era when it was necessary to reconstruct destroyed cities. Designers, who before would collaborate with architects and urban planners, started then to play an independent role, complementing the pragmatic and rational tendencies of Modernist architecture and urbanism. 
The importance of these urban elements to cities is evident. They make "the city accessible to everybody and easier to get around in" (Creus, 1996, p. 9). Ramps and sign panels properly situated can facilitate citizens' locomotion and orientation. Pieces of street furniture also help citizens effectuate their everyday activities. Bus shelters, streetlights, and bicycle racks can be cited as crucial elements to support people's common needs. The function of stimulating the use of public spaces can be attributed to the pieces of street furniture. They are capable of providing these areas with a comfortable and attractive quality. In this sense, they are able to aggregate people. Benches and tables in squares and parks fulfill this purpose.

Ultimately, "the furniture itself may be conceived as art" (Main \& Hannah, 2010: 3). 'Two too large tables' (Figure 7) by Allan and Ellen Wexler at Hudson River Park, in New York City, for example, "are designed to encourage interaction (and perhaps smiles)" (Main \& Hannah, 2010: 3). They possess, nevertheless, a sculptural character that differentiates them from the ordinary functional urban furniture.
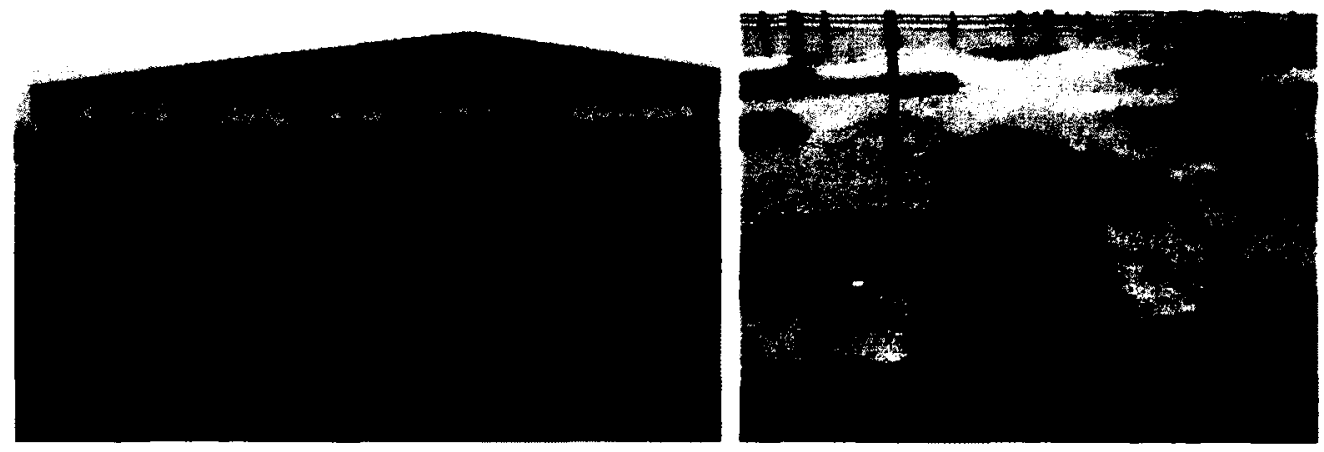

Figure 7. Two Too Large Tables (From Main \& Hannah, Site furnishings : A complete guide to the planning, selection, and use of landscape furniture and amenities. Copyright 12010 by John Wiley \& Sons, Inc. Reprinted by permission of John Wiley \& Sons, Inc.) Photo credit: Bill Main 
Likewise, the seating designed by Martha Schwartz (Figure 8) also presents singular characteristics. It replaced the previously mentioned Richard Serra's Tilted Arc sculpture at Jacob Javits Plaza in New York, becoming the new dominant element in the space (Main \& Hannah: 4). Besides boasting an exceptional silhouette, the bench "reanimates the space and reconnects the plaza to its context," (Main \& Hannah, 2010: 4), allowing multiple seating opportunities. In this case, "the aesthetic of the furniture defines the character of the space" (Main \& Hannah, 2010: 4).

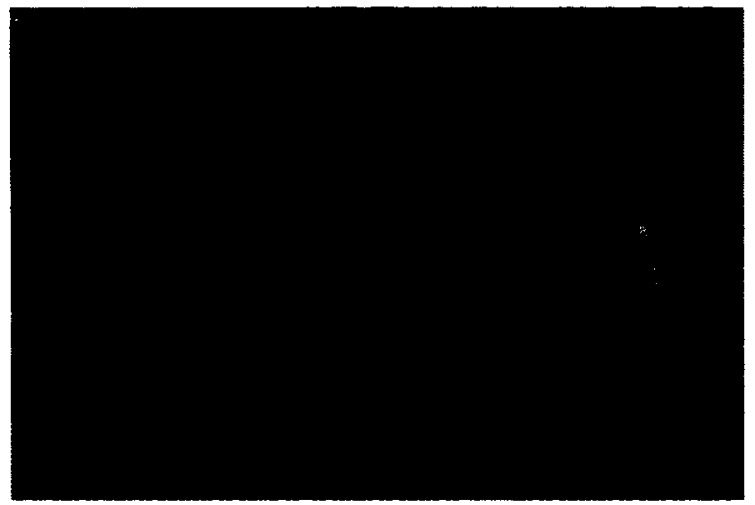

Figure 8. Jacob Javits Plaza seating in New York (From Main \& Hannah, Site furnishings : A complete guide to the planning, selection, and use of landscape furniture and amenities. Copyright 2010 by John Wiley \& Sons, Inc.

Reprinted by permission of John Wiley \& Sons, Inc.) Photo credit: Martha Schwartz Partners

\subsubsection{Design versus art}

In a context where design products and works of art share the same space, a comparison between design and art enriches the discussion. 'Design is a fundamental human activity, as well as the name of a number of quite specific professions (Lawson \& Dorst, 2009: 24). The term embraces the professional fields of architecture,engineering, interior design, interaction design, software design, graphic design and product design, whose boundaries are "vague and tending to become more so" (Lawson \& Dorst, 2009: 26). 
Even the distinction between design and art seem to be hazy when conceptual design is defined as "the art of seeing the design situation in multiple ways or 'seeing as"' (Lawson \& Dorst, 2009: 26). The artistic side of design is manifested in the creative aspect of the activity. Creativity in the design process is often characterized by sudden occurrence of a significant event; the so-called 'creative leap' (Lawson \& Dorst, 2009: 34). Nevertheless, research has shown that the solution development process is much more gradual and rarely relies on an 'eureka' moment (Lawson \& Dorst, 2009: 36).

But is design art? Lawson and Dorst utter that "there are no 'requirements' for art" (2009: 41). While design is always to some extent grounded by functionality, by the obligation to relate to the needs of people and the requirements of stakeholders, art is not functional; it does not need to make 'sense' (Lawson \& Dorst, 2009: 41). In general, artists are free to develop themes or inspirations that will give rise their works by themselves.

In creating the solution for a design problem, the designer, on the other hand, must consider the demands of the stakeholders within a project. To arrive at a good solution the designer needs to create a design in which all the issues and demands of the stakeholders are addressed in an integrated manner (Lawson \& Dorst, 2009: 42). In order to do so, designers must employ skills related to 'formulating', 'representing', 'moving', 'evaluating' and 'managing' (Lawson \& Dorst, 2009: 50). These include identifying and framing a problem or opportunity, drawing, writing, modelling and making representations of the designs, performing objective and subjective evaluations, briefing and others (Lawson \& Dorst, 2009: 40-60).

But a designer must not only be "technically competent but also have a well-developed aesthetic appreciation" (Lawson, 1997: 9). Space, form, and line as well as colour and texture 
are the very tools of trade for the environmental, product or graphic designer (Lawson, 1997: $9,10)$. After all, the final product of the design process will always be visible to the user. In this sense, design professionals share the territory with artists who are also capable of creating an aesthetic experience (Lawson, 1997: 10). However, designing requires more than just aesthetic abilities. Designers must understand the nature of the users and their needs (Lawson, 1997: 10). For this reason, many design programs have recently included behavioural and social science courses (Lawson, 1997: 10).

Yet designers are no more social scientists than they are artists or technologists (Lawson, 1997: 10). They have a knowledge of the materials' structural functionality and manufacturing processes. Designers must solve externally imposed problems, satisfy the needs of others and create [functional and] beautiful objects (Lawson, 1997: 157) (Figure 9).The interdisciplinary nature of the activity allows design professionals to create integrated solutions to multilayered problems. That is why Lawson argues that if he had to emphasize a single quality of designers, he would choose "the ability to integrate and combine" (1997: 59).

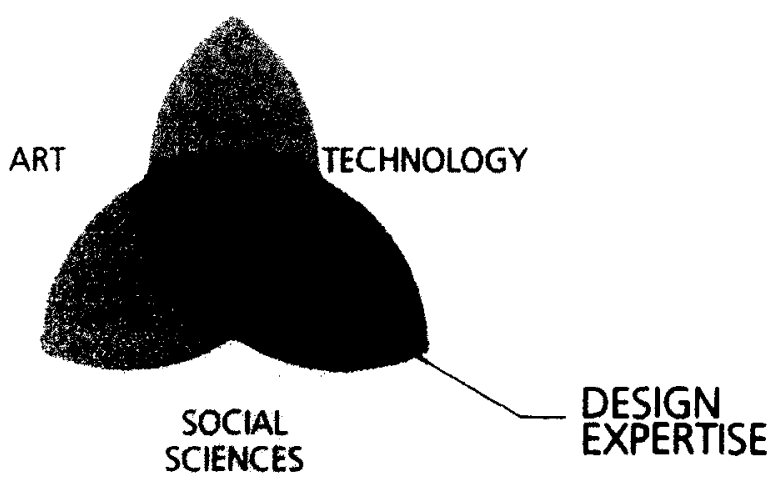

Figure 9. Design expertise 
A piece of good design is rather like a hologram; the whole picture is in each fragment. It is often not possible to say which bit of the problem is solved by which bit of the solution. They simply do not map on to each other that way (Lawson, 1997: 59).

This is particularly true for urban spaces where projects incorporate numerous stakeholders from different fields and call for an integrated solution that respects the established constraints and fulfills the users' needs.

\subsubsection{Trends in public spaces}

The urban needs are constantly changing (Siu, 2009). Since the demands for the design of public spaces are evolving, designers must be prepared to create products that satisfy the users' new desires. Kries (2006: 23) exemplifies some of the new trends in public spaces by stating that "wireless Lan hot spots allow us to work and communicate anywhere within public areas" and "plasma screens and other façades transform high rises into communicative structures."

New trends in urban spaces also include branding cities (Ooi \& Stöber, 2008), promoting art, culture and local identity, and encouraging the creative industries (Rantisi \& Leslie, 2006). In the sections below, cases of some cities illustrate the current directions cities are taking in order to become competitive and offer a better quality of life for city dwellers. Other cities' attitudes towards design development is important to this study that intends to include industrial designers in the development of urban projects. The idea is to present illustrative examples that may inspire the development of design plans for the City of Ottawa. 


\section{a. Montreal}

In Montreal, Commerce Design Montreal (CDM) is a policy which was introduced by the local government to enhance the urban experience and also brand Montreal for international consumption (Rantisi \& Leslie, 2006: 364). Having a culture of public and non-profit support for architecture and design, the city identified design as having the function of being an "agent of urban-economic development and renewal" (Rantisi \& Leslie, 2006: 365). The recognition came through the designation as the UNESCO City of Design in 2006. Montreal was the first North American city to receive this title.

The origins of Commerce Design Montreal are linked with a report issued by a Ministerial Committee in 1986. In studying the Montreal economy, design, along with other industries, was identified as a key sector in the local economy (Rantisi \& Leslie, 2006: 367). In 1995, the Commissioner of Design launched the first CDM contest (Rantisi \& Leslie, 2006: 368). The objective of the contest was to "'hard-brand' the landscape of the city for both visitors and residents, and to position Montreal as a 'design destination"' (Rantisi \& Leslie, 2006: 368).

Rantisi \& Leslie argue that competitions are capable of transforming private places of business into cultural destinations "comparable to the art museum" (2006: 368). In their opinion, consumers are also educated as "design citizens" (Rantisi \& Leslie, 2006: 369) who can recognize the aesthetics of the city.

Unfortunately, the program does not focus on public art or public spaces. It has become, nonetheless a reference for other cities. The Times Square Alliance Business Improvement District (BID), for example, has adopted the model of CDM policy also focusing on interior 
design but including architecture, signage, public art and public space components as well (Rantisi \& Leslie, 2006: 374).

\section{b. Toronto}

The city of Toronto does not seem to have a specific policy to stimulate design activity in urban spaces. It boasts, nonetheless, the Coordinated Street Furniture Program that aims to create "an aesthetically appealing, functional, safe and accessible public realm" (City of Toronto, 2010).

One of the key objectives of the program is "to achieve high quality and well designed street furniture in all areas of the City" (City of Toronto, 2010). The process involved diverse stakeholders in public consultations, a best practices study, and design charrettes. The request for proposals (RFP) called for a family of products that encompassed cohesive, flexible, functional, and high quality design to reflect Toronto's identity (City of Toronto, n.d.).

The successful proponent was the company Astral Media which signed a 20-year term contract (City of Toronto, n.d.). With an advertising-funded approach, the city foresees a revenue of $\$ 428$ million generated from advertising activities over this contract (City of Toronto, $n . d$.). Nevertheless, advertisements are restricted only to transit shelters and the info pillars.

\section{c. Chicago}

In Chicago, a street furniture competition in 2011 promised to exhibit good design on the streets. Organized by Architecture by Humanity Chicago, the contest invited designers to develop one or more pieces of street furniture that could revitalize a vacant site, be universally 
accessible, and stimulate multi-generational community interaction (Architecture for Humanity Chicago, n.d.).

Architecture for Humanity Chicago is a chapter of Architecture for Humanity, "a charitable organization that seeks architectural solutions to humanitarian issues and brings design services to communities in need" (Architecture for Humanity Chicago, n.d.). Winning projects were expected to have at least one piece of their street furniture built in the spring of 2011 and installed in a neighbourhood for one year.

This is a very interesting initiative for many reasons. In a city where there is a coordinated street furniture program, for example, it might be beneficial to have some temporary diversity. In addition, in this case, street furniture is elevated to a level of artefact that can improve community life and ameliorate abandoned and underused spaces. Finally, organizing competitions might be an inexpensive method of obtaining excellent design projects.

\section{d. London}

Slightly different from Montreal and Toronto, London, UK has an organized structure to supervise the design of buildings and urban spaces. It was created by the mayor at the time, who was concerned with improving the aesthetic qualities of the city (Charney, 2007: 197).

In June 2006 Livingstone announced plans for a new architecture and urban design unit (Charney, 2007: 200). Design for London, as the new unit was named, merged staff from different areas and engaged in enhancing the quality of city-wide design. The main objective was to make London "a world leader in sustainable urban planning, design and architecture (Charney, 2007: 200). 
Nowadays, Design for London still works on behalf of the Mayor of London, supporting neighbourhoods and project deliverers to "shape a better city" (Design for London, n.d.). Design for London has been praised as a model for the future of locally-led, collaborative planning and urban design: helping to bring forward better places and spaces for all citizens (Design for London, n.d.). To that end, collaborators work as design advisors for boroughs and support their plans for development.

The importance that urban elements are currently acquiring becomes evident through looking at the varied examples of cities which are attempting to provide their public spaces with good quality design. More than being just a background in the urban scene, they have turned key aspects into pleasurable experiences. Moreover, investing in the design of these elements has been considered an intelligent strategy for branding and differentiating cities and attracting tourists (Rantisi \& Leslie, 2006). Many times, the government utilizes the private sector to support design programs. Design competitions appear to be a good way to acquire quality projects to improve the environment.

\subsection{Participatory design research processes}

When providing a pleasurable user experience is the primary objective in a project, designers are required to obtain information about the users' needs and desires. In public spaces, it is not different. Besides obtaining information about the public, city planners are also expected to follow a democratic decision making process.

Citizen participation in design and planning has increased rapidly in the past few years to the point where it is a frequently praised practice (Sanoff, 2000: 22). It was "one of the major 
social movements of the 1970s" (Sannof, 1981: 157) and still today is a subject often discussed in design research. Many scholars (Burns, 2000; Siu, 2003; Siu, 2007; Sanders, 2006) suggest user participation as a form of providing a better experience and creating a better user-fit design in the urban or architectural context. The concept of participation in design, nevertheless, varies and has been evolving in recent decades.

Iacofano, Moore \& Goltsman (1988: 78) identified four possible political strategies for interactive decision-making: pseudo participation which refers to situations where the population is deceived by a fallacious impression that they are influencing decisions; consultation when the city demands the city dwellers' opinion on projects already in progress; partial participation which allows the general public to influence some decisions; and full participation that represents a democratic and legitimate division of the decision making power (Iacofano et al., 1988: 78) (Figure 10).

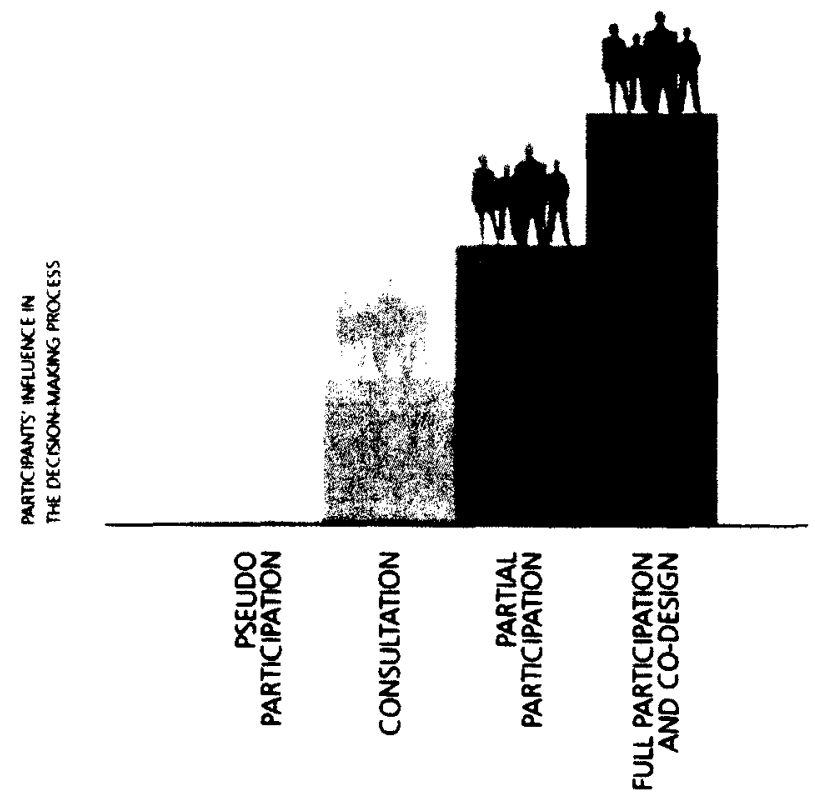

Figure 10. Interactive decision-making scale 
As pseudo participation cannot be considered an actual form of engagement, consultation or dialogue might be regarded as the first level on the scale of participatory design. Most of the public involvement programs fall into this category (Iacofano et al., 1988: 78). Based on the concept of 'drawing from'the users' knowledge as a source of information, the dialogue consists of asking the public to comment on the designer's proposal while the design is in progress (Siu, 2003: 72). Surveys and questionnaires are used as a tool to obtain more information about the user. Consultation a cost-effective method which also does not require a substantial sharing of decision making power.

Partial participation refers to situations where two or more parties are included in the decision-making process. While one party can influence the other, the power to make the final decision rests with one party only. It is possible for this strategy to degenerate towards pseudo participation (lacofano et al., 1988: 78).

Related to the full participation concept, co-design is a more focused aspect of the usercentred approach. It represents a higher level on the participatory design scale and "goes a step further in involving the user in the [up-front] design process with the designers" (Siu, 2003: 72). In this case, users are the 'experts of their experiences' (Sleeswijk Visser, Stappers, Van Der Lugt, \& Sanders, 2005) and express their thoughts, feelings, and dreams through tools and techniques developed by designers. The interest in such instruments has been growing lately (Sanders \& Stappers, 2008: 13) possibly because they enable the designer/researcher to access people's tacit knowledge, which can unveil latent needs (Sanders, 2002).

In the co-design process, the researcher who might be a designer assumes the role of a facilitator (Sanders \& Stappers, 2008: 13, 14). This means leading, guiding, and providing 
scaffolds, as well as clean slates to encourage people at all levels of creativity (Sanders \& Stappers, 2008: 14).

Co-design practice faces many hurdles. As stated by Sanders and Stappers (2008: 9), a premise for co-creativity is the idea that all people are creative. This idea is not commonly accepted, mainly by the business community. In addition, "co-designing threatens the existing power structures by requiring that control be relinquished and given to potential customers, consumers or end-users" (Sanders \& Stappers, 2008: 9). Distributing and sharing the control is not easy for businesspeople who have been in control for a long period of time (Sanders \& Stappers, 2008: 9). Finally, co-creation is often seen "as [an] academic endeavour with little or no relevance for the competitive marketplace" (Sanders \& Stappers, 2008: 10). This view of codesign is starting to change, in part because of the successful collaborative experiences between companies and universities.

This research investigates an instance of public participation. The aim is to understand how participation happened in the Preston Street project and how decisions were made. Even though researchers defend the utilization of public participation in the urban environment, professionals may encounter many barriers in implementing this practice. It may thus be important to conduct studies which address these difficulties as well as to attempt to find ways to enable effective practices.

\subsubsection{Public, community and design participation}

Lee (2006: 5) differentiates public, community and design participation. Whereas public participation "aims to facilitate active citizenship" (Lee, 2006: 5) and enables the public to take 
part in the decision-making process, community participation "has a close relation to community development activities" (Lee, 2006: 5). Design participation, on the other hand, is "initiated by designers, design-related stakeholders or user groups" (Lee, 2006: 7) with the aim of generating user-centred design solutions. Both public and community participation, nevertheless, might merge with the domain of design participation when projects involve design and design inputs.

Sannof (2000: ix) defends community design as "an umbrella term that also embraces community planning, community architecture, social architecture, community development, and community participation." According to him, the community design movement has been exploring "how to make it possible for people to be involved in shaping and managing their environment" over the past few decades (Sannof, 2000: x). He points out, however, the distortions that the term participation has suffered in order to encompass both "attendance at ongoing public meetings" and describe the situations where "everything has to be checked with everyone before any decision is made" (Sannof, 2000, $x$ ).

In any case, participatory design has been an active research field for several decades, which is "an acknowledgement that users' direct involvement in the design and decision making process has a positive influence and that its investigation generates continued insight and knowledge" (Luck, 2003: 523). Some researchers use strong statements such as "architecture has become too important to be left to architects" (De Carlo, 2005: 13) and "design is now too important to be left to designers" (Brown, 2009: 37) to reinforce the current trends which indicate that designers should share the design process with the users.

Many cases of this sort of interdisciplinary collaboration are discussed in the literature. The results are encouraging. Among the outcomes of active user involvement in the design of 
urban products or services, authors cite increasingly positive attitudes towards the system in development (Iacofano et al., 1988) and enthusiastic support from participants (Lennon, Bannon, \& Ciolfi, 2006). "Questions such as who should participate, and how they should be involved, and when" (Sannof, 1981: 157) have, therefore, already been answered in the urban and architectural realm in different manners and for different purposes.

\subsubsection{An interdisciplinary activity}

Some of the hurdles encountered by professionals in public participation and co-design processes might be connected with their interdisciplinary nature. Sanders \& Stappers define codesign as "the collective creativity of designers and people not trained in design working together in the design development process" (Sanders \& Stappers,2008: 6). Kleinsmann developed a different definition, which emphasizes the interdisciplinary aspect of the process.

Co-design is the process in which actors from different disciplines share their knowledge about both the design process and the design content. They do that in order to create shared understanding on both aspects, to be able to integrate and explore their knowledge and to achieve the larger common objective: the new product to be designed (as cited in Kleinsmann \& Valkenburg, 2008: 370-371).

In this sense, not only co-design but also other participatory design processes might also be considered interdisciplinary since the designer and the public contribute to the project with their different backgrounds. If interdisciplinarity is an "individual as much as a group affair, with team members allowing the perspectives and methods of others to interpenetrate and influence their thinking and understanding of a problem" (Sillitoe, 2004, p. 14), participatory actions are a good example of interdisciplinary activities, where designer and user ideally work collaboratively in order to reach a common goal. The concept of interdisciplinarity, however, becomes broader in this context where it does not result only from the union of different 
academic disciplines, but from the combination of different perspectives on a problem or topic. Although the public may not represent a specific discipline in the process, they contribute to the project with their valuable knowledge from their experience.

Moreover, in participatory projects regarding the urban space, besides the designer and the general public, there is a more extensive list of stakeholders who should be involved in the process. The inclusion of politicians, for instance, is important to "create a climate in which government action can realize community ideas" (King et al., 1989: 25). The planners can guarantee the continuity of the discussion on the strategies that follow the workshop (King et al., 1989). These actors provide knowledge about government policies, interests and restrictions, a subject that other participants are often not familiar with. They are capable of enhancing the interdisciplinary collaboration for the development of projects for the urban environment.

The Preston Street rehabilitation process involved multiple stakeholders with very diversified backgrounds. It is fundamental to observe the interdisciplinary aspect of the process since the final results of this sort of project depend on a good communication and relationship between participants. Studies focused on how to avoid conflicts and enhance collaboration in teams are certainly needed, especially today when interdisciplinarity is considered a trend for obtaining innovative design solutions, even at the micro scale.

\subsubsection{Evaluating the performance of designed environments}

After the completion of a project, it makes sense to evaluate the results obtained. Several research methods were developed to measure the success of spaces after their completion. PostOccupancy Evaluation (POE), for instance, examines "the effectiveness for human users of 
occupied designed environments" (Zimring \& Reizenstein, 1980: 429). Originating from "the extraordinary confluence of interests among social scientists, designers, and planners" (Zimring, 1997: 306), it was introduced in the 1960 s as a reaction to problems experienced in building performance at that time (Preiser, 1995: 19).

Post-Occupancy Evaluation is a diagnostic tool and system which allows facility managers to identify and evaluate the critical aspects of building performance systematically (Preiser, 1995: 19). It is concerned with measuring "user satisfaction with the built environment" (Green \& Moss, 1998: 35). In other words, it aims to assess a building performance "from the building user's point of view" (Preiser \& Nasar, 2008: 85).

POEs can assume three different forms depending on the level of effort undertaken: indicative, investigative, and diagnostic (Preiser, 1995: 22). Methods range from qualitative selfreports of likes and dislikes to quantitative multivariate analyses, from verbal scales to observations of use, and last but not least, expert judgments (Preiser \& Nasar, 2008: 84). A POE analysis usually includes three phases: planning, conducting, and applying (Preiser \& Nasar, 2008: 89) or analysis and presentation of results (Green \& Moss: 1998). The examination is carried out in field settings almost invariably (Zimring \& Reizenstein, 1980: 431) with a bottomup approach (Preiser \& Nasar, 2008: 89). It requires, nonetheless, that "nurturing and empathy replace obedience and authoritarian solutions" (Preiser \& Nasar, 2008: 89).

When applied to public spaces, POE is extremely compatible with citizen participation. In fact, Kaplan (1980) related the case study in an urban park where the public participated both in the development of the space and in its assessment after completion. To her, "the process of obtaining their input both before the park was designed and once it was created was part of such 
participation" (Kaplan, 1980: 507), or in essence, this post-occupancy evaluation was another stage of the participatory process. Still in Kaplan's opinion, "participation can go even further" (Kaplan, 1980: 507). She believes that the sense of ownership that people acquire in the process could be applied to a better use of the park and also to encourage users to take care of the park.

The completion of a project does not represent its end. It is necessary to recognize at what point the project intentions were achieved. And what is more important, it is essential that designers and planners learn valuable lessons from their project experiences. Since the study intends to perceive the participants' perspective on the final results of the process, POE may be an appropriate method to obtain information from users of the spaces. With a formal evaluation by the public it would be possible to perceive the effectiveness of the participatory method employed.

\subsection{Framing the research}

The analysis of the literature connected with urban spaces, and its tangible and intangible aspects as well as the participatory design processes guided the elaboration of questions that could possibly be addressed by the research. The main questions the researcher was interested in were how interdisciplinary participatory process could enhance the development of urban elements for public spaces and what the role of the industrial designer was or could be in this context.

From the theoretical exploration, it was possible to perceive that streets are currently emerging as promising spaces for leisure and socialization. People react differently to diverse 
urban elements and attribute meanings to objects and places, which strongly influence their experiences. The industrial designers' expertise allow these professionals to be involved in discussions regarding the technical, aesthetic, and social aspects of urban spaces. Public participation is presented as a potential way to develop projects that will appeal to users, in spite of the challenges of implementation.

A case study of a street reconstruction would be the ideal opportunity to learn if the practice in participatory design reflects the theory. In other words, through the investigation of an actual instance of public participation, the researcher would be capable of comparing the views of stakeholders and users and verifying, at the same time, whether they share a system of symbolic and practical meanings. In addition, it might be possible to identify the role that industrial designers assume in this context. Finally, the researcher would consider the effectiveness of a participatory process in the development of urban elements. 


\section{CHAPTER 3}

\section{METHODS}

The research methods are primarily qualitative. The choice of approach was based on the importance that participants' interpretations and descriptions would assume in the context.

Qualitative research is an inquiry process of understanding based on distinct methodological traditions of inquiry that explore a social or human problem. The researcher builds a complex, holistic picture, analyzes words, reports detailed views of informants, and conducts the study in a natural setting (Creswell, 1998: 14).

The intention of the study was to build a detailed understanding of a process. This standpoint should respect the complexity of the different participants' perceptions. It was not the purpose of the investigation to provide an unidimensional view of the research problem. On the contrary, the researcher aimed to explore the human aspect of the picture. In this sense, one can affirm that the analysis followed an interpretive paradigm since realities are considered "multiple, constructed, and holistic" (Pickard, 2007: 12). This multilayered perspective could only be achieved through detailed descriptions of the stakeholders views on the process and related methods of inquiry.

The nature of the research questions also pointed to a qualitative approach. In contrast with quantitative questions which commonly ask "why and look for a comparison between groups (e.g., Is Group 1 better at something than Group 2?) or a relationship between variables, with the intent of establishing an association, relationship, or cause and effect (e.g., Did Variable X explain what happened in Variable Y?)" (Creswell, 1998: 17), this study searched for 'hows' and 'whats'. The initial forays into the topic described what is going on (Creswell, 1998: 17). Hence, the first question the study aimed to answer was how interdisciplinary public 
participation processes could foster the development of urban elements. Also, what roles design would assume in such a context. Then, it was necessary to understand how urban projects were developed, who was involved, and how the public participated in the decisions. Finally, the last query to be answered would be what could be learned from the processes analyzed. The lessons could later be applied to other cases.

The best way to approach such a problem is to address a specific project as a case study. A case study is an exploration of a 'bounded system' or a case (or multiple cases) over time through detailed, in-depth data collection involving multiple sources of information rich in context (Creswell, 1998: 61). Instrumental case studies are useful when the "the purpose is to investigate a particular phenomenon or theory and the case itself becomes less important other than as a vehicle for our investigation" (Pickard, 2007: 86). In this instance, the case was used as an instrument to illustrate a general issue (Creswell, 1998: 62).

The Preston Street rehabilitation project is fairly recent. This means that the researcher had access to a "wide array of information about the case to provide an in-depth picture of it" (Creswell, 1998: 39). Also, participants were able to remember fundamental facts related to the process. In short, contextual material was available to describe the setting for the case (Creswell, 1998: 39).

The fact that the research was predominantly qualitative does not mean, however, that quantitative techniques were not utilized in its course. As defended by the pragmatic worldview (Creswell, 2009: 10), the measurement instruments utilized included qualitative and quantitative methods which derived from the theoretical framework presented in the previous chapter. The data collection and analysis was based on grounded theory methods, the fundamental principle 
of which is to generate theory through "joint collection, coding, and analysis is of data" (Glaser \& Strauss, 1967: 43). This method of dealing with data enables the researcher to generate knowledge that could be applied to broader contexts, that is, "to undertake research to develop theory" (Creswell, 1998: 38).

In order to promote a methodological triangulation (Pickard, 2007: 86) (See Figure 11), data was gathered from multiple sources which complement each other, according to the qualitative research principles (Creswell, 1998: 19). Three different methods were applied in the data collection stage: interviews, questionnaires, and archival research. The next sections describe each one of them in terms of setting, sampling, measurement instruments, data collection procedures, and data analysis. Prior to the referred methods, a pilot study was conducted to provide a better understanding of the relationship between city users and the urban elements (See Appendix B for more details).

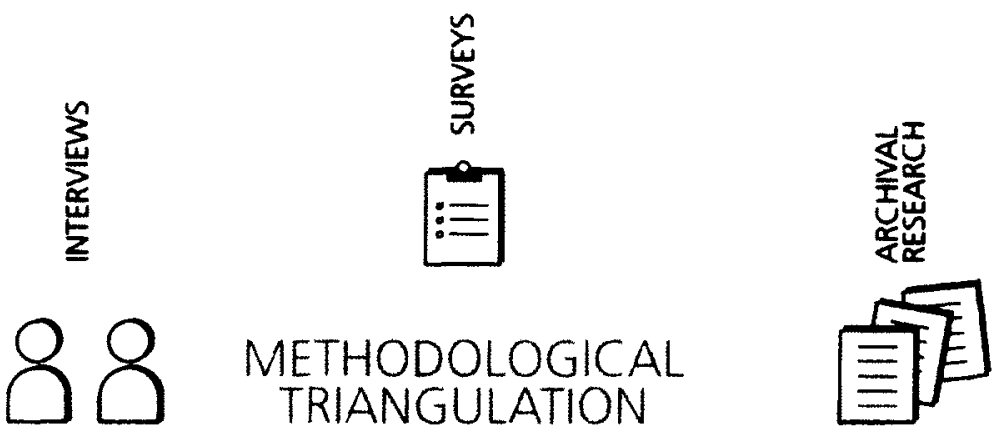

Figure 11. Methodological triangulation

Interviews with stakeholders who directly participated in the process were followed by surveys with users. By talking to the experts of the project, the researcher was able to acquire a general overview of the process and collect the aspects that were later evaluated in the 
questionnaires. Then, the public was asked to express their opinions on topics which had already been discussed in the interviews. This sequence of methods allowed the researcher to compare the experts' views on the streetscape elements with everyday user's perceptions. The archival research was conducted simultaneously with the other methods.

\subsection{Interviews}

Data collection methods in grounded theory involve primarily interviewing (Creswell, 1998: 38). Interviews were, thus, the first data collection method employed in the research, "for meanings are formed through experience and shared in the small talk of everyday life" (Friedmann, 1999: 8). The semi-structured interviews had an exploratory character and were conducted with the purpose of providing the researcher with an overview of the decision making processes related to the street rehabilitation. Moreover, the aim here was to identify the relevant issues that could be investigated in-depth.

The advantage of such a method is being able to obtain a large amount of information about the process. Besides providing the researcher with a better understanding of the process, they pointed to several options of issues that could be investigated in depth. Nevertheless, the large volume of data gathered may also be considered the weakness of the same method. As opposed to questionnaires, where only useful information is collected, in the case of the interviews, the researcher had to be able to identify throughout multiple notes the points which were relevant to the research. The criteria for distinguishing between valuable and useless data were always based on the research questions. Topics related to these queries and possible answers were considered important to the research. 


\subsubsection{Setting}

The interviews took place in locations suggested by participants. Interviewees frequently decided to meet in their workplaces. In other cases, they chose to answer to the questions in coffee shops located near their homes or workplaces.

\subsubsection{Participants}

The sampling procedure utilized in the research was purposive sampling. It included stakeholders in the Preston Street reconstruction project, and experts on public art and industrial design topics. Such experts took part in other urban projects in Ottawa or were members of the City of Ottawa's programs connected to urban issues.

Participants in the study were from diverse academic backgrounds and occupied diverse positions in varied organizations. In total, 12 people were interviewed. Among them, there was one landscape architect, two industrial/graphic designers, one project manager, one business owners' representative, two artists, two Public Art Program representatives, one community representative, one Italian community representative, and one manager of the Integrated Street Furniture Program. A complete description of participants' positions and backgrounds is presented in Appendix C.

\subsubsection{Ethics}

The project was reviewed and cleared by the Carleton University Research Ethics Board. The board members attested that the procedure would not offer any emotional or physical risks to interviewees. Interviewees voluntarily consented to answer to the 
interview questions and were also given the right to withdraw from the research until a specific date (Appendix D).

\subsubsection{Data collection procedures}

The semi-structured interviews were conducted according to a script (See Appendix E for examples of interview scripts) with questions that the researcher prepared before each session. When the interview developed in a different direction that was interesting to the research, the researcher probed for more details and added new questions to the dialogue.

Most of the queries were open-ended. The intention was to encourage the interviewee to talk as much as possible about the specific issues connected to the research and share their knowledge. Probing techniques were employed in order to stimulate participants to voice their opinions and concerns.

Since participants had different backgrounds and were involved in diverse ways in the process (or in some cases in different processes), the questions asked varied from interview to interview. Some inquiries, however, such as the level of satisfaction with the project were raised in the majority of the cases. Repeatedly, the interviewee put the researcher in contact with other stakeholders who were, then, be interviewed in the next interview rounds.

The interviews were conducted with the participants individually, at the time they suggested. The procedures took from 30 minutes to 1 hour on average, depending on the interviewees' availability. On many occasions, they chose to maintain the dialogue even after all the questions of the script were complete. In these cases, the duration of the interviews was extended by 30 or 40 minutes more. 
During the interview, the researcher documented important points and quotes through notes. The idea was to have an open conversation where participants could feel comfortable discussing their experiences about their interdisciplinary relations with other stakeholders as well as their feelings about the final results. No audio recorder device was utilized.

Participants in the interviews were occasionally contacted by email afterwards. In these instances, they were required to clarify issues which became apparent while the research progressed. Such queries referred most of the time to government policies and plans of action.

\subsubsection{Data analysis}

As is common in qualitative research, large amounts of data needed to be reduced to a few themes and categories (Creswell, 1998: 17). To that end, the researcher used an open coding process where "initial categories of information about the phenomenon" were formed by segmenting information (Creswell, 1998: 57). After each interview, notes were reviewed and the most important points were noted on small pieces of paper. At the end of the interviewing process, the notes were organized hierarchically in an affinity diagram (See in Chapter 4, Page 64, Figure 13). To each cluster of notes, labels that briefly described the group were generated. Later, clusters were grouped again in larger categories which were named accordingly.

With the fundamental categories of information defined, the researcher reviewed the interview notes. This time, the idea was to identify patterns in participants' perceptions of the process. Interviewees' quotes which reinforced such ideas were also coded. This was done with the objective of substantiating the findings and providing multiple perspectives (Creswell, 1998: 17). The final result of this stage of the data analysis was a table with the same categories as the 
affinity diagram (See Appendix F). Attitudes related to each category were quantified according to the number of people who expressed them. Finally, illustrative quotes completed the diagram.

\subsection{Questionnaires}

The purpose of survey research is to gather and analyze information by questioning individuals who are either representative of the research population or are the entire research population (Pickard, 2007: 95). The strength of questionnaires as a data gathering method is the ability to obtain quantifiable information about the general public's reaction to the street reconstruction. Emotions and experiences towards the space can be transformed into percentages and charts as in Chapter 4. Such methods allow for a balance between an interpretive and a more objective approach. Whereas surveys are designed to produce a generalization within the population, case studies are concerned with individual perception, beliefs and emotions (Pickard, 2007: 101).

The weaknesses of such a method are connected with the idea that the numbers are not capable of totally explaining participants' opinions. Regardless of the fact that people sometimes struggle to attribute low grades to aspects they do not like, the explanations and comments the public expressed during the sessions were utilized as a means to transform the numbers and percentages into richer information. This way, when a grade 1 in a scale from -3 to 3 was attributed to an element accompanied by strong statements such as "I hate them", the comment deserved more attention than the grade itself.

Questionnaires were used with the general public with the intention of grasping their opinions about the overall project, the pieces of art and street furniture which were installed on 
the sidewalks. If, on the one hand, the interviews focused on people who were directly related to the decision-making process; the questionnaires, on the other hand, concentrated on everyday people, the actual users of the space and their perceptions of the environment.

\subsubsection{Setting}

The setting for the completion of the questionnaires was Preston Street itself. This allowed participants to visualize the aspects they were judging at the same time as they answered the questions. Thus, points of the street where there were examples of the pieces of urban furniture as well as sculptures were selected. Figure 12 indicates the spots of Preston Street which served as the setting for the administration of surveys.

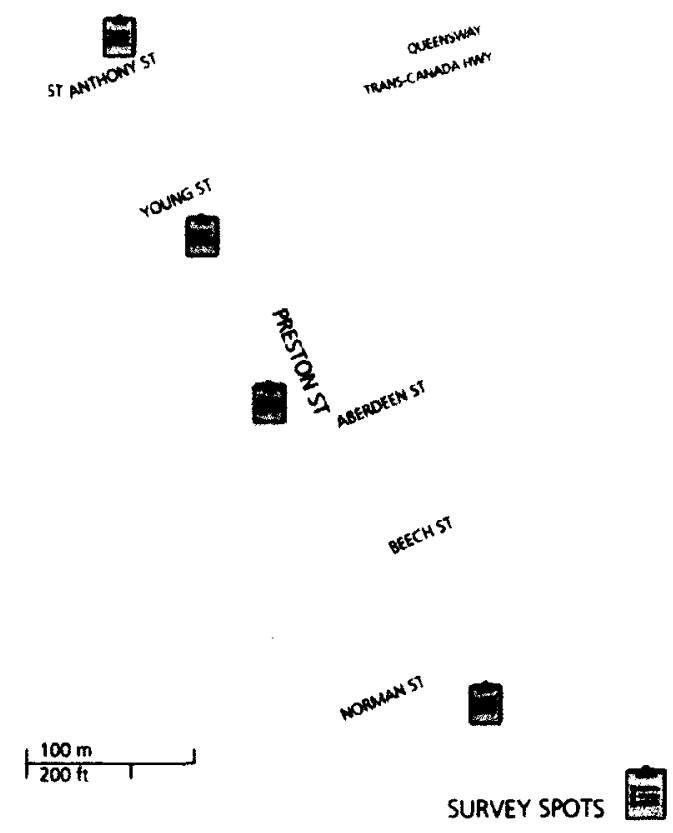

Figure 12. Questionnaires setting 


\subsubsection{Participants}

This time, a convenience sample of participants was utilized. People who were available and accessible to answer the questionnaire on Preston Street at the time the researcher was present were considered participants. No particular knowledge or experience of the topic was necessary to fill the survey out. The total sample included 30 people who were related to the street in varied ways, that is, visitors, residents, and employees.

\subsubsection{Ethics}

The questionnaire procedure was reviewed and cleared by the Carleton University Research Ethics Board as well. The board members attested that the procedure would not offer any emotional or physical risks to interviewees. The researcher guaranteed the anonymity of participants and the confidentiality of the information provided by them. Informed consent forms notified participants of the research goals (Appendix G). By signing the documents, interviewees agreed to voluntarily participate in the study. Debriefing sheets were also prepared to apprise participants about who to contact in case they had any questions or concerns.

\subsubsection{Measurement instruments}

An Overall Liking Score (OLS), "a rapid survey of occupant satisfaction" (Bordass \& Leaman, 2005: 350) was used as a basis to assess the users' feedback on the street reconstruction. The OLS is a post-occupancy evaluation technique that was developed by ABS Consulting in collaboration with the University of Manchester Institute of Science and Technology (UMIST) (ABS Consulting, n.d.). It is "an analytical approach that measures how 
people feel about their work environment" (ABS Consulting, n.d.). Overall, An OLS survey evaluates how much occupants like and how important they find each aspect of a building.

Even though this kind of questionnaire was created to evaluate indoor spaces, the questions were adapted in this case to suit the research needs. The structure of the survey and the scales were maintained nonetheless. The fact that OLS surveys can be rapidly filled out and provide a graphic representation of the users' likes and dislikes in a space represented a great advantage to the study.

An OLS questionnaire enables the researcher to calculate the likeness score of an environment through a formula which is detailed in Appendix $\mathrm{H}$. Responses to the questionnaires can also be represented in charts to provide the 'fingerprint' of a building (Levermore, 1994: 114) (Appendix H). This technique has been used since 1992 to assess over 100 buildings, and, for this reason, it is considered to be in a mature stage of development (UBT Feedback Portfolio: Techniques, n.d.).

\subsubsection{Data collection procedures}

As previously indicated, the researcher and an assistant positioned themselves in spots which allowed participants to view the items they should rate. They approached passers-by on the sidewalk, inviting them to participate in the survey. When people agreed, they were informed about the research goals and were asked to sign an informed consent form.

The researcher or assistant would, then, start to ask the questions. In some cases, participants preferred to fill the survey out by themselves. In these instances, interviewers positioned themselves beside the interviewees and stayed available to answer any questions and 
solve doubts. Most of the time, however, the research team administered the questionnaires. The process took on average 5 to 10 minutes. While discussing the questions in the survey, the interviewers would sometimes probe the participants for more comments and explanations, especially when they attributed the lowest and the highest grades to the aspects of the streetscape.

The survey (Appendix I) was divided into sections. The questions in section A touched on topics such as people's relation to the street, the amount of time they spent in public outdoor spaces, as well as their participation in public consultation meetings regarding the reconstruction project. Section B asked participants if they liked each aspect of the streetscape and how important they considered these factors. Even though the Little Italy Arch was installed prior to the reconstruction, it was featured in the questionnaire as an artefact, the scores of which could be compared to those of the sculptures. The last section required participants to rate their experience of the street. They were expected to situate their perceptions of the streetscape somewhere in a scale between beautiful and ugly, pleasant and unpleasant, unique and generic, pedestrian friendly and pedestrian unfriendly, and favourable to socialization and unfavourable to socialization.

At the end of the survey, the research team would thank participants for the time they spent answering the questions. In addition, they handed out debriefing sheets with the university ethics committee contacts, in case interviewees wanted to follow up. 


\subsubsection{Data analysis}

A survey software was utilized to help quantify participants' answers. Every response was uploaded into the system which was able to provide numbers and percentages related to each question. Answers to the first question were used as a filter to the analyze the likes and dislikes and the level of importance attributed to the aspects of the streetscape.

Besides obtaining the general results for the total range of participants, the idea was to make a comparison between the grades assigned by visitors, residents, employees and business owners on Preston Street. Charts of each group's responses to the section B of the survey were created in order to provide an immediate visual representation of the results (See Chapter 4, Pages 77-79, Figures 19-22).The likeness fingerprint and the overall liking score were also calculated.

Moreover, charts representing the answers to section $\mathrm{C}$ were generated. They allowed a rapid understanding of how participants experience and perceive Preston Street. By scrutinizing results, it was possible to recognize the space's qualities from the users' point of view.

Comments related to the questions were compiled. They complemented the numbers and percentages generated by the surveys. Often, observations regarding certain aspects of the street made by different participants coincided, which reinforced the importance of not only looking at the statistics but also examining the rationale that supports them.

\subsection{Archival research}

Archival research is the analysis of already collected and available sources of information to answer a research question or set of questions (Miller, 2007: 96). This last research method 
was employed to complement the data gathered through the two other methods. It consisted in examining textual documents regarding the City of Ottawa and the Province of Ontario's programs and strategies.

In the course of the interviews, some uncertainty concerning topics such as Business Improvement Associations (BIAs), the Percent for Art program, the Integrated Street Furniture program, and other strategies involving design and art emerged. The information provided by participants was not detailed enough to explain the complexity of such topics. The researcher, therefore, looked for documents that could describe them more in-depth. These documents were, on many occasions, recommended by the interviewees as a way to supplement and reinforce the data they provided.

\subsubsection{Data collection procedures}

Many of the textual documents which have been analyzed in the study are accessible on the internet. Searches on the City of Ottawa and the Province of Ontario websites were usually enough to obtain a soft copy of them. In case the researcher was not able to find them, expert participants were contacted to request sources for the required information. Less frequently, interviewees offered hard copies of documents relevant to the investigation. In addition, the researcher occasionally collected documents which were available in public consultation meetings. 


\subsubsection{Data analysis}

The archival research data analysis involved numerous documents issued by the City of Ottawa and the Province of Ontario (See Appendix J for a complete list of documents). The study of such documents had very clear and direct goals. Documents related to actual finished or ongoing projects were explored with the purpose of understanding how the process is/was conducted and who is/was involved in it. In this sense, the steps in the public art decision making process as well as the name of the stakeholders who participated in it were identified in the projects backgrounders and FAQs. As the archival research was done simultaneously with the other methods, the analysis of such files allowed the researcher to recognize individuals who should subsequently be interviewed .

Reports in connection with the city's plans for future years and guidelines for the development of urban spaces were inspected with the objective of detecting policies for design activity or the inclusion of design in Ottawa's public areas. Searches with the keyword 'design' were conducted in order to find out if the term was at the very least mentioned at some point in the strategic plans.

Since the policy regarding street furniture addresses a subject which is greatly related to industrial design activity, the Integrated Street Furniture program was more thoroughly reviewed. The objective was to understand the program goals and accomplishments. More specifically, the researcher intended to understand how the decisions regarding the objects placed in urban spaces would be made and the guidelines that would drive such actions. Finally, the analysis aimed to identify stakeholders who have been involved in planning and managing the program. 
The data collected through the archival research and the two other methods presented in this chapter are revealed in the following section of the thesis report. The discussion generated by the juxtaposition between the findings and the literature is disclosed subsequently. 


\section{CHAPTER 4}

\section{RESULTS}

The results of the data gathering process are presented in this chapter. They were ordered according to the categories which evolved during the data compilation and analysis. All topics explored here were selected specifically with the intention of answering the research questions. That being so, in the next sections, the researcher attempted to understand how an interdisciplinary participatory process functions in actual practice and if it is capable of enhancing the development of urban elements. As the case study takes place in Ottawa, this involves the context of the city, and its policies and strategies regarding public art and design. Then, the stakeholders who were involved in the process were listed and possible roles for designers were explored. The participatory art project undertaken by the artist cj fleury was also examined. Finally, with the purpose of comparing the stakeholders' view to the everyday users' perception of the project final results, the public's opinions about the numerous aspects of the street were exposed.

It is fundamental to reinforce that this portion of the chapter should, as much as possible, disclose facts exempt from the researcher's judgement and opinion. One must be conscious, nevertheless, that total impartiality and exemption is nearly impossible since the study followed a course determined by the choice of research methods, questions, and directions. In this sense, decisions assumed when the investigation was in progress have probably influenced its results. Still, in this part of the report, the researcher endeavoured to reproduce thoughts and opinions expressed by participants without including any value judgement. 


\subsection{Overview of the results}

The interviews allowed a general understanding of the rehabilitation process that was undertaken on Preston Street. The main ideas discussed in the meetings were organized in the affinity diagram below (Figure 13).

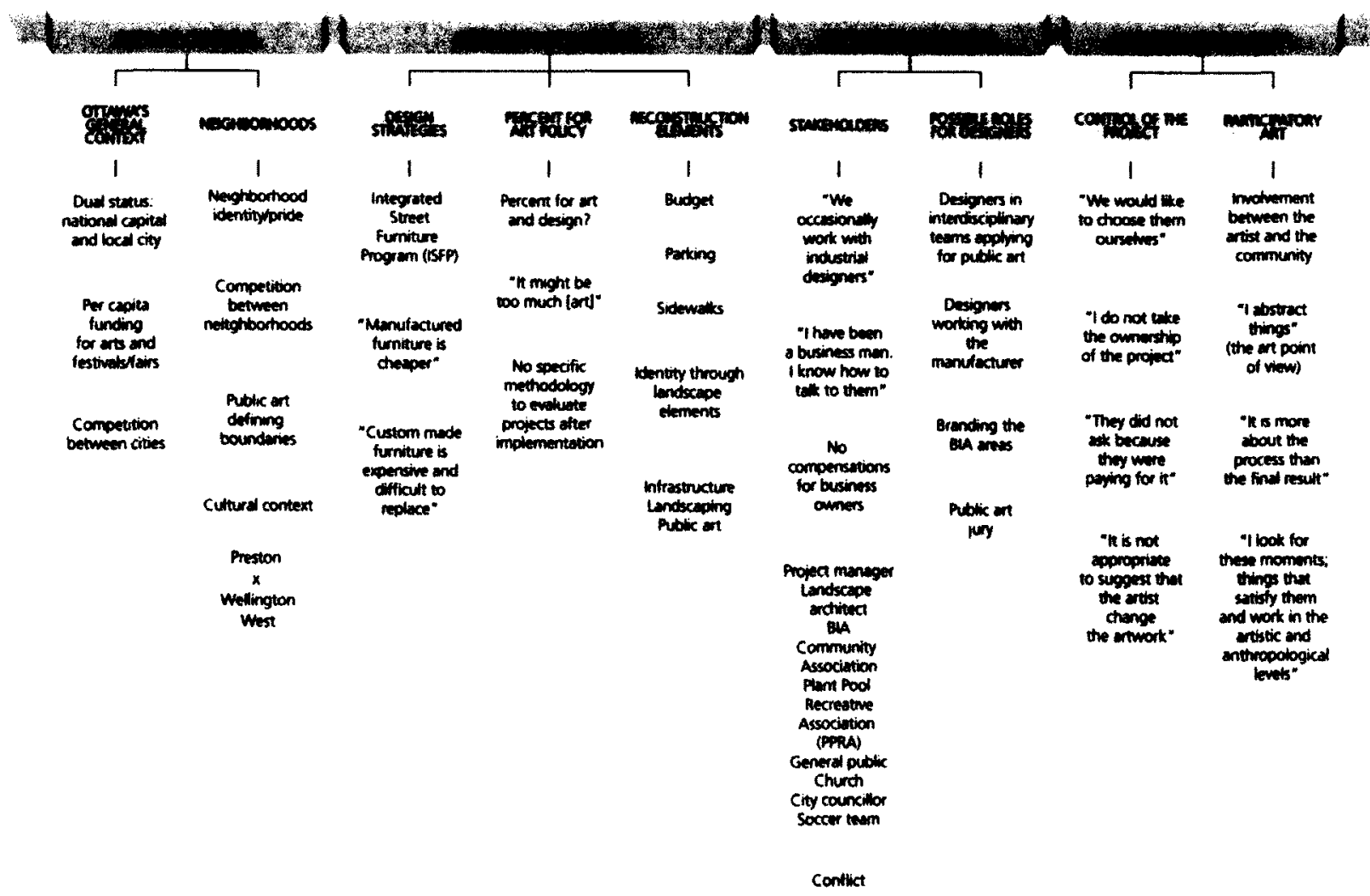

Figure 13. Affinity diagram

The categories and topics mentioned in the diagram served as a basis for a matrix for organizing the interviewees' behaviours and attitudes in groups. Participants' quotes illustrate and substantiate the findings. For more details, refer to Appendix F.

These categories are reviewed in detail in the following sub sections of the chapter. 


\subsection{City of Ottawa}

Despite the substantial increase in municipal per-capita funding for arts and festivals/ fairs, Ottawa has not yet achieved average competitiveness with Canada's six other largest single cities (City of Ottawa, 2010a). Besides the need for awareness, education, incentive and recognition, Ottawa's dual status as the national capital and a local city poses a challenge for the local sector. The city represents the entire country; however, it has its own identity to present, its singular cultural, natural and documentary heritage to preserve, and its local artists to support (City of Ottawa, 2010a).

\subsection{Ottawa's strategies}

Event though the investments in art and culture might be far from the ideal, the city has developed some strategies which are intended to preserve and develop the city's identity as well as foster its competitiveness with other cities in Canada and around the world. "We want to transform Ottawa into an interesting place where people want to stay", claimed Julie DuPont, City of Ottawa Cultural Planner.

\subsubsection{Public Art Program and the Percent for Art policy}

The art strategies adopted by the city aim to preserve its local identity as well as to turn it into a relevant cultural destination for tourists. To that end, the Public Art Program is responsible for three main areas: (1) acquisitions, (2) exhibitions, and (3) commissions (City of Ottawa, n.d.b). DuPont explained the community engagement projects and the Percent for Art policy are connected to the commissioning area. According to this policy, one percent of the funds for new 
municipal spaces is put aside for public art in order to beautify urban spaces and make art accessible to every citizen (City of Ottawa, 2010b).

The process of choosing the artefacts to be placed in public spaces starts with the City of Ottawa's call for expressions of interest from regional artists. The request for proposals includes deadlines, a neighbourhood profile, selection criteria, design requirements, budget, and a description of the submission procedure (City of Ottawa, n.d.d).

After researching the community's historic and cultural context, the artists submit their proposals. "The Public Art Program receives on average 20 to 25 projects, which are evaluated and shortlisted to 3 to 5 finalists", DuPont explained. The finalist artists then prepare maquettes to be displayed in the public consultation sessions. These events are open to the community. Participants are invited to talk to the artists and write comments about the projects.

Considering the comments made by the community, an Art Selection Committee chooses the winning proposal. Melissa Ramsden, the City of Ottawa Public Art Project Coordinator, clarified that the jury is usually composed of the project manager in an advisory role, a landscape architect/architect, artists, and community/business/facility representatives with some public art experience. The evaluation criteria comprise artistic excellence, experience, architectural integration, reflection of the natural and cultural environment, public safety, and durability (City of Ottawa, n.d.c). DuPont reinforced that the jury has the final word because they are the experts. In her words, "We want good art".

The last stage of the process consists of fabricating and installing the artefacts. The final product unveiling is commonly followed by opening celebrations, walking tours with the artists, information sessions, and community activities for children. These events are intended to help 
people engage with and recognize the new urban elements as part of the community environment. Ramsden believes that when the community is well organized, as in the case of Wellington and Preston Streets, the results are more positive.

The Public Art Program receives some feedback from the community through press clippings, phone calls, and conversations during the information sessions. According to DuPont, in some instances, it takes some time for the community to develop a connection with the pieces. Nonetheless, no specific methodology is used to measure the success of the implemented projects and their economic impact. Ramsden expressed interest in having the results of such projects evaluated.

\subsubsection{Integrated Street Furniture Program}

Other than carrying on a very specific public art program, the city of Ottawa does not seem to have another incentive program for the development of unique products for its public spaces. It does, however, have plans to unify the appearance of its street furniture equipment. The Integrated Street Furniture Program (ISFP) intends to "improve the public realm by providing consistent, high quality, and flexible street furnishings that will extend to urban, suburban, and rural areas" (City of Ottawa, 2009: 6). Based on successful examples of a number of North American cities, the program aims to involve the private sector in the design, fabrication, installation, maintenance and replacement of the pieces of street furniture. These services are to be provided by such companies at little or no cost to the municipality in exchange for advertising rights. 
The ISFP development process to date has included public consultation events, stakeholder interviews, consultations with BIAs (Business Improvement Areas) and workshops with the design community (City of Ottawa, 2009: 18). Such discussions generated the core design principles which should guarantee the quality of the urban elements. Hence, the artefacts must be "functional, modular, innovative, accessible, and appropriate to Ottawa as the Nation's Capital" (City of Ottawa, 2009: 20).

A Request for Proposal (RFP) for an array of street furniture pieces was published in 2010. Nevertheless, only one submission was received by the deadline on June 14 . According to Lee Ann Snedden, the City of Ottawa's former Integrated Street Furniture Project Manager, this single proposal did not comply with the RFP requirements. Currently, the City of Ottawa plans to revise and examine its advertising strategy and the program is on hold.

\subsection{Preston Street rehabilitation}

This subsection turns to the specific case study conducted on Preston Street. It clarifies who the stakeholders were and how major decisions were made in the course of the project. In addition, it uncovers the stakeholders' view of industrial design and explores the art process undertaken by the artist selected by the public art jury.

\subsubsection{Stakeholders}

An extensive list of stakeholders was identified through the research. The following image (See Figure 14) represents the level of involvement of the stakeholders and the public participants in this research process. The lines indicate connections between them which were 
recognized during the project. The researcher organized the stakeholders' structure into core, secondary, and tertiary stakeholders.

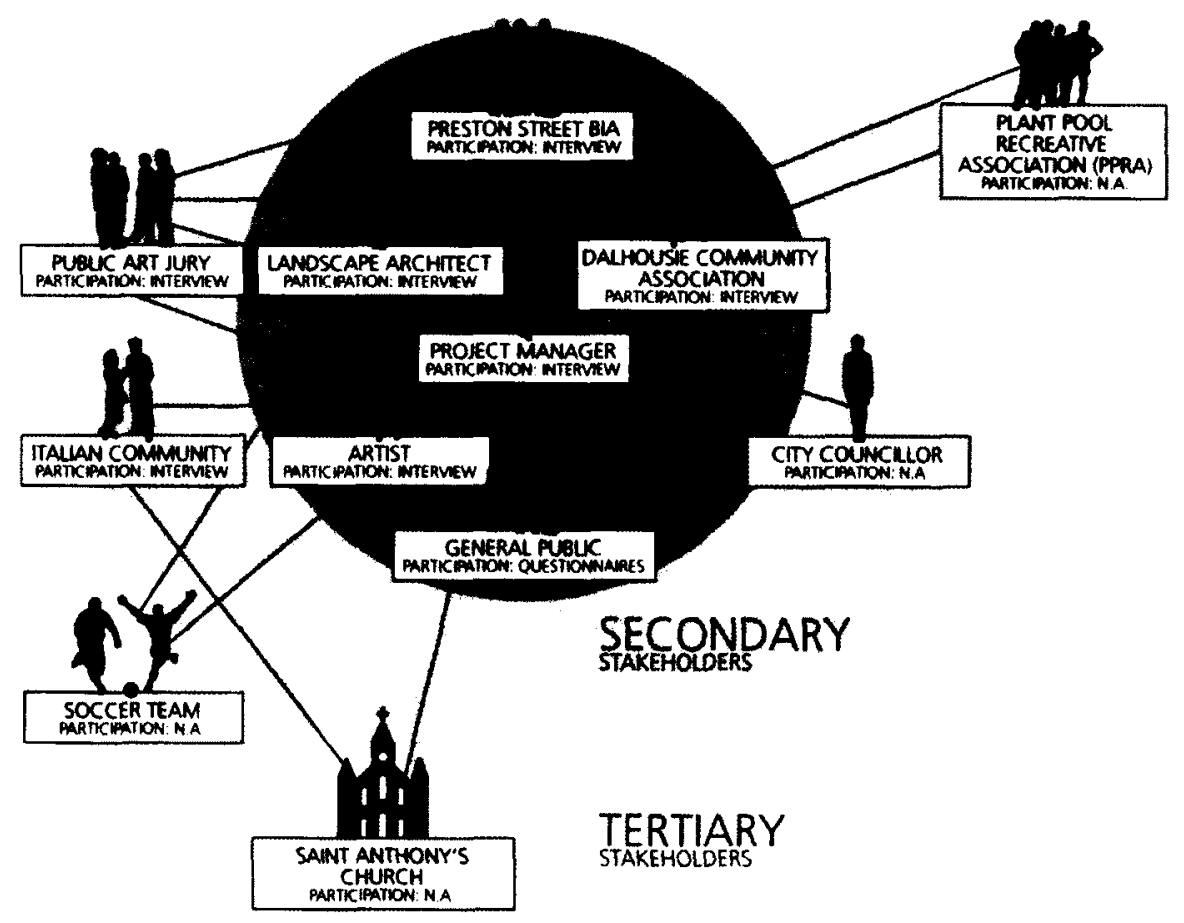

Figure 14. Stakeholders diagram

As one could expect, the core group directly participated in the process. Their contribution to the project was therefore more evident. Secondary and tertiary stakeholders were occasionally involved in the decision-making process. Their opinion was normally requested when aspects of the project could directly affect their lives. In the case of the soccer team, for 
instance, the field was also to be included in the reconstruction. For this reason, they approved modifications related to this area.

The researcher gave preference to contacting individuals who had a more active participation in the process. In this sense, at least one representative of each entity in the core group was approached during the study. Some members of the secondary group participated in interviews as well.

Rather than trying to explain the dynamics of the entire process, this study clarifies some relevant aspects of the decision-making process regarding the urban elements. Open House meetings were organized for the purpose of congregating experts with the public. In these assemblies, the project was presented to the community and community members were provided with an opportunity to discuss the proposals. Smaller meetings with a Public Advisor Committee were also organized. This committee, which had a more decisive role in the process, was composed by members of the Preston Street Business Improvement Area and the Dalhousie Community Association. According to Ravi Mehta, the Preston Street Project Manager, it was possible to have more focused discussions and "better immediate feedback" in these more intimate gatherings.

Whereas the decisions related to public art were made according to procedures related in section 4.3.1 (Public Art Program and the Percent for Art policy), the choice of the street furniture was in part accredited to the Preston Street Business Improvement Association (BIA). "They selected one of the options I presented to them", explained Chantal Gaudet, the Landscape Architect. 


\subsubsection{Possible roles for designers}

The researcher did not identify any industrial designer directly involved in creating solutions for the project. When questioned about custom made street furniture, which figures as a way industrial designers could participate in the process, many decision makers agreed that custom design is more expensive than manufactured products. Furthermore, they had the opinion that this former sort of furniture is more difficult to replace.

Some interviewees, however, envisioned possible roles that these professionals might play. Ravi Mehta, the Project Manager, believed that they could help guide both the installation and winter disassembly processes. To him, furthermore, "benches do not always follow the same installation pattern. Designers could make the location of the bolts more consistent." Mehta also points out how difficult it may be to empty litter bins. "I think designers can help make this process easier."

cj fleury, the artist who won the City of Ottawa public art competition for Preston Street, anticipated another opportunity for designers in this context. "Teams can be interdisciplinary. I applied with the intention of working with the novelist Mark Frutkin, who has studied Italian culture and written a book specifically about Italian piazzas. I do not see why industrial designers could not apply with artists for public art projects as well". In fact, designers have already participated in juries that evaluate the art submissions. In the case of Preston Street, an industrial designer was indeed involved in the art selection process. Carla Ayukawa lives in the neighbourhood and believes that her background in product, environmental graphic design and exhibition design helped in the decision regarding the projects that were installed on the street. 
“Designers have knowledge about materials, maintenance, and longevity, which can be beneficial to the process. They also have the notion of how pieces fit in the environment".

James Acres, a graphic designer, was a judge in the Hazeldean public art project also conducted by the City of Ottawa. He is convinced that his design education and experience supported the evaluation of the artworks. "I was capable of observing criteria such as legibility, level of detail, longevity, and integration of the pieces in the space". He is of the opinion that designers have more to contribute to public spaces. "I think there is more room for collaborations between artists and designers. You go to other cities and you see a pretty interesting integration between design and art".

\subsubsection{The community-based art process}

The method utilized by cj fleury to develop her art project called 'Postcards from the Piazzas' deserves distinct attention in this study. Apart from the consultation process that happened in the open house meetings, the artist included the Italian community in the development of the sculptures in a deeper way. fleury interviewed community members in their houses, business places, restaurants, at the Saint Anthony's Soccer Club and on the street. She contacted diverse groups such as the elderly, shopkeepers, organizers of the bicycle races, and the Preston Street Business Improvement Association. In some cases, people helped her develop concepts so that they would be presented in a correct and respectful manner. Giovanna Panico, a member of the Italian community, was a key contributor to the process for instance. Non-Italians also participated providing valuable information about activities on Preston Street in the past and expressing their perceptions of Italians in Canada. As an artist, however, fleury defends her 
singular role and the responsibility of driving the project to a cohesive completion, on time and on budget.

This was not her first experience in participatory art nonetheless. Her earliest formal project involving the community was Enclave, the Women's Monument Against Violence at Minto Park in Ottawa, which was co-designed with the landscape architect Mary Leigh Faught. The development of the artwork included numerous meetings with the Women's Urgent Action group as well as other fundraising and publicity activities. "At this point, I noticed that art could make changes to public spaces and to society." That memorial became a place for people to gather every time a woman is murdered. The impact of this art project made cj conscious that art could serve wider concerns. "Participation became central to my interest".

The participatory character of her art process was very well appraised by stakeholders interviewed in this research. Lori Mellor, the Preston Street BIA Executive Director, affirmed that cj got into the psyche of the community. "She talked with the community about their stories and triumphs. The Italian community is so proud"'. Carla Ayukawa, member of the public art jury for the Preston Street reconstruction, revealed that considerable weight was put into community involvement in the evaluation process. According to Ayukawa, it was important that individuals be able to participate. "It was more about the process than the final result. The work would be shaped by what the artist would learn from the interviews".

In this sense, cj's work was truly connected to the concept of new genre public art. "With the community at the centre of the art making process, the art-object becomes secondary to the process itself', as stated by Lulashnyk (1999: 6) in her M.A. thesis. The community is 
considered a creative and imaginative entity and the process of getting involved with the community members and working with them is what matters to fleury.

\subsection{The general public's perspective}

Even though fleury's methods and work were viewed positively by many stakeholders interviewed in the study, it was necessary to listen to the general public's perception not only about the sculptures but also about the results achieved by the reconstruction in general. In the surveys conducted on Preston Street, the majority of respondents (57\%) live right there in Little Italy. The other segment (43\%) breaks down into visitors (30\%) and people employed in the neighbourhood (13\%). The following chart (Figure 15) illustrates the participants' relation to Preston Street.

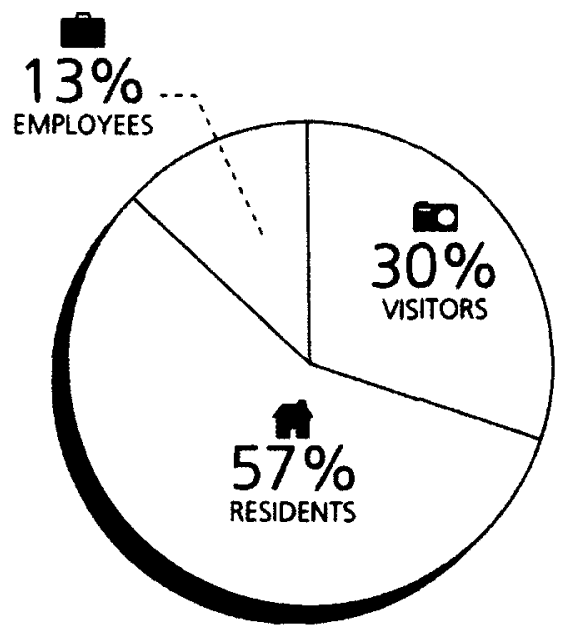

Figure 15. Participants' relation to Preston Street

Most respondents (37\%) spend more than 2 hours per week in Preston Street's public outdoor spaces. The second largest category of participants (23\%) usually stays in these spaces 
for less than 30 minutes over a week. A total of $20 \%$ enjoy the street's public areas for 1 hour a week whereas $13 \%$ benefit from such places for approximately 2 hours a week. Only $7 \%$ spend only 30 minutes per week in these areas. Figure 16 represents the time participants spend per week in Preston Street's public outdoor spaces.

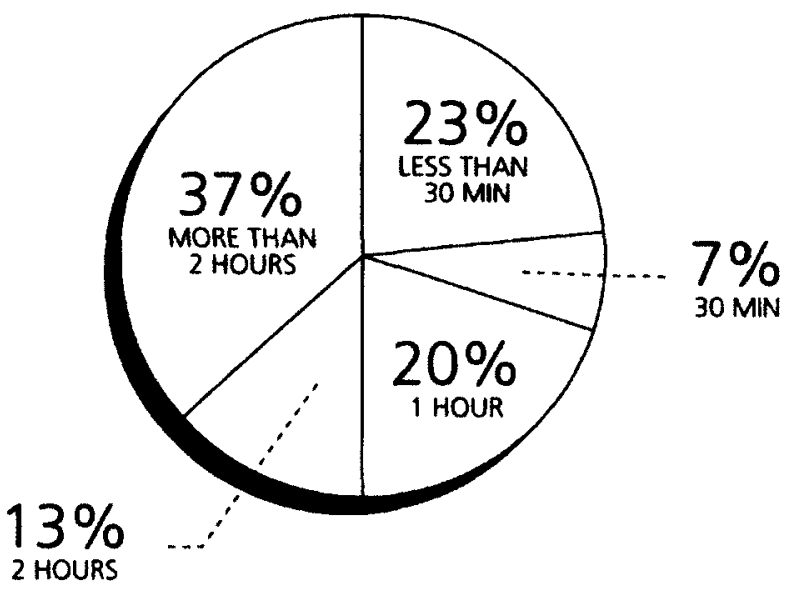

Figure 16. Time spent per week in Preston Street's public outdoor spaces

The activity most performed on Preston Street is walking, representing a percentage of $39 \%$. Following that, eating is the second most common activity on the street, being practiced by $20 \%$ of respondents. Shopping, exercising and sitting were other activities mentioned by participants. Such activities describe respectively $19 \%, 11 \%$ and $11 \%$ of the responses. Figure 17 breaks the activities down into their specific percentages. 


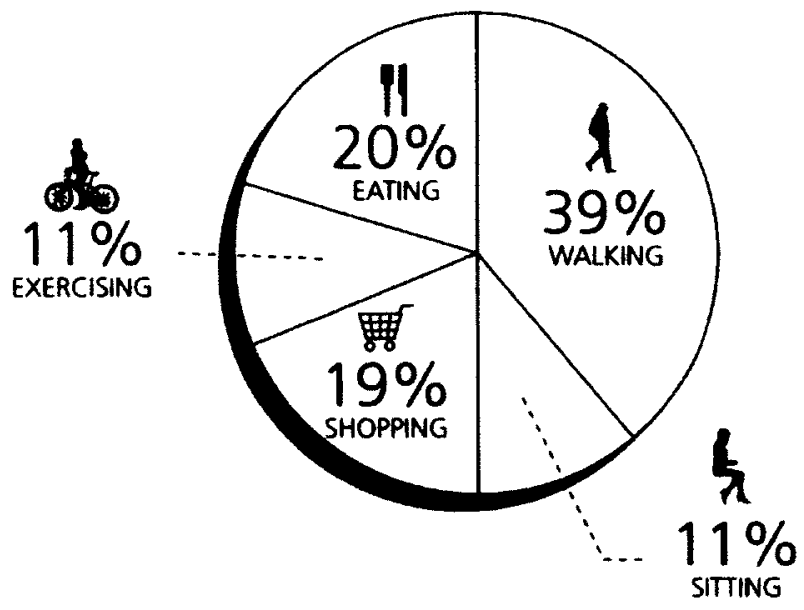

Figure 17. Activities performed in Preston Street's outdoor spaces

Only $7 \%$ of the total of participants took part in public consultation meetings. This percentage indicates that, among 17 residents, 9 visitors, and 5 employees, only 2 respondents were involved in the presentations regarding this reconstruction project. Figure 18 represents the percentage of participants who engaged in public consultation meetings.

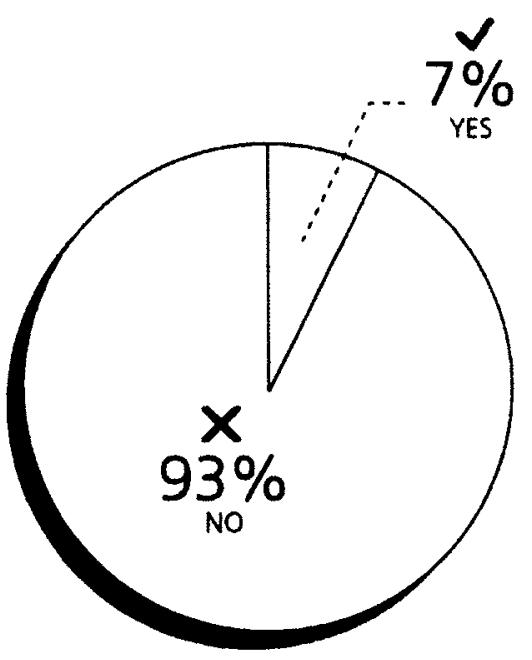

Figure 18. Participation in public consultations 
Among the public participants, the elements most liked by these respondents are the sidewalk space with a 2.27 out of 3 score, followed by the bench design with (score: 1.83 out of 3), the street lamp design (score: 1.77 out of 3) and the amount of trees (score: 1.5 out of 3). The design of litter bins and tree grates received an intermediary likeness evaluation on average. They added up to a score of 1.27 and 0.93 out of 3 points. The elements least liked by respondents were the Little Italy arch with a -0.1 out of 3 score, succeeded by the sculptures (score: 0.2 out of 3) (Figure 19). For comparisons between the likeness scores that residents, visitors, and employees attributed to the urban elements, consult Appendix K.

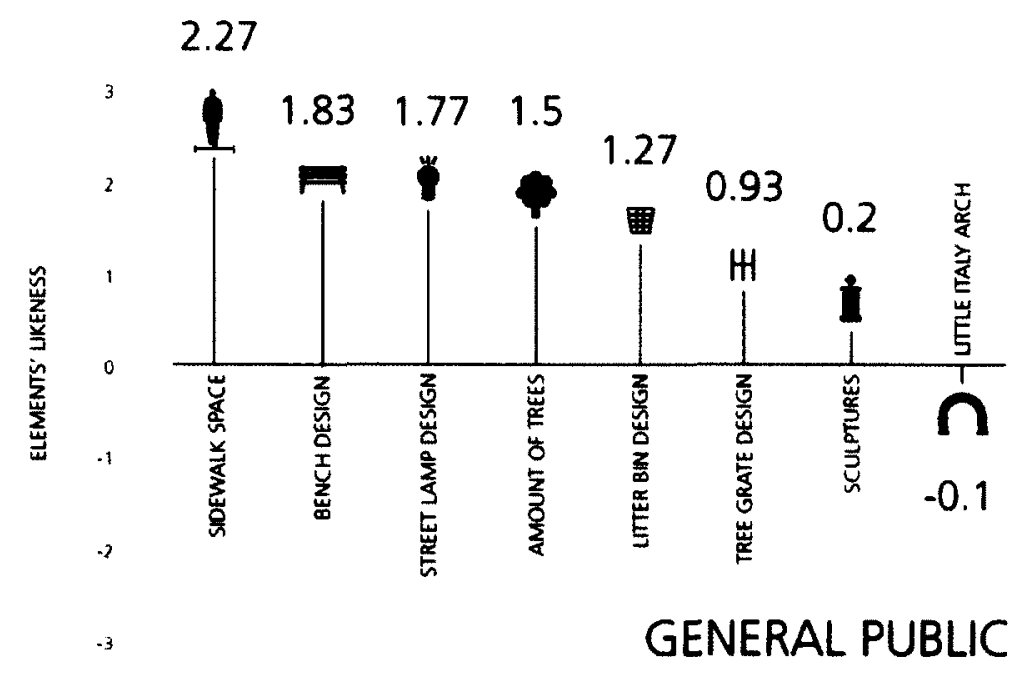

Figure 19. Elements general likeness

The elements' likeness and importance might differ. This means that respondents may not like some of the elements features but might recognize their importance in the system. In this case, the elements' likeness seemed to diverge from the importance participants attributed to them. According to respondents, the amount of trees (score: 2.6 out of 3), sidewalk space (score: 2.4 out of 3), and street lamp design (score: 2.17 out of 3) are the most important elements for 
instance. The design of the litter bins and the benches also received the relatively high scores of $2.1,1.67$, and 1.53 out of 3 points. The arch and sculptures received an importance score higher than their likeness score (1.4 points out of 3 ). To participants, the least important elements are the tree grates with a score of 0.43 out of 3 points (Figure 20). For comparisons between the importance that residents, visitors, and employees attributed to the urban elements, refer to Appendix K.

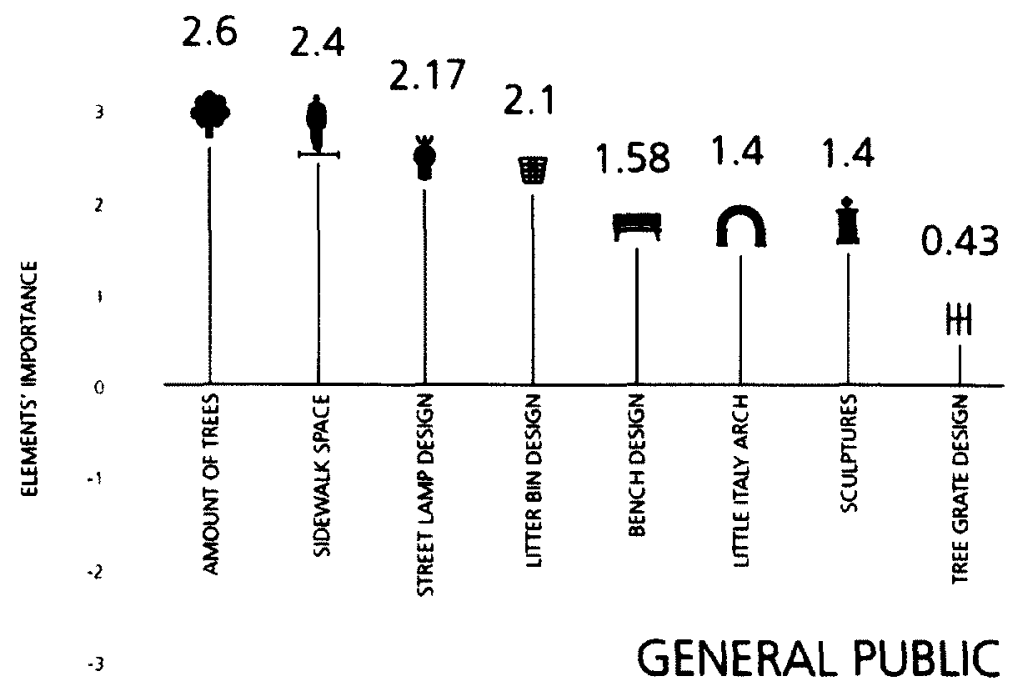

Figure 20. Elements general importance

The likeness fingerprint includes both the likeness and the importance score, normalizing questions score to +100 and -100 . By observing Figure 21 one can notice that all aspects received a positive average score. As such scores are rather similar, not many insights resulted from the visual analysis of the chart. 


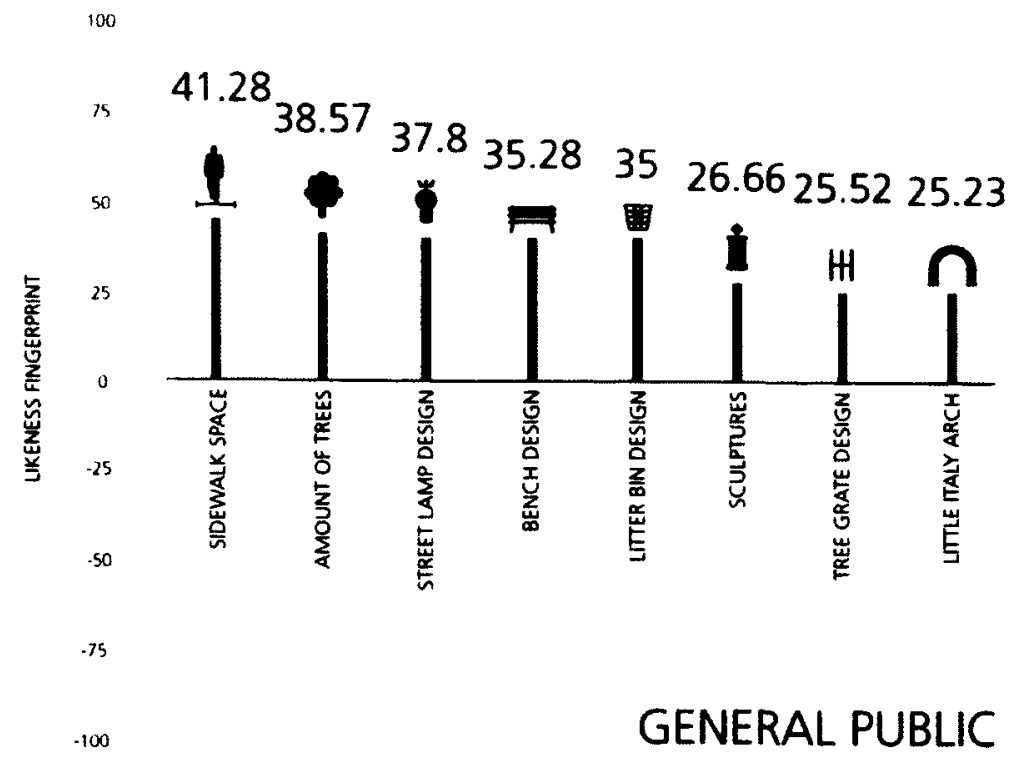

Figure 21. Likeness fingerprint

The overall likeness score is the average of the fingerprint bars. In this case, the overall likeness score of the street was $33.17 \%$ (Figure 22).

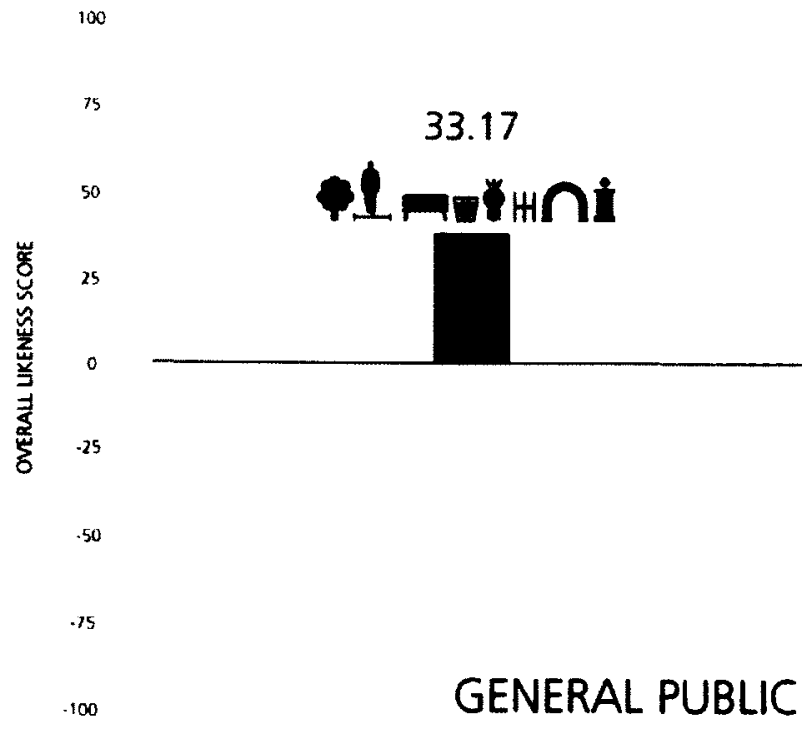

Figure 22. Overall likeness score 
The semantic scaling questions supplement the liking queries (Levermore, 1994: 113). In this questionnaire, the semantic section was intended to provide an understanding of how the users perceived the general space. Rather than rating elements separately, participants evaluated the overall street qualities. They were required to situate their perception of the street on a scale that went from 1 to 7 , where 1 was the most positive version of the attribute and 7 , the most negative. The answers to this set of questions concentrated mostly on the positive extremity of the attribute scale. One might note, nevertheless, that the pleasure of the experience, the pedestrian friendliness, and the socialization aspects received more favourable grades than the street appearance and uniqueness. This comparison becomes clearer when the graphic representations in Figures 23, 24, 25, 26 and 27 are observed. The charts represent the users evaluation of the space in a scale from 1 to 10 , where 1 is the most positive version of the quality and 7 is its most negative form.

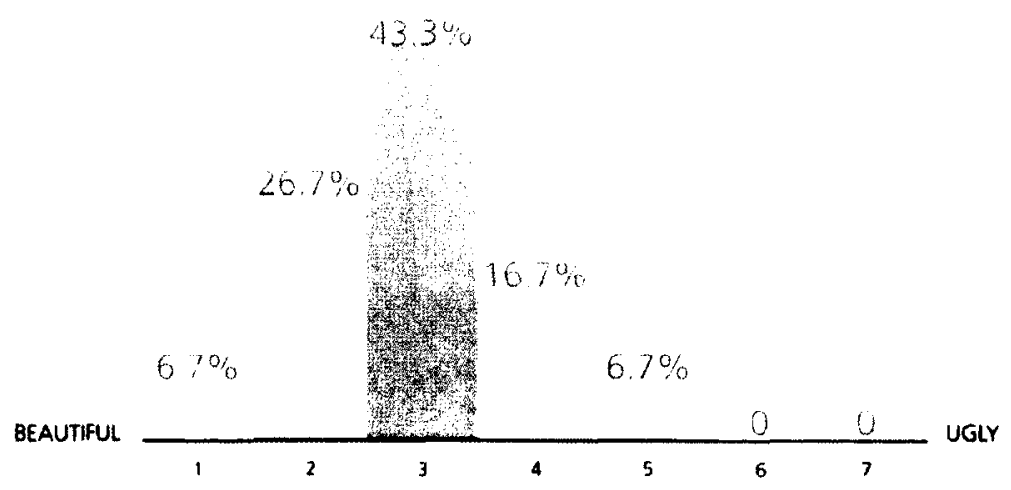

Figure 23. Beauty scale 


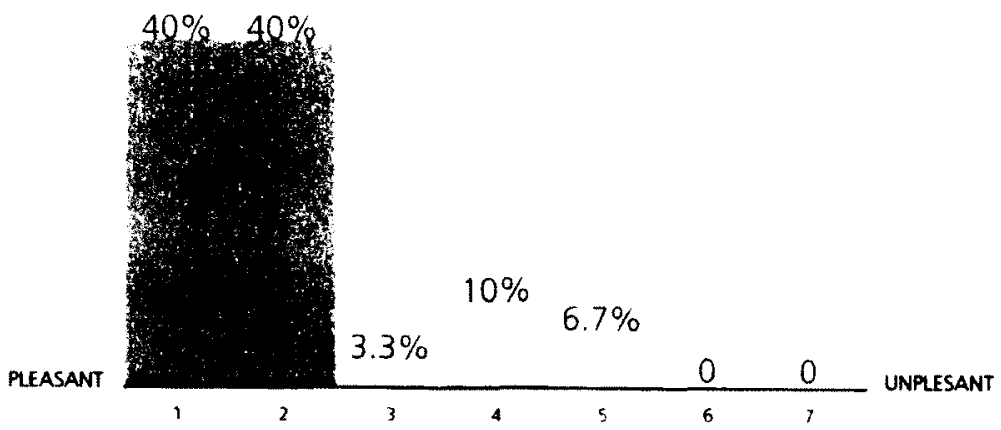

Figure 24. Pleasure scale

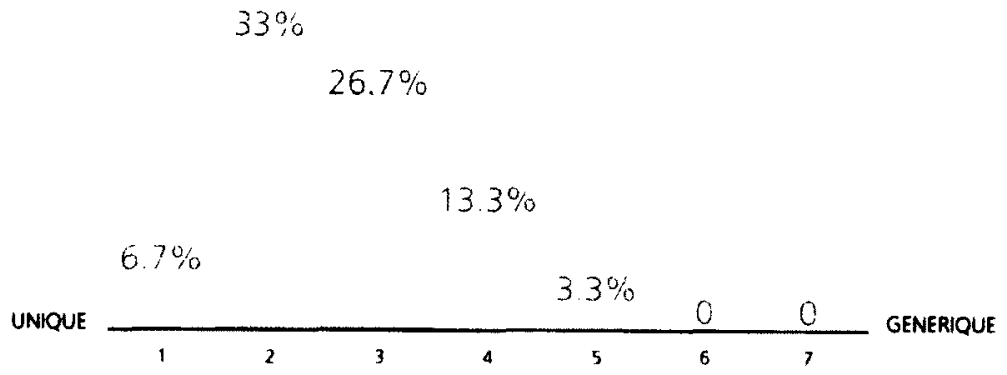

Figure 25. Uniqueness scale

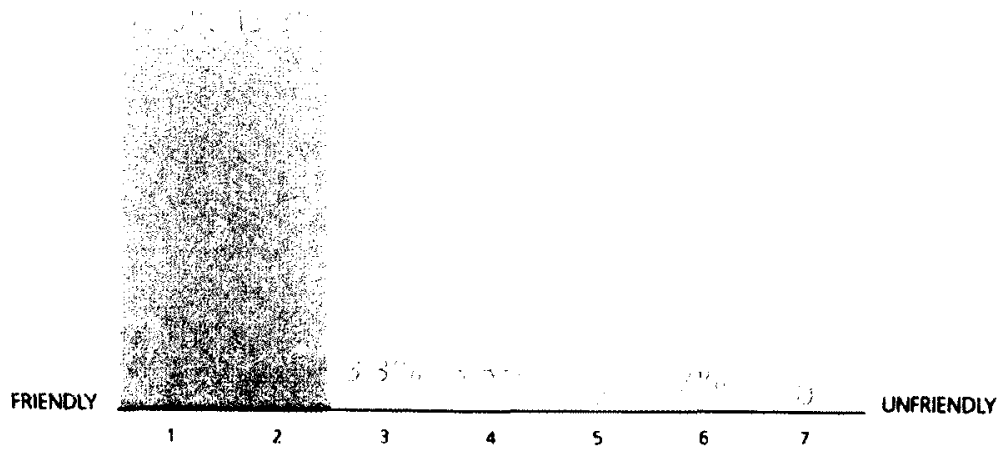

Figure 26. Pedestrian friendliness scale 


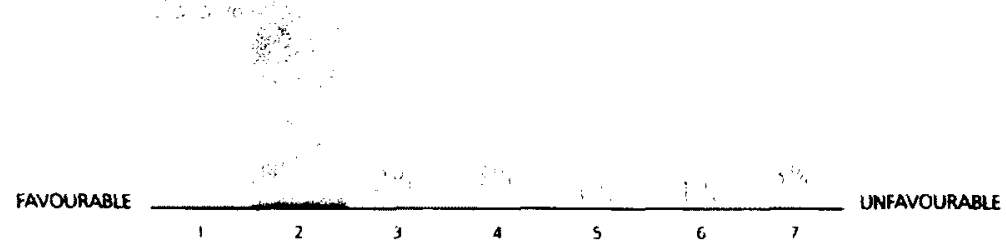

Figure 27. Favourableness to socialization scale

The public's comments about the streetscape elements (Table 1) support the grades they attributed to them. It is easier, for example, to understand why users rated tree grates in a relatively low position when one analyzes the repeated remarks about their rusty state. Observations about the arch and sculptures are also clarifying. It seems that people consider it important to have a separation between neighbourhoods. Nevertheless, the appearance of the Little Italy arch may not come across as a favourable feature.

In regard to the sculptures 'Postcards from the Piazzas', the public showed signs of being aware of the importance of having art on the streets. Many of the respondents, nonetheless, declared not to understand them. Some also stated that they had never noticed them or that their style did not please them. Of course, there were users who revealed that they liked and admired them as well. 
Table 1. Public's comments

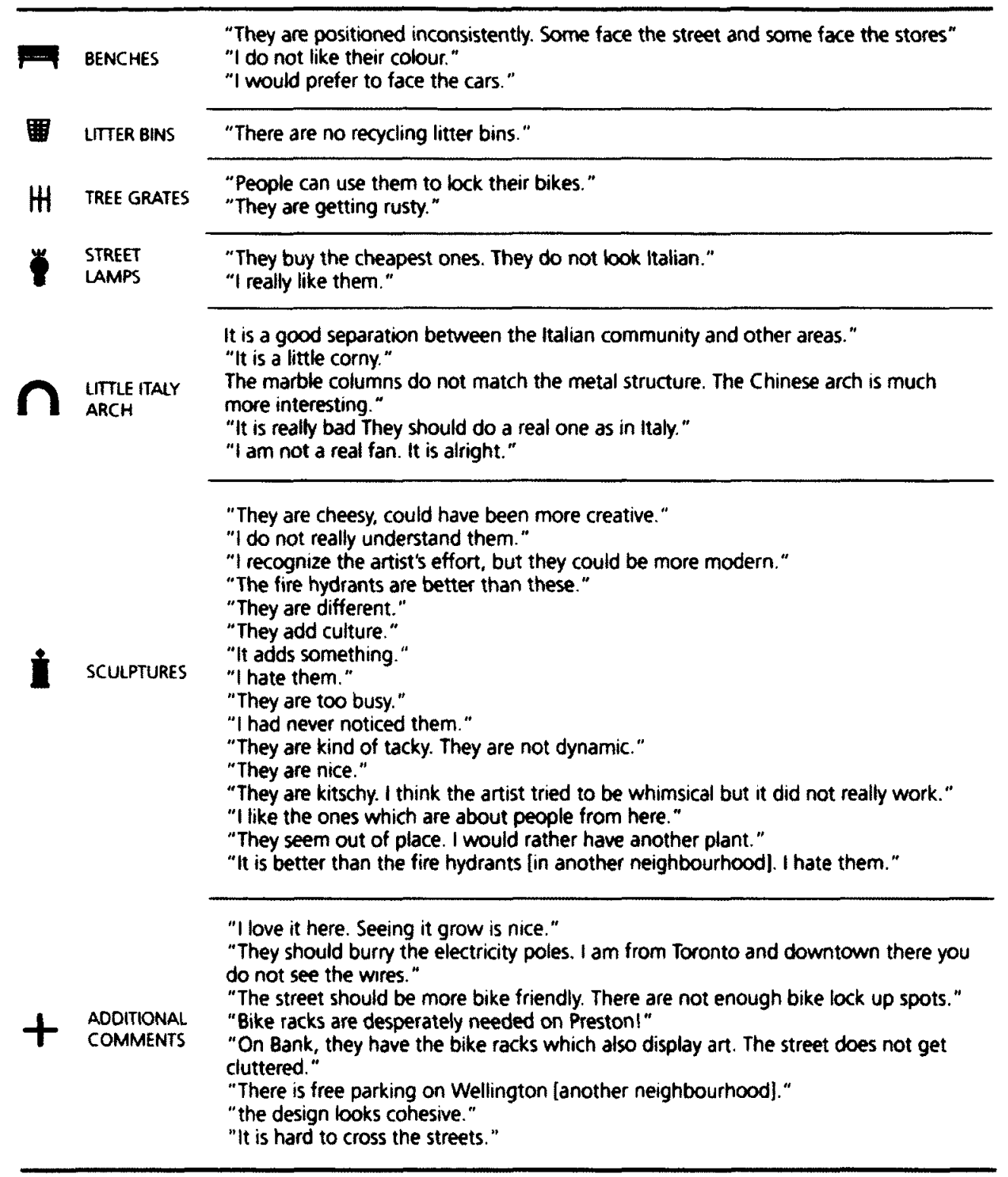

Additional statements connected with other elements may also be clarifying. They may

help improve the street usability. The most remarkable ones concern sidewalk space and 'bike

friendliness'. Some members of the public emphasized the lack of bike lock up spots and the sidewalk clutter. 


\subsection{Summary of findings}

A project such as the rehabilitation of Preston Street involves an extensive list of stakeholders. This interdisciplinary process faces hurdles such as the different languages and forms of representation inherent in each profession and the interests that each entity represents. Such factors occasionally led to conflicts.

One of the most significant findings of the research was that designers seem to be practically absent in projects regarding urban spaces in Ottawa. Furthermore, the city has no specific strategy to leverage design activity as an aspect of the local culture.

Even though industrial designers are rarely involved in the discussions connected with the projects, the population is invited to participate in open house meetings where proposals are presented and deliberated. Only a segment parcel of the community, however, appears to attend such assemblies. Only 2 out of 30 respondents participated in the public consultation meetings.

Albeit the slight divergencies between residents, visitors and employees, the population showed signs of being rather satisfied with the overall results of the Preston Street rehabilitation process. The majority of people spend more than two hours on Preston's outdoor spaces, performing activities such as walking and eating. The public rated most of the streetscape elements with average to low scores.

The most significant discrepancy concerned the Little Italy Arch and the public art installation. Despite the fact that these elements received low likeness scores, they were considered rather important by respondents. Whereas the former apparently did not result from a participatory process, the latter involved the community in its development stage. Although interviewees demonstrated extreme contentment with the sculptures, many street users declared 
not to have noticed or understood them. The same users considered the overall space more pleasurable and pedestrian friendly than beautiful and unique.

The discussion generated by these findings is unveiled in the following chapter. Debates about the effectiveness of the process and possible opportunities for improvement were also reserved for the discussion section. 


\section{CHAPTER 5}

\section{DISCUSSION}

Prior to the data collection, the research questions concentrated on how interdisciplinary participatory process can foster the development of urban elements and what roles design could play in this context. After gathering and analyzing the data, the inquiries slightly changed their focus. Noticing that designers were not involved in the development process, the research started to build around questions such as how to include designers? and how to improve this interdisciplinary process? The latter inquiry also embraces the sub-questions how to achieve more user participation?, how to obtain results that are as meaningful to the population as to the stakeholders?, and how to obtain more cohesive results?

This section endeavours to integrate the theoretical background presented in the literature review with facts and events identified in the case study. The research attempted to recognize phenomena described by scholars in factual circumstances in order to discuss the previous questions. It results in suggestions for enhancing the process as well as recommendations for further research to be developed.

\subsection{The system of meanings associated to participatory processes}

By observing the stakeholders reactions to the reconstruction project, it makes sense to state that their participation influenced their views about the final results. The fact that these agents dedicated their time and efforts to the rehabilitation of the street might have prompted an emotional attachment to the space. The idea of the strong connection with the street is supported 
by statements such as " $M y$ business owners take very good care of their properties" by the Preston Street BIA Executive Director Lori Mellor and "The other thing I am very proud of is that [after the reconstruction] people are starting to make improvements to their facades" by the landscape architect Chantal Gaudet. Eric Darwin, President of the Dalhousie Community Association, also demonstrated a strong connection with the project by stating "We raised that structure so that it became a bench". When stakeholders have such intense relationship with the project, it may be difficult for them to have an impartial judgement of the process outcomes.

In the participatory art process that was undertaken by cj fleury, this point becomes even more perceptible. Stakeholders demonstrated great satisfaction with the method employed by the artist. To them, the fact that community members were somehow involved in this creative activity may have imbued the sculptures with several symbolic qualities.

It is possible, for example, that the involvement of everyday users in this aspect of the project symbolized to direct stakeholders that the reconstruction process was a democratic action. By allowing local people to participate more in depth in the development of public art, decision-makers may feel that they have practically promoted the full participation of the public, which implies that everyone had equal influence in the overall decision making process. Furthermore, the dialogue between the artist and Italian community members may have indicated to direct participants that the sculptures would incorporate authentic Italian characteristics.

The research attempted to discover if the symbolic meanings that the urban elements represented to direct stakeholders would also be recognized by the general public. As defended by Barthes, the urban context is resistant to fixed significations (Barthes, 1967), and, as in the 
example of the Eiffel Tower, people may interpret urban elements in a manner completely different from the planner's intention (Barthes, 1979) (For more details, see Chapter 2, Page 15). It is fundamental to note that, in contrast to the gardens in Vienna whose meanings "evolved historically and spatially" (Rotenberg, 1996: 88) and were learned by city residents as children (See Chapter 2, Page 16), the changes to the landscape of Preston Street were less gradual and less continuous. They were disruptive.

In the case of the public art installed on the street, even though stakeholders considered them "terrific" and "amazing pieces of art", many everyday users declared that they did not understand the sculptures. It is evident thus that, in this instance, the artefacts had different significations for people directly involved in the project than for the passersby. The referred hypothesis is reinforced by a declaration of the member of the public art jury Carla Ayukawa: "I like it, but because I know what it is about." Some participants did express their appreciation for the artworks. These individuals were possibly capable of developing a connection with the objects by attributing their own meanings to them. In any case, to people who have not participated in the creation of the art, the final result is more important than the process.

The application of a community-based method was not enough to guarantee an immediate connection between the population and the artefacts. It is somehow surprising that the pieces of street furniture which did not involve as much public participation as the sculptures were appraised more appreciatively by the population. Nonetheless, when compared to the arch, which apparently did not involve any public participation, the art installation received higher scores. It is possible that the nature of the object as well as the participation influences the way people react to it. Objects with a clear function and purpose might be more easily approved by 
users than art, a subject about which everyone is entitled to opinions even if they are as simple as 'I like it' or 'I do not like it'.

Furthermore, the sculptures refer to Italian themes. As mentioned by some interviewees, even though Italians used to live on Preston Street until the 60's, now many of them have moved to other locations in the city. This might mean that the symbols attached to the sculptures were not shared by some users of the space. This leads to another point, which was emphasized by Julie DuPont, City of Ottawa Cultural Planner. In some cases, the connection between a community and the pieces of art is not immediate. Place is constituted though reiterative social practice - place is made and remade on a daily basis (Cresswell, 2002: 25). Through new experiences in this recently modified space, people may develop a different relationship with the artefacts. For this reason, the guided tours promoted by the Preston Street BIA, where the artist explains the sculptures meanings, might be an effective way to foster linkages between city users and the artworks.

The disconnection between some members of the community and the street elements may be a sign of urban alienation (Friedmann, 1999: 4) (See Chapter 2, Page 17). Besides the need for formal evaluations of projects implemented in urban spaces, a question that arises at this point is if only a portion of the public is included in the design process, how is it possible to create products and spaces that will be meaningful to the majority of the population? It is probably impossible to involve all users in a participatory project regarding the spaces and products they will use. In the case of public art, as formerly discussed in this report, some researchers (Matthews, 2010: 15) believe that abstract themes allow the audience to formulate 
their own understanding of the pieces of art and, therefore, formulate emotional responses to them. The Postcard from the Piazzas sculptures presented mostly representational elements. Whereas it is true that abstract forms of art allow more flexibility for interpretation, it does not make sense to require artists to only produce this sort of manifestation. It might be fairly reasonable, however, to demand that artists as well as designers consider more opportunities for users to "actualize and modify designs to make them more suitable to their needs and desires" (Siu, 2003: 71). In this sense, these objects may also acquire new engaging functions besides those of contemplation and reflection. Future studies might compare the public's relationship with objects that allow "gaps" for them to fill in with their own meanings and creativity to objects that have a more rigid appearance and/or function.

Anish Kapoor's Cloud Gate (See Chapter 2, Page 24) is an example of an artwork which is capable of engaging the audience in an delightful experience. The population became so connected to the installation that they attributed the nickname 'The Bean' to the piece which also turned into a symbol of the city of Chicago. Besides its flexible character which allows for multiple interpretations, other attributes such as its massive size and its reflective surface might have contributed to its full impact as a piece of art.

\subsection{Increasing user participation}

Citizens are delighted to participate in the affairs that affect their lives (Kaplan, 1980: 507). This became absolutely evident in the survey procedures. Passersby would sometimes avoid being approached, but they often changed their minds when informed about the subject of the questions. "If it is about the street I agree to participate", they would recurrently answer. 
That being so, why did so small percentage of the population take part in the public consultations? As revealed by the questionnaires, only $7 \%$ of the respondents were involved in the open house meetings regarding the reconstruction of Preston Street. This indicates that of a total of 30 people, only 2 individuals were engaged in the decision-making process.

There could be many reasons why the majority of the general public does not attend the assemblies. It may, nevertheless, be more meaningful to the present research to discuss the fact that currently users have to pursue decision makers and experts in formal gatherings in order to express their ideas. Some researchers believe that design professionals should interact with everyday users to get their input. Designers can no longer hide themselves in studios (Siu, 2003: 73). Siu, for instance, is convinced that design professionals "need to conduct more empirical research" (Siu, 2003: 73).

It is well known that, by talking to and observing people at the same time that they are using the space and the products embedded in them, experts and decision makers will learn more about the users' needs, than by discussing plans in closed rooms (Luck, 2003; Sanders, 2002; Sanders \& Simons, 2009; Siu, 2009; Sleewijk Visser, 2009). Through the application of surveys on Preston Street, for instance, the researcher was capable of acquiring a situated perception of the users' perspective about the space, the amount of time they spend there and the activities they like to perform. Dialogues with the general public about products that they were actually seeing generated several insights. This enabled the researcher to target the 'real' user who in fact experiences the space rather than talking to people who are not familiar with its issues. This sort of approach may be adopted both in the project development and evaluation stages. 
Public consultation meetings allow landscape architects and other professionals to present the design intent to the community. However, it is important to note that some people may have difficulties interpreting technical drawings and graphic representations produced by urban designers and landscape architects. This issue was indeed raised by Chantal Gaudet, the landscape architect involved in Preston Street project. It is fundamental that both parts develop a common language so that they understand each other's point of view.

\subsection{Including industrial designers}

The Percent for Art policy triggers a critical discussion about the sidewalk space. The policy determines that the artwork should be placed in the same location as the construction was undertaken. Many streets have recently been reconstructed in Ottawa. In order to have public art on these areas, sculptures have been located on the sidewalks. The sidewalk must also accommodate pieces of street furniture, infrastructure and underground elements. Landscape designers, in interviews and conversations, claimed that sometimes it is difficult to distribute these different elements in the same space.

The solution adopted in many cases was to install a large number of smaller pieces of art along the sidewalk. When the purpose of public art is to be noticed and become a landmark, the size together with colour and texture may be a factor that contributes to such properties. When asked about the sculptures on Preston Street, some passersby claimed not to have noticed them before. Obviously, their location on the sidewalk might be regarded as a key aspect to be analysed. The artworks cannot be placed in the centre of the walkway otherwise they would 
obstruct the flow of pedestrians. Therefore, they were installed on the side of the passage aligned with pieces of street furniture, sign panels, and fire hydrants.

As previously mentioned, some objects placed in urban spaces can promote triangulation, that is, stimulate linkages between people who otherwise would not interact (Whyte, 1980: 94). It may be interesting, nonetheless, to debate whether artefacts of such small magnitude located in these specific spots are capable of encouraging the public to connect and socialize.

One solution to the space issue on the sidewalks may be to combine elements and functions into single artefacts. Multifunctional products might occupy a smaller area without depriving the public of articles that they need. A tree grate might be conceived as a bike rack or a bench. A bench may serve as a support for sitting, accommodating receptacles for garbage as well. By incorporating more than one function in a single product, it might be possible to save a satisfactory amount of space. Further, as a respondent commented in one survey, on Bank Street, the bike racks feature art and simultaneously function as support for bicycles. As argued by Main \& Hannah (2010) street furniture may be designed as artwork. In this more elaborated perspective on the association between design and art, the product assumes sculptural characteristics that could distinguish it from the other artefacts that serve the same function.

A conceivable advantage to this strategy is that, in a city where a unified street furniture program is under way, it could be possible to have some custom-made pieces that would break the monotony of a very uniform system. Moreover, when the barriers to proposing customized street furniture are related to their cost, one might consider the possibility of including this interdisciplinary association between design and art in the Percent for Art program. Additional 
research may investigate whether with the incorporation of a familiar function to the artwork, the process of public's connection with the piece is facilitated.

Furthermore, it makes sense to involve the industrial designer in the public art topic. This sort of art is particularly different from the art that is exhibited in galleries. Public artworks must comply with requirements of longevity and resistance, which are more related to infrastructure and design objects than to pieces of art which are ideally kept in spaces with controlled temperature and humidity conditions (Figure 28). As "technologists" (Lawson, 1997: 10), designers are experts in industrial materials and production processes. Furthermore, the public art audience is much broader than the museums' public. It includes not only people who appreciate art but also individuals who are not interested in the subject and have no other choice but to be exposed to it.

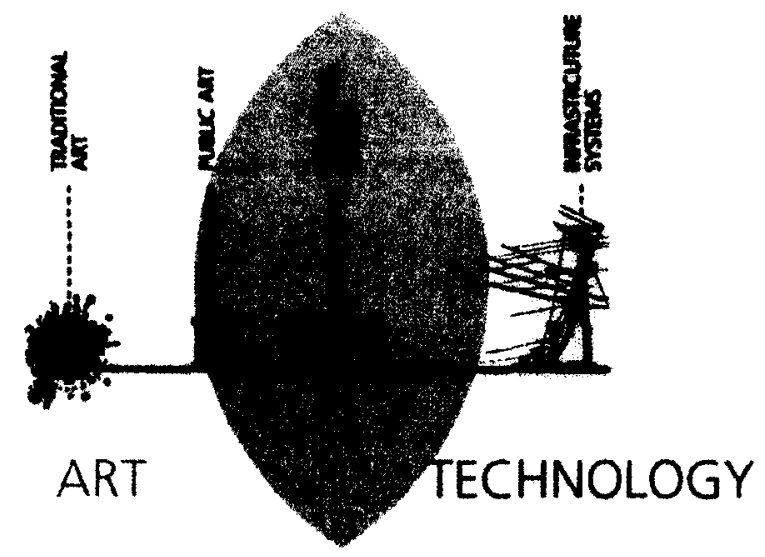

Figure 28. Industrial design as a midpoint between art and infrastructure

Again, as mentioned in Chapter 2 (see page 32), designers are trained to investigate "the nature of the users and their needs" (Lawson, 1997: 10). The previously discussed participatory 
methods such as co-design and co-creation practices (See Chapter 2, Pages 39, 40) might serve as tools to enable designers to work closely together with everyday users to identify their needs and inspirations (Sanders \& Simons, 2009). In this sense, they may also support the creation of the artefacts that will fulfill many people's expectations.

Lastly, designers in general have a well-developed "aesthetic appreciation" (Lawson, 1997: 9). They can, therefore, add their knowledge about space, form, line, colour and texture to the process (Figure 29).
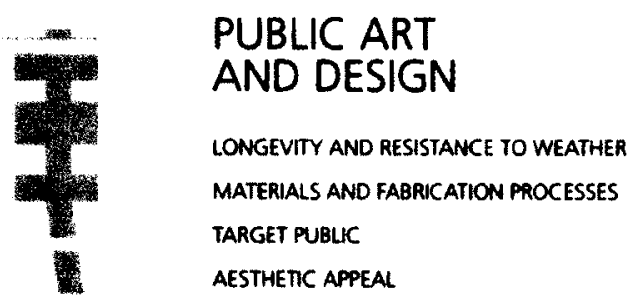

Figure 29. Similarities between requirements for public art and design

As part of a recent trend, graphic and interaction designers have been working together in the development of objects for urban spaces. As illustrated by the Crown Fountain example (See Chapter 2, Page 26), there has been a tendency to apply interactive technology to urban elements. James Acres, the graphic designer interviewed in the data collection stage of the research, emphasized that there is more room for collaboration between visual artists and designers. "In Victoria, BC I saw interesting objects that looked like sculptures but featured interactive maps of the city. I am sure it does not cost much money, but it changes the way we experience the space". 


\subsection{Additional roles for industrial designers}

Besides the connection with the urban elements and the sidewalk space, more can be improved in this interdisciplinary process. Many interviewers mentioned the occurrence of conflicts during the project. Whereas some attested to not being listened to in the decisionmaking process, others expressed the dissatisfaction with the lack of opportunities to discuss aspects of the plan with other stakeholders.

Conflicts in interdisciplinary processes have been widely discussed by researchers who attempt to identify their causes and propose possible solutions. Among the critical factors that affect cross-function cooperation, the discipline's diverse culture and the use of domain-specific language configure as some relevant ones, which can cause a clash of views, perspectives and values (Badke-Schaub, Goldschmidt \& Meijer, 2010; Jehn, 1995; Jehn,Northcraft \& Neale, 1999; Kim \& Kang, 2008). In the case of the Preston Street rehabilitation, it is possible that both factors may have influenced the dynamics of the process.

Some authors suggest that a facilitator is needed to mediate interdisciplinary practices. Sanders and Stappers (2008: 13), for instance, believe that the researcher, who may be a designer, should assume the role of mediator in the co-design process. This means that this agent should learn how to lead, guide, support, and encourage users in expressing their creativity in the design development activity. The facilitator is not necessarily a designer. As mentioned by Sanders and Stappers , "the social psychologist who becomes a design researcher, for example, does not just bring interviewing skills (...) but can also bring in background knowledge and literature on theories (...) which can guide and/or inspire the design" (2008: 13). Industrial designers, nonetheless, are in some way naturally inclined and trained to occupy this position. 
Design is an interdisciplinary discipline which involves an expertise in social science, art and technology (Lawson, 1997: 10). Being used to interdisciplinary issues as part of their academic formation, industrial design professionals may spontaneously assume this role which requires leading teams to develop the best outcomes possible.

Accordingly, interdisciplinarity is not just a trend. Nor is it a new movement. On the contrary, it has been a part of complex projects for a long time and it is essential to the solution of multi-layered systems problems. The Preston Street case might suggest the need for a new category of professionals who are qualified to understand the dynamics of interdisciplinary teams, and, what is more, individuals who are prepared to work in such groups assisting them to achieve the best outcomes. These mediators might have a background in design or other disciplines that are interested in understanding the hurdles and benefits associated with interdisciplinarity.

\subsection{Bringing industrial design to urban spaces}

It seems to be a trend in many cities to stimulate design activity. In the examples raised in a prior chapter, the importance attributed to design was manifested by the creation of design programs, departments and competitions. Not by coincidence, most cities that foster the development of design present the finest and most innovative urban elements. And this is regarded by some municipal governments as a strategy to boost the interest of tourists and improve city dwellers' daily life. As part of a broader process of inter-urban competition, city governments have increasingly sought to 'position' themselves as centres of creativity (Rantisi \& 
Leslie, 2006: 364). By investing in design, these cities believe that they are increasing their chances to compete with other locations in the world.

One of the most intriguing findings in the study was connected with the fact that no industrial designer was directly involved in the development of solutions for the Preston Street project. Moreover, the City of Ottawa has no clear strategy to foster the incubation and showcase of high end design in urban spaces.

One may argue that, due to its dual status, Ottawa is in an unusual situation where two government organizations deal with the urban environment. Whereas the National Capital Commission (NCC) represents the federal level, the City of Ottawa operates in the municipal level. Both organizations work in partnership in some specific areas. The NCC does have an industrial design department, which may have reinforced the municipality's position of not getting involved in design discussions. There are areas in the city, nonetheless, such as Preston Street, where projects are not under the NCC's responsibilities. Should these spaces remain unserviced by design consultants then? Furthermore, we can claim that the fact that the NCC has a public art department did not hinder the municipality from creating its own public art program.

In introducing the Percent for Art policy, the City of Ottawa has achieved the first step towards becoming a centre of creativity. Now, the next action could be focused on design as a creative and cultural activity. Interviewees anticipated a series of roles that industrial designers might play in the present circumstances. Among their suggestions were applying for public art in interdisciplinary teams and working with street furniture manufacturers to facilitate the installation and removal processes. In addition, some designers have already taken part in public art juries to support the selection of artworks for specific locations. 
The study identified the opportunity for creating pieces of street furniture with sculptural characteristics to enhance the identity of different neighbourhoods. Maintaining the unique character of the neighbourhoods indeed emerged as one of the most crucial aspects of the Preston Street project as well as other cases observed by the researcher. This might indicate another possibility for designers to be involved in the urban spaces. Because they have the abilities of "social scientists, artists, and technologists" (Lawson, 1997: 10), these professionals may have a more global view of the process. Similar to art directors, they might become agents that would ensure that the project has a cohesive language that complements the neighbourhood image. This may include, for instance, branding the spaces and creating concepts and palettes of colours to be utilized in the project, guiding the choice of street furniture, public art and other elements.

At any rate, if Ottawa aspires to strengthen its "position as a creative city" (Ayukawa \& DuPont, 2010: 1), it will be necessary to assume a clearer direction regarding design activity, emphasizing the design of its urban elements. Many cities such as Montreal and London have created their own models for development. These might work as a resource for Ottawa to frame its strategy according to its ambitions and limitations. The organization of design competitions with private sector support may be the most inexpensive way to take this next step. 


\section{CHAPTER 6}

\section{CONCLUSION}

This research explored interdisciplinarity in two different ways. First, the theoretical framework incorporated the body of knowledge developed by diverse disciplines to investigate urban elements and spaces. Then, the object of the case study, the Preston Street Reconstruction Project, also presented an interdisciplinary nature, engaging professionals from different fields and the general public. This case study provided the opportunity to explore more general issues through an instance of a rehabilitation process. The contributions of the investigation were, then, applicable not only to the specific context of the investigation but also to other related circumstances. As with every research project, the study faced some limitations. It was impossible to explore all the questions that evolved from the analysis in the time frame defined by the research program. Such pending inquiries were converted into directions for further research regarding the same topic.

\subsection{Research questions}

The research primarily intended to understand how interdisciplinary public participation processes could enhance the development of urban elements. In addition, it attempted to learn what roles design and designers would assume in this context. As it is natural in qualitative research, the questions slightly changed in the course of the analysis. While data was being collected and examined, additional queries also evolved. After realizing that designers were not involved in the development of the project, the researcher became interested in exploring ways 
to include designers and ameliorate the interdisciplinary process. Such matters led to more specific points such as how to obtain more user participation, how to achieve results which are as meaningful to the general public as to direct stakeholders, and how to acquire more cohesive projects.

\subsection{Context}

The Preston Street project case study served as an excellent vehicle for the exploration of the questions which emerged during the study. As might be expected, it incorporated interdisciplinary and participatory issues. Not only were professionals from diverse backgrounds involved in the decision-making process, but also community members. Actually, public participation has recently become a common practice in Ottawa and many other cities. This does not mean, however, that people who are involved in such projects are working with a formula that can always be applied to any circumstance. It does not imply either that these actions will always generate positive outcomes.

Public participation might be pointed to as one of the factors that may improve the urban experience. For this reason, participatory processes are closely related to a study that aims to ensure that "the invaluable free joys of public urban life will be available city-wide to all of us in the cities of the present and future" (Gehl, 1989: 17).

Other factors might also influence the way people experience urban spaces. Intangible attributes such as symbolic meanings acquired by a space are "an important component of the urban quality" (Francis, 1987: 94). The tangible urban elements also affect the urban experience. Even though the term may embrace other artefacts in the urban realm, the study focused on 
public art and street furniture products. Whereas the former is commonly under the responsibility of artists, the latter is often part of the designers' duty. But what is the difference between design and art? Lawson and Dorst defend that while art does not have to comply with any requirements and is not functional, design is always committed to functionality, needs of people, and requirements of stakeholders (2009: 41). Yet, designers share the attribute of "aesthetic appreciation" with artists (Lawson, 1997: 9).

The Preston Street rehabilitation process involved both public art and street furniture components. It represented a legitimate opportunity to evaluate the interdisciplinary process of selection and the development of the pieces. It also provided a chance to analyze the public's reaction to the different urban elements which were incorporated into the streetscape. At the same time, the researcher could observe municipal strategies regarding public art and design.

\subsection{Results}

Notwithstanding the fact that the City of Ottawa aspires to reinforce its image as a creative city (Ayukawa \& DuPont, 2010: 1), no specific strategy regarding design activity seems to have been implemented so far. As part of the endeavour to become a competitive city, however, Ottawa developed a Public Art Program and a Percent for Art policy that guarantees that pieces of art be showcased around the city's public spaces. In addition, the Integrated Street Furniture Program evolved as an effort to improve the urban environment.

As a reflection of the city's unclear attitude towards design, the list of stakeholders involved in the project did not include industrial designers apart from a judge in the public art selection who was also a community member. Interviewees, nonetheless, envisioned roles that 
could be assumed by such professionals. They range from facilitating the installation and removal of street furniture to joining interdisciplinary teams in public art competitions.

Interview participants also demonstrated appreciation for the process employed by cj fleury to develop the sculptures which would be placed on the street. Already recognized for her participatory methods, the artist talked to community members to formulate the concepts for the artworks. In this sense, the process would become part of final product, as stated by Carla Ayukawa, a member of the public art jury.

The general public rated most of the streetscape elements with average to low grades. They do not seem to actively participate in the public consultations organized by the city. In addition, they did not express the same contentment with the sculptures as the interviewees. For instance, many participants argued they did not understand the pieces. Finally, qualities such as beauty and uniqueness of the space were assessed with lower scores than pedestrian friendliness and pleasure offered by the street.

\subsection{Contribution}

The research provided an evaluation of several aspects of the reconstruction. Its main contribution, however, is more general and can be applied to other contexts. It is related to the role designers may undertake in urban projects. As previously stated, no industrial designer was directly involved in any stage of the project.

By analyzing this study, one might affirm that urban elements are an important aspect of the urban experience in public spaces. The investigation contributed to a better understanding of 
how people relate to these elements, which involved exploration of the concepts of triangulation and urban alienation.

Public participation may enhance the selection and development of these elements if the interdisciplinary exchange between experts is effective and the population is truly engaged. This way, participants might share a system of meanings that will be attached to the urban products.

If involved, industrial designers could contribute to enhance this interdisciplinary process and improve its outcomes. These professionals might assume the role of a facilitator who will encourage the creative exchange between team members. They may also work to produce representations of the project which can be more easily understood by non-experts in consultation meetings. The attention designers dedicate to "the nature of users and their needs" (Lawson, 1997: 10) might also be beneficial to the process. By observing for example, the activities city users perform in the spaces and the amount of time they spend there, industrial designers might support the development of products which will better support the population's needs.

Designers may also be involved in the public art topic. Their interdisciplinary knowledge about materials and fabrication process, aesthetics, and social sciences might support the creation and evaluation of pieces of art that might appeal to a large portion of the population. Since this kind of art largely differs from the art seen in museums and galleries, design professionals might add an expertise to the process that will contribute to the artefacts' longevity and durability as well as the consistency of the pieces in the general context of the project. At the same time, their aesthetic ability might be employed to foster the streets' beauty and uniqueness. 
Cities have recently invested in design and branded themselves as 'City of Design' as a strategy to position themselves as creative centres and as touristic attractions. The city of Montreal, for instance, defends a model of design-led urban development stimulated by the Commerce Design Montréal initiative (Rantisi \& Leslie, 2006: 374). As alternatives for the City of Ottawa to start fostering design activity, the study envisions the organization of competitions which motivate design students and young designers to formulate solutions for the city's public spaces. This sort of initiative has proved to be an inexpensive and efficient way to bring design to the streets also in Montreal (Rantisi \& Leslie, 2006) and other cities.

An even more immediate action could involve designers in competitions connected to the Percent for Art policy. The capacity industrial designers boast to support and lead the creation of unique products which may reinforce the local identity of Ottawa's neighbourhoods has been previously discussed in this thesis.

It is true that policies concerning design activity are much needed. Assuming that Ottawa intends to enhance its image as a creative city (Ayukawa \& DuPont, 2010), one must consider that design should be regarded as a creative industry that may transform this city into a remarkable place. Initiatives similar to Percent for Art are a first step towards more unique urban spaces. Next, efforts must be made to promote more specific strategies to encourage the development of design products for the streets.

\subsection{Possible directions for future research}

The case study approach has some limits which have hampered application of research findings (Francis, 1987: 73). In many cases, it is difficult to compare results because comparable 
methods are not always used. In addition, findings may be too specific to a particular situation. Despite the fact that the researcher attempted to avoid such limitations by attending diverse public consultation meetings and interviewing individuals who were connected to other projects, one cannot deny that other municipal case studies may complement the findings presented in this thesis.

While in this research only 30 members of the general public answered the survey, a larger number of participants may provide a more complete panorama of the users' perspective of the results of the rehabilitation process. Comparisons between case studies and evaluations of a variety of reconstruction projects might provide the city with valuable knowledge that could be applied to future projects.

It would be interesting, for example, to compare the public art processes related to other urban projects in Ottawa to the one developed for Preston Street. The public's reaction may vary according to theme, material, size, and location of the pieces. Furthermore, their capacity to prompt the triangulation process might also change according to such features. As already discussed, some researchers (Matthews, 2010:15) are convinced that abstract themes can more easily be accepted by the population, providing people with the pleasurable experience of formulating emotional responses to them. In this sense, one could contrast figurative sculptures or objects with the ones which allow gaps for users to fill in with their own meanings and modify them according to their needs (Siu, 2003: 71).

Siu argues that allowing users to participate in the decision-making process is better than offering more flexibility to users $(2003,71)$. Among the problems that stakeholders faced in the participatory process was the difficulty that experts may have to present their proposals to non- 
experts. The general public often experiences difficulties interpreting technical drawings. In addition, only a small portion of the population attends consultation meetings albeit the research identified the community eagerness to participate in discussions regarding their neighbourhood. Further investigations on the use of maquettes may discover whether three-dimensional representations are more easily recognized by non-experts than two-dimensional drawings. Furthermore, such research may verify if people can better understand the project outcomes when presentations take place in the actual project setting.

Regarding the strategies the city can adopt in the future, a more extensive research comprising design policies and strategies implemented by other cities around the world may support the elaboration of a design plan for Ottawa. Researchers should focus not only on the actions but also in their impact. Cities such as Montreal promote a design-led urban development as previously discussed (Rantisi \& Leslie, 2006: 374). Still, it is fundamental to support the advantages of stimulating design activity through reliable data. One might, for example, compare the development of a city that does not foment design with another that invests in such activity. Yet, one thing is true: if a city is "defined by the planning of its public spaces" (Creus, 1996: 7), industrial designers have a lot to contribute to improve the image cities reflect to the world. 


\section{BIBLIOGRAPHY}

ABS Consulting (n.d.). Overall Liking Score (OLS): Occupant feedback is fundamental for continuous improvement. [Brochure].

Architecture for Humanity Chicago (n.d.). Street Furniture Competition 2011 retrieved June 9, 2011 from http://www.afh-chicago.org

Ayukawa, M., \& DuPont, J. (2010). OpenOttawaLibre : An Interdisciplinary Approach to Building Creative Cities. Open Source Business Resource: Interdisciplinary Lessons, (August).

Badke-Schaub, P., Goldschmidt, G., \& Meijer, M. (2010). How Does Cognitive Conflict in Design Teams Support the Development of Creative Ideas? Creativity and Innovation Management, 19(2), 119-133.

Barthes, R. (1967). Semiology and urbanism. In J. Ockman, \& E. Eigen, Architecture culture, 1943-1968 : A documentary anthology (pp. 413-418). New York : Columbia University Graduate School of Architecture, Planning, and Preservation : Rizzoli.

Barthes, R. (1979). The Eiffel tower, and other mythologies (1st American ed. ed.). New York : Hill and Wang.

Bordass, B., \& Leaman, A. (2005). Making feedback and post-occupancy evaluation routine 1: A portfolio of feedback techniques. Building Research \& Information, 33(4), 347-352.

Brown, T. (2009). Change by design: How design thinking transforms organizations and inspires innovation. New York: Harper Business.

Burns, A. (2000). Emotion and Urban Experience : Implications for Design. Design Issues, 16(3), 67-79.

Charney, I. (2007). The politics of design: architecture, tall buildings and the skyline of central London. Area, 39(2), 195-205.

City of Ottawa (2009). City of Ottawa Integrated Street Furniture Policy and Guidelines [brochure].

City of Ottawa. (2010a). Ottawa 20/20 Arts and Heritage 5-Year Plan Progress Report [brochure]. 
City of Ottawa (2010b). The Wellington Marbles, Marcus Kucey-Jones and Ryan Lotecki, marble, 2010 backgrounder [press release].

City of Ottawa (n.d.a). Little Italy. Retrieved July 18, 2011 from http://ottawa.ca/visitors/about/ neighbourhoods/little_italy_en.html

City of Ottawa (n.d.b). Public Art. Retrieved March 15, 2011 from http://www.ottawa.ca/ residents/arts/public_art/index_en.html.

City of Ottawa (n.d.c). Postcards from the Piazzas by cj fleury backgrounder [press release].

City of Ottawa (n.d.d). Preston Street Official Public Art Unveiling: Postcards from the Piazzas by cjfleury $F A Q$ [press release].

City of Ottawa (n.d.e). Preston Street Rehabilitation-Albert Street to Carling Avenue. Retrieved July 18, 2011 from http://ottawa.ca/residents/construction/projects/preston/index_en.html

City of Toronto. (2010). Vibrant Streets Toronto's Coordinated Street Furniture Program: Street Furniture Design \& Policies. Toronto.

City of Toronto. (n.d.). Coordinated Street Furniture Project Backgrounder. Toronto.

Cresswell, T. (2002). Theorizing Place. Thamyris/Intersecting, 9(21), 11-31.

Creswell, J. W. (1998). Qualitative Inquiry and Research Design: Choosing among Five Traditions. Thousand Oaks, Calif.: Sage Publications.

Creswell, J. W. (2009). Research design: Qualitative, quantitative, and mixed methods approaches. Thousand Oaks, Calif.: Sage Publications.

Creus, M. Q. (1996). Urban areas, furniture and elements. In J. M. Serra (Ed.), Elementos urbanos : Mobiliario y microarquitectura $=$ urban elements : Furniture and microarchitecture (pp. 6-14). Barcelona : Editorial Gustavo Gili.

Dawson, E. (2010). Postcards from the Piazzas: A sculptural walking tour in Little Italy [brochure].

De Carlo, G. (2005). Architecture's public. In P. B. Jones, D. Petrescu and J. Till (Eds.), Architecture and participation [electronic source] (pp. 3-22). New York : Spon Press.

Design for London. (n.d.). Retrieved June 8, 2011 from http://www.designforlondon.gov.uk

Florida, R. (2002). The Rise Of The Creative Class: And How It's Transforming Work, Leisure, Community And Everyday Life. New York, NY: Basic Books. 
Francis, M. (1987). Urban Open Spaces. In E. H. Zube \& G. T. Moore (Eds.), Advances in Environment, Behavior, and Design (Vol. 1, pp. 71-106). New York, London: Plenum Press.

Friedmann, J. (1999). The city of everyday life: Knowledge / power and the problem of representation. DISP 136-7 (pp. 4-11). Zurich: ETH.

Gehl, J. (1989). A Changing Street Life In a Changing Society. Places, 6(1), 9-17.

Gehl, J. (2003). Winning back the public spaces. Conference lectured at the symposium (In)visible Cities. Spaces of Hope, Spaces of Citizenship, Centre of Contemporary Culture of Barcelona, 25-27 July, 2003.

Gilloch, G. (1996). Myth and Metropolis: Walter Benjamin and the City. Cambridge, UK: Polity Press in association with Blackwell Publishers.

Glaser, B. G., \& Strauss, A. (1967). The Discovery of Grounded Theory: Strategies for Qualitative Research (p. 271). Chicago: Aldine Transaction.

Green, S. D., \& Moss, G. W. (1998). Value management and post-occupancy evaluation : closing the loop. Facilities, 16(1/2), 34-39.

Hein, H. (1996). Symposium : Public Art. Art Criticism, 54(1), 1-7.

Hildebrand, G. (1999). Origins of Architectural Pleasure. Berkeley: University of California Press.

Holman, V. (1997). Public Art: The Problems and Potential of Multiple Meanings. Journal of Art \& Design Education, 16(2), 127-135.

Iacofano, D. S., Moore, R. C., \& Goltsman, S. M. (1988). Public involvement in transit planning : a case study of Pierce Transit, Tacoma, Washington, USA. Design Studies, 76-85.

Jacobs, J. (1962). The Death and Life of Great American Cities. London: Jonathan Cape.

Jehn, K. A. (1995). A Multimethod Examination of the Benefits and Detriments of Intragroup Conflict. Administrative Science Quarterly, 40(2), 256-282.

Jehn, K. A, Northcraft, G. B., \& Neale, M. A. (1999). Why Differences Make a Difference: A Field Study of Diversity, Conflict, and Performance in Workgroups. Administrative Science Quarterly, 44(4), 741-763. 
Kaplan, R. (1980). Citizen Participation in the Design and Evaluation of a Park. Environment and Behavior, 12(4), 494-507.

Keates, S., \& Clarkson, P. J. (2003). Countering design exclusion: An introduction to inclusive design. London; New York: Springer.

Kelly, M. (1996). Public Art Controversy: The Serra and Lin Cases. The Journal of Aesthetics and Art Criticism, 54(1), 15.

Kim, B.-young, \& Kang, B.-kyu. (2008). Cross-Functional Cooperation with Design Teams in New Product Development. International Journal, 2(3), 43-56.

King, S., Ferrari, D., Conley, M., \& Latimer, B. (1989.). Co-design : A process of design participation. New York : Van Nostrand Reinhold.

Kleinsmann, M., \& Valkenburg, R. (2008). Barriers and enablers for creating shared understanding in co-design projects. Design Studies, 29(4), 369-386.

Kries, M. (2006). On the relationship between design and city. In M. Kries (Ed.), Designcity : Design for urban space and the design city discussion (pp. 21-24). Berlin, Germany: Transform-Berlin.

Lawrence, D. L., \& Low, S. M. (1990). The Built Environment and Spatial Form. Annual Review of Anthropology, 19(1), 453-505.

Lawson, B. (1997). How Designers Think: The design process demystified. Oxford; Boston: Architectural Press.

Lawson, B., \& Dorst, K. (2009). Design Expertise. Oxford, Uk; Burlington, MA: Architectural Press.

Lee, P. M. (1998). Public Art and the Spaces of Democracy. Assemblage, 35(35), 80-86.

Lee, Y. (2006). Design participation tactics: Redefining user participation in design. Design Research Society International Conference Proceedings (Vol. 4, pp. 1-15). Lisbon, Portugal.

Lennon, M., Bannon, L., \& Ciolfi, L. (2006). Space to reflect: combinatory methods for developing student interaction design projects in public spaces. CoDesign, 2(2), 53-69.

Levermore, G. J. (1994). Building Services Engineering Research and Technology. Building Services Engineering Research And Technology. 
Levine, C. (2002). The paradox of public art: democratic space, the avant-garde, and Richard Serra's "Tilted Arc." Philosophy \& Geography, 5(1), 51-68.

Luck, R. (2003). Dialogue in participatory design. Design Studies, 24(6), 523-535.

Lulashnyk, K. (1999). "More people than materials or techniques": The community-based public art of c.j. fleury (Master's thesis). Carleton University, Ottawa, Canada.

Lynch, K. (1960). The Image of the City. Cambridge, MA: The MIT Press.

Main, B., \& Hannah, G. G. (2010). Site furnishings : A complete guide to the planning, selection, and use of landscape furniture and amenities. Hoboken, New Jersey: John Wiley \& Sons, Inc.

Matthews, T. M. (2010). Reuniting the mind and body: Anish Kapoor's Cloud Gate and the phenomenological experience (Master's thesis). The Florida State University.

Miller, S. A. (2007). Developmental research methods. Sage Publications.

Ooi, B. C., \& Stöber, B. (2008). Embedding the Arts and Culture in Branding Berlin and Singapore. Creative Encounters.

Pickard, A. J (2007). Research methods in information. London: Facet Publishing.

Preiser, W. F. E. (1995). Post-occupancy evaluation : how to make buildings work better. October, 13(11), 19-28.

Preiser, W. F. E., \& Nasar, J. L. (2008). Assessing building performance : Its evolution from from post-occupancy evaluation. International Journal of Architectural Research, 2(1), 84-99.

Rantisi, N. M., \& Leslie, D. (2006). Branding the design metropole : the case of Montréal, Canada. Area, 38(4), 364-376.

Rotenberg, R. (1996). Extraordinary Vienna: Identity and the Metropolitan Project. City \& Society, 8: 82-100.

Sanders, E. B.-N. (2002). From user-centered to participatory design approaches. In J. Frascara (Ed.), Design and the social sciences: Making connections (pp. 1-8). London; New York: Taylor \& Francis Limited.

Sanders, E. B. (2006). Design serving people. In Yrjö Sotamaa (Ed.), Cumulus Working Papers (pp. 28-33). Helsinki : Painotalo Miktor. 
Sanders, E. B.-N., \& Simons, G. (2009). A social vision for value co-creation in design. Open Source Business Resource, (December), 1-5.

Sanders, E.B., \& Stappers, P. J. (2008). Co-creation and the new landscapes of design. CoDesign, 4(1), 5-18.

Sanoff, H. (1981). Human exchange techniques for citizen participation in town revitalization. Design Studies, 2(3), 157-164.

Sanoff, H. (2000). Community Participation Methods in Design and Planning. New York, Toronto: John Wiley \& Sons, Inc.

Senie, H., \& Webster, S. (1989). Critical Issues in Public Art. Art Journal, 48(4), 287-290.

Sillitoe, P. (2004). Interdisciplinary experiences : Working with indigenous knowledge in development. Interdisciplinary Science Reviews, 29(1), 6-23.

Siu, K. W. (2003). Users' Creative Responses and Designers ' Roles. Design Issues, 19(2), 64-74.

Siu, K. W. (2007). Guerrilla Wars in Everyday Public Spaces : Reflections and Inspirations for Designers. International Journal of Design, 1(1), 37-56.

Siu, K. W. M. (2009). Public design for changing urban needs. Paper published in the Proceedings of the IASDR 2009 Conference.

Sleeswijk Visser, F. (2009). Bringing the everyday life of people into design. (Doctoral dissertation). Delft University of Technology.

Sleeswijk Visser, F., Stappers, P. J., van Der Lugt, R., \& Sanders, E. B.-N. (2005). Contextmapping: experiences from practice. CoDesign, 1(2), 119-149.

Trancik, R. (1986). Finding Lost Space. New York: John Wiley and Sons.

UBT Feedback Portfolio: Techniques (n.d.). In Usable Buildings. Retrieved May 24, 2011 from http://www.usablebuildings.co.uk.

Whyte, W. H. (1980). The Social Life of Small Urban Spaces. Washington, D.C.: The Conservation Foundation.

Whyte, W. H. (1988). City: Rediscovering the Center. New York: Doubleday.

Zimring, C. (1997). Postoccupancy Evaluation : Issues and Implementation. Handbook of Environmental Psychology (pp. 306-319). 
Zimring, C. M., \& Reizenstein, J. E. (1980). Post-Occupancy Evaluation: An Overview. Environment and Behavior, 12(4), 429-450. 
APPENDIX A

Postcards from the Piazzas: A sculptural walking tour in Little Italy brochure 

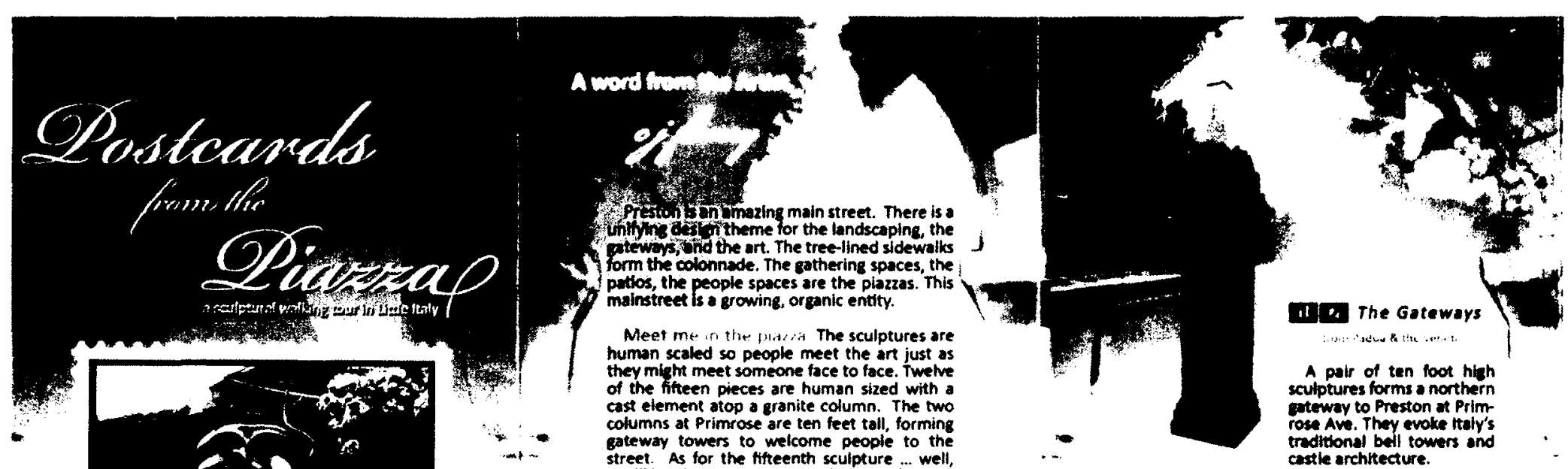

A pair of ten foot high

cculptures forms a northern

rose Ave. They evoke itrily's

tradtional bell towers and

galeway lowers to welcome

castle architecture.

vou'll just have to come see why it is different'

The vine-carved columns are inspired by local grope

The sculptures are visual postcards. Like vines which still survive in neiehborhood yards, and by

postcards and letters, they connect the "old

souvenirs, they hotd memories. There are no

physical postards on the at, nor do the

sculp found in various spots on the sculptures, in

several languages. Just like meeting someone.

you'll have to stop, look, lean, turn around a

bit, and employ all your senses to figure out

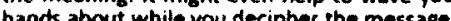

tealian pazzas are local eathering spots, where peopie Dante sculpture celeter parade with their thin sun and other stars; the Ello Copola sculpture also evokes the powerful Italian sun which sees all on Earth, including the The fourth imauage on

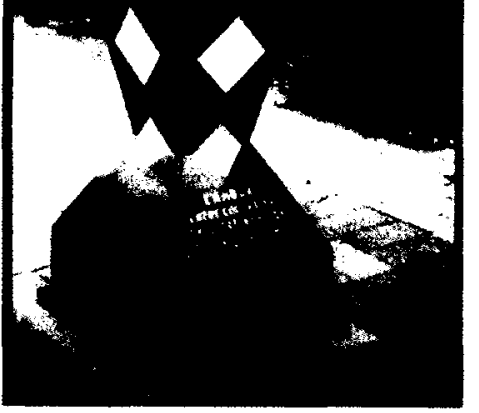

Each sculpture is linked to a different italian theme, and each one is inspired by a specific piazza in the various regions of italy. But the message is not limed to that one geographic with lots of community input. I met quite number of wonderful ltalian-Canadians when creating and refining these pieces, and they heip tell people's stories about life at home, at work, of celebrstions, good times and bad. in canada, and about particular people here live today in the community. People who I am thrilied to now call friends. Reach out and touch the art, connect with the peoples stories. hin your hands wher the seopres,

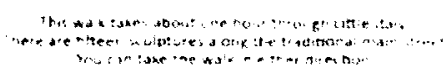

Wwing hisfory only losts so long. then 1 th piece on the piata hos someone's
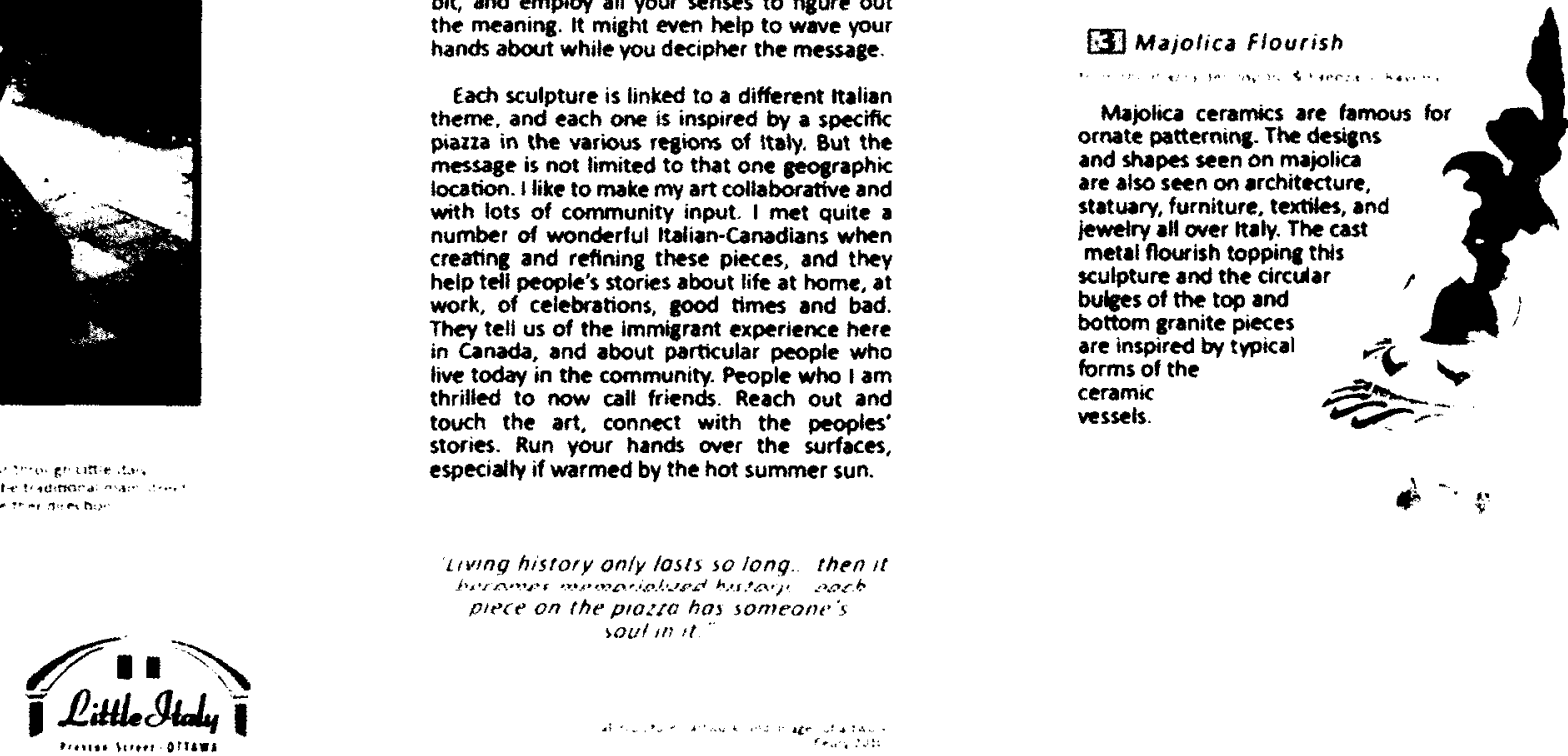


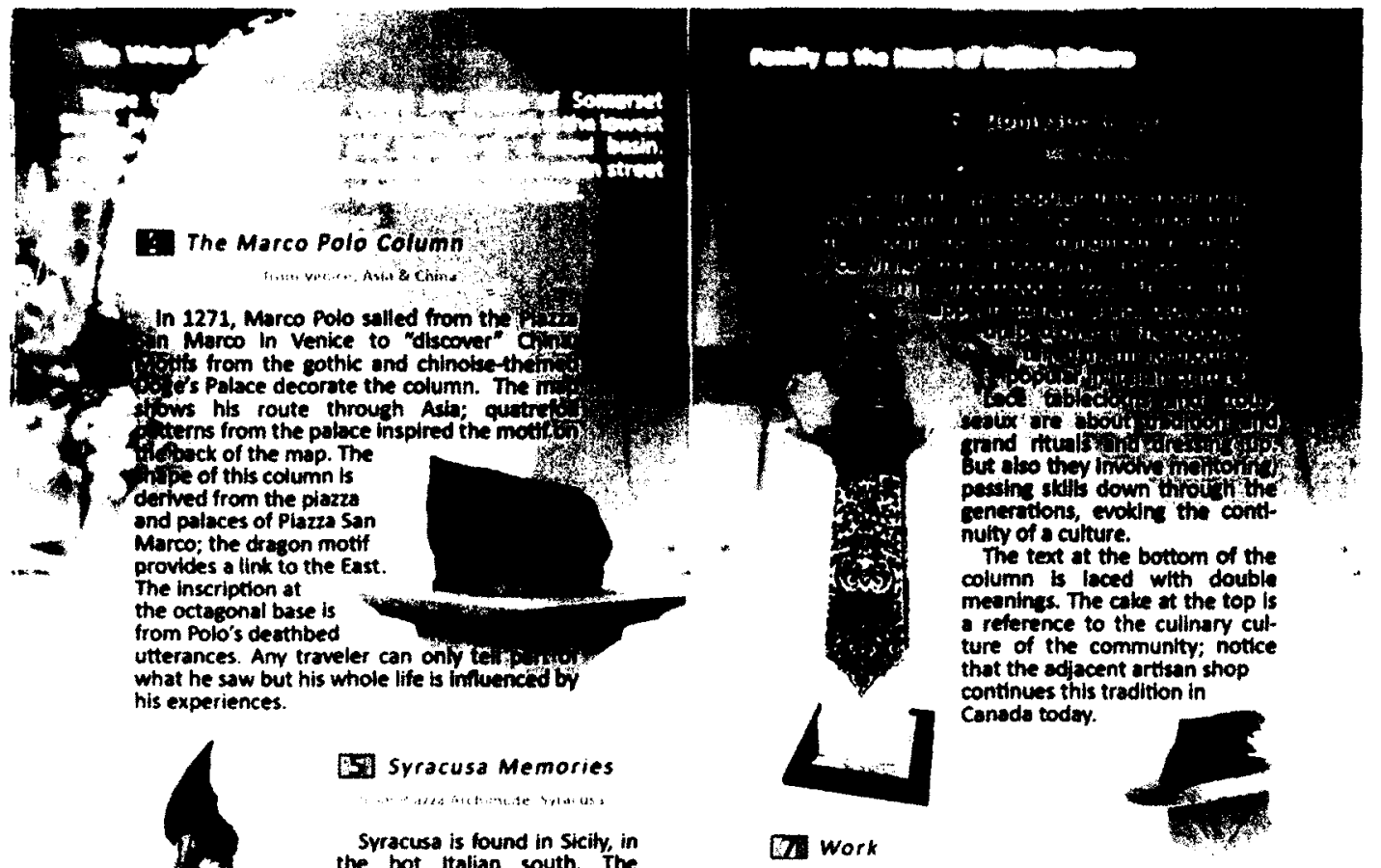
vellow granite column shape pays homage to the traditional architectural form and cotours of the south.

Emigration broke family ties and separated couples. work saved money and then brought over relatives and other villagers. Traditional occupations were abandoned in favour of whatever jobs could be found at the bottom of the Canadian economic ladder. Hard work and time resulted in en improved standard of living.

of food, and the fish mott's are art, exer The cast fish tail on top of this column re minds us of generations of fish enced in this column are inspired by real implements used by early immigrants. Construction, an important socializing venue for men. and of lovers waiking around The letters and string thed package on top of the column may be presents from home, of gitis bick to the family portance of tools. 


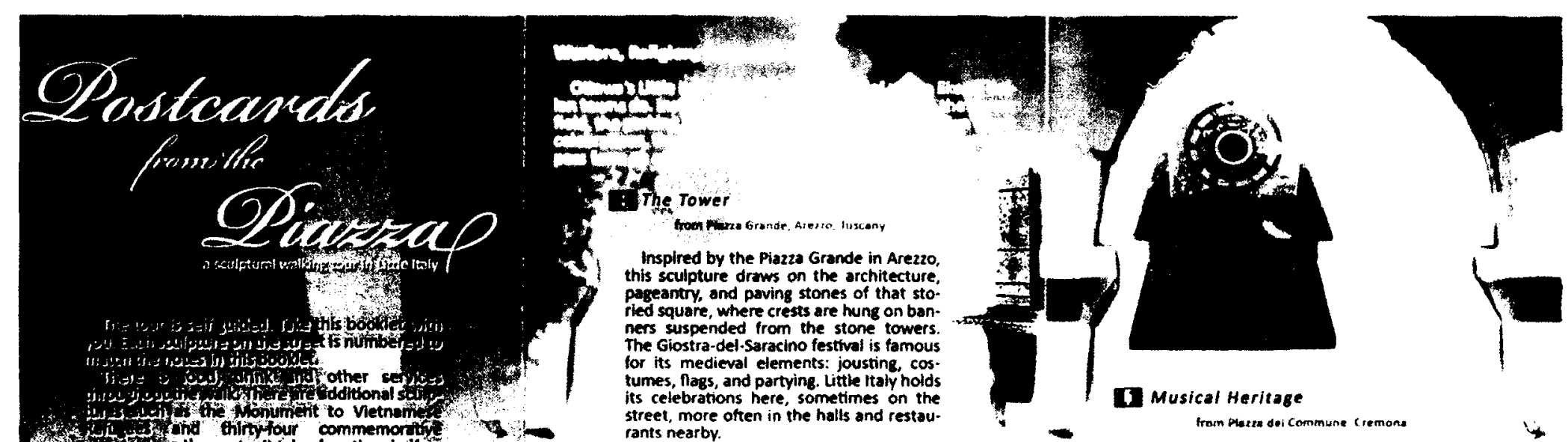

To sot to Utele katy...

Littie italy is less than a five-minute drive west of the downtown along Albert or Somerset 5 Alternately, from the Queensway, exit at Rochester St or Bronson Ave and proceed west. There is and tree To get there by public trons bus and get cif at either end of Preston; or the No.14 bus Carling Avenue Station. The No. 2 and points.

$$
\text { "Ottawa }
$$

Postcards from the Plazze was commissioned by the City of Ottowa's Public Art Program. One per cent of funds for municipal development projects is set aside for public art in order to beautily urban spaces and make art access
to everyone. ortowo.co/residents/arts

$$
\text { Latledtaly }
$$

Prestonstreet.com
97 1/2 Norman Street. Ottawa, k1S 3K5 street, more often in the halls and restau-

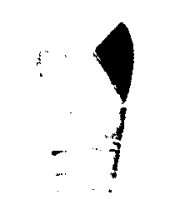

[9] St Anthony of Padua$$
\text { trom vaxu }
$$

This sculpture is based on St Anthony - the person - and the origidel santo. The ture of the thalian building part of which is deemed vatican space. The brocade- and lace-patterned cast mitre on top references the

From an angle, the silhouette resembles on open hsh mouth: St An. thony is renown
to the fishes.

10. of Poets and Heroes

Many believe soccer originated near Plorence. A plaque dating from 1565 on the basilca sanca croce morks the half. is created on the square cach contests are among Rentissancecostumed teams from each quarter of the city.

Here in Ottawa, the st Anthony soccer Club a few feet and weddings. The luurel-leafed victory wreath itopithis inside the club.

In Florence, the square is owerlooked by $\triangle$ Dante statue. Here the text around the wreath refers to Damte, Heroes, and History. steno Rossanese is credited with developing

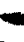

Opera and other forms of mustcal performance and seatre feature prominemty in tealan religious and echoes the paver pattern in Cremona. The pink granite and clock face also reference the piazza. Cremon is well known for its musical instrument craftspeople. the most famous violin maker beine Stradivarius.

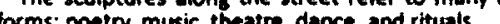

Eld food

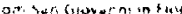

The first talian grocery store on Preston Street was run right here by three generations of the coincidentally originally from san Giovanns in Fiore. that now occupies the original groceterio. The rough and bulky column shape refers to the more rustic elements of village life, echoes the form of a rustcin in fibre, and refers to the countryside of haly. A Norman arch over low-sloped stairs in San panied by troditional leslian fruits. Look for other typical calibresi fruits and vegetables on the granite;

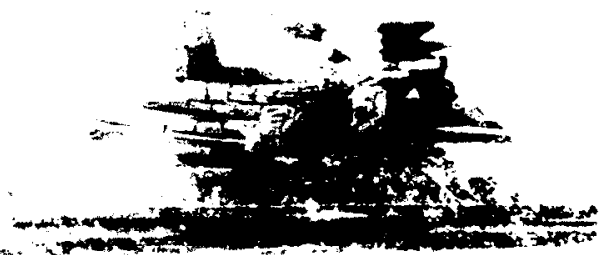



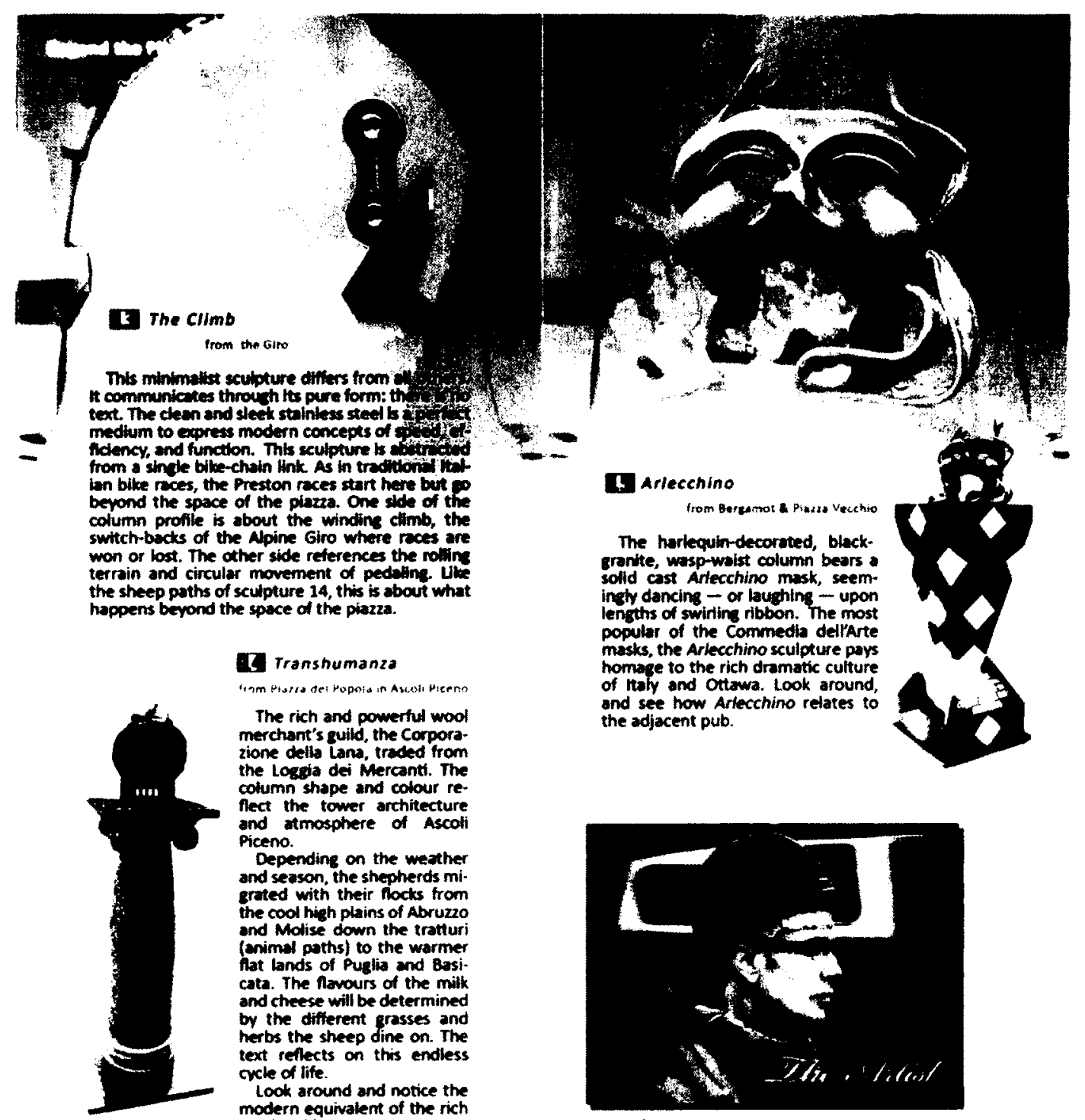

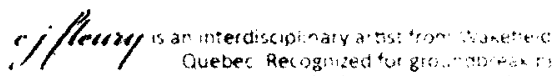

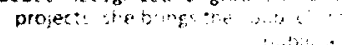




\section{APPENDIX B \\ Interact and Include: Countering Exclusion and Enhancing the Urban Experience Through Co-creation}

Paper published and presented at Include 2011, Helen Hamlyn Centre for Design, Royal College of Art, London, UK 


\title{
Interact and Include: Countering Exclusion and Enhancing the Urban Experience Through Co-creation
}

\author{
Maria Gabriela Sanches \\ Lois Frankel \\ Carleton University, Ottawa, Canada
}

\begin{abstract}
Public spaces should be utilised, enjoyed and celebrated by the whole population. In these areas, human diversity can be embraced and appreciated as an opportunity for rich urban experiences. Frequently, however, they reflect the exclusion of portions of society. Excluded people do not feel that these spaces also belong to them. Involving end-users in the design of products they are going to utilise in the future may be an efficient way to minimise exclusion. This study probes the integration of city planners, politicians, and the general public in the creation of urban elements. More specifically, it argues that when interaction is a component of these elements or the activities accommodated by them, they may help counter exclusion. As a pilot experiment, an interactive installation was set in a gathering space in Ottawa, Canada. A study was conducted to compare participants' behaviour during the experiment to the population's behaviour when there was no stimulus. Initial results substantiated the artefacts' potential to promote inclusivity and improve the urban experience.
\end{abstract}

\section{Keywords}

inclusivity, interaction, urban experience, co-creation, public spaces

Our cities need to be public spaces where we are giving the best of what the city has to offer to everyone [1]. Urban areas should be occupied and used by city dwellers, offering them pleasurable and enjoyable experiences. But do these spaces really serve as many community members as they could? Do they invite the whole population to utilise them and take responsibility for their preservation? This paper intends to provide a broader comprehension of the nature of inclusivity in public spaces. Even though these areas should work as an example of inclusivity and social responsibility, a quick look at any city's gathering spaces might reveal some evidence of exclusion and underuse. The study attempts to identify who is often excluded from the urban spaces and the reasons why this happens. Urban exclusion might result in 'urban alienation' [2], a concept which is explored in this research.

Co-creation is presented as a possible solution to social and urban exclusion. Highly recommended when a social change is intended [3], the co-design process suggests the involvement of the general public, urban planners, politicians, and designers in the development of the urban elements that are used in public spaces. In this case, the gap 
between the user and the designer may be drastically reduced [4], which enables designethis professionalr to better understand the users' public's needs and cultural specificities. The user, in his/her turn, may feel more involved in the community issues and may develop an emotional attachment towards the products [2].

Addressing participatory interaction in urban spaces is another endeavour of this paper. It argues that interactive products and activities may foster inclusivity and improve the urban experience. These stimuli might promote what Whyte [5] has called the triangulation process, which happens when linkages between people who may not even know each other are encouraged.

The assumptions behind the ideas presented in this study were investigated through an urban experiment. Unexpected objects were installed in a selected public gathering space in Ottawa, Canada. The participants' behaviour during the experiments was compared to the public's behaviour when there was no stimulus. The objective was to identify changes in the nature of the space when urban elements encourage interaction. Observations regarding inclusivity and the urban experience are described.

\section{Background}

The practice of inclusive design is still far from being widespread. Examples of poor inclusive design are everywhere [4], and, until now, many products have been developed to serve an average population [6]. As a result, numerous potential users, forgotten by designers, are deprived of their right of choice [7]. Many people with cognitive and physical differences are forced to buy 'special' products which very often are neither attractive nor suit their style of life. Such circumstances reinforce the necessity for stimulating inclusive thinking in designers.

A first step towards a better understanding of the concept of inclusive design may be in exploring its definition. According to Keates and Clarkson [4], "an inclusively designed product should only exclude the users that the product requirements exclude". A kettle that must boil water, for example, should only exclude the users who have not enough strength to move the weight of the kettle with the water inside it. Designers often fail to consider the difficulties that people with different capabilities might face using the products [4].

Inclusive design should be encouraged because "good inclusive (universal) design is good design" [4]. A product that fulfils the elderly or impaired people's needs may also meet the average population's demands. This is exactly what happened to the OXO Good Grips potato peeler, which was designed to address the difficulties people who suffer from arthritis experience in the kitchen [8]. It became a successful design case because, in addition to solving arthritic problems, the OXO Good Grips products attracted a range of users who appreciated their user-friendly qualities [8].

\section{The nature of inclusivity in public spaces}

The commercial appeal is not the only reason why inclusive design should be stimulated. Providing products that support the whole population in maintaining independence and extending quality of life is clearly a moral imperative [4]. In public 
spaces, the necessity for inclusive design is even more evident since the target public is wider. It includes every city dweller who chooses to make use of these areas.

Kerb-cuts are an example of successful inclusive design which helps not only wheelchair users cross streets, but also benefits parents with strollers, cyclists, and people carrying trolley-cases [4]. Many urban centres suffer from a lack of inclusivity nonetheless. For example, ethnic minorities, people with low incomes, or those who are disadvantaged in some way continue to live in the areas with the worst pollution and the heaviest traffic [1].

Apparently not only this parcel of the population feels excluded from the urban environment. The general public is often not involved in the discussions regarding public spaces, which also contributes to a lack of attachment between people and the urban elements [2]. City planners and politicians frequently make decisions without the knowledge and participation of the population. King, Ferrari, Conley, and Latimer claim that when people who are the most affected by the changes are not involved in the planning process, they are likely to become alienated [2]. Even though their study was considered controversial at the time, it makes sense to affirm that alienated people do not feel that the public space also belongs to them. Likewise, they do not feel connected to the urban elements.

Cities need planning that recognises that every individual has the right to full and equal participation in the built environment-and that through their direct involvement they can shape their own environment to meet their own needs [1]. A possible result of this approach may be the reduction of vandalism because the spaces will probably be more intensely used and people themselves might feel socially responsible for them.

\section{Co-creation and inclusivity}

Co-creation could be an efficient tool to counter urban exclusion and alienation. Besides possessing a social value that "provides a real opportunity for significant change" codesign enables the designer to increase "their empathy for the users" [3, 4]. When designers understand the user's needs well, they may be capable of developing more inclusive products.

In the co-creation process, designers work more closely with the users [9]. The gap between them is, therefore, bridged, which guarantees that necessary information will flow directly from the source (the user) to the destination (the designer), increasing the potential for understanding.

An inclusive co-design process regarding public spaces should involve all the stakeholders in this topic. The general public, city planners, politicians, and designers would work together in order to find solutions to the problems they face and also to create opportunities for pleasant urban experiences. The process becomes an interdisciplinary experience where "diversity is a key driver: if all participants are of the same background, perspective, and opinion, the outcome may be limited and even predictable" [3].

Each stakeholder plays an important role in the development of urban elements and activities and contributes equally to the process with his/her distinct background. The public or the users are the experts of their experience; urban planners and politicians or the choosers are the experts on the government policies and interests; and designers 
are the experts of the design process [9]. They are capable of translating the valuable data obtained from the other stakeholders into the products that meet everyone's needs.

By participating in the design discussion, the public may become more aware of the problems the community faces. They may also claim a share in the success of the final product [2], and develop an affective relation with it.

\section{Interaction and the enhancement of the urban experience}

Public spaces will only be enjoyed and celebrated when they provide people with pleasurable experiences. Burns believes that the urban experience is "atrophying" [10]. Whilst passive contemplation and spectatorship are increasing, interpersonal relationships are being replaced with "the packaged messages of a commodified culture of spectacle and merchandising" [10] in urban spaces.

Interactions with urban elements and connections between city dwellers could transform the urban experience. This study defends the idea that people should play an active role, not only by participating in the development of urban elements and activities but also by building their own experiences while interacting with objects and other individuals in public spaces.

This sort of interaction between people in urban spaces refers to Whyte's idea of triangulation, as previously noted. To Whyte, triangulation is "the process by which some external stimulus provides a linkage between people and prompts strangers to talk to each other as though they were not" [5]. The author defends that street characters make the city environment friendlier. He cites the example of an individual who voluntarily directs the traffic in midtown New York. His performance is capable of drawing members of the crowd together and stimulating conversation among them.

In similar fashion, physical objects or even sights might stimulate connections between people. Sculpture can have strong social effects [5]. An analysis of the Chase Manhattan plaza before and after the installation of 'Four Trees" by Dubuffet concluded that it has had a positive impact on pedestrian activity [5]. People were attracted to the sculpture and interacted with it, standing under it or beside it, touching it, or talking about it. The same effect was observed at the Federal Plaza in Chicago where the huge Alexander Calder's stabile was installed [5].

Linkages between people or between the public and some urban elements may also contribute to promoting inclusivity in public spaces. When the population feels so connected to the city that it becomes an important aspect of their lives, it may be possible to affirm that there is urban inclusivity.

\section{Methodology}

Recent research, such as the convex mirror experiments conducted by Urban Experiments in partnership with the City of London in 2009 revealed that simple interventions in public spaces might result in relevant changes in the way people relate to them (Figure 1) [11]. Anish Kapoor's Cloud Gate in Chicago, US also makes use of reflective surfaces to provide the public with a unique urban experience (Figure 2) [12].

Inspired by these examples, a pilot experiment was carried out in Ottawa, Canada to explore the assumptions presented here. It consisted of setting three-dimensional 
artefacts with mirrored faces in a selected urban space. These objects were to be accessible to the public and encourage interaction. Details related to the construction of the artefacts, the public's safety and the experiment schedule were negotiated between the researcher and the NCC (National Capital Commission).

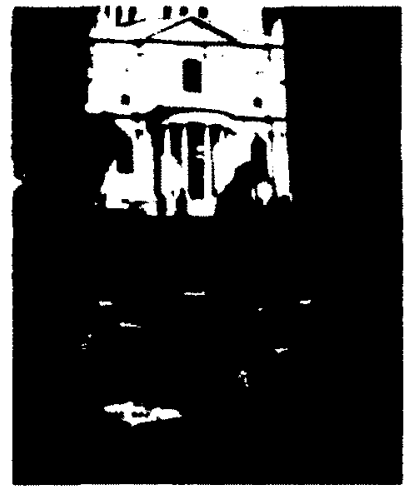

Figure 1: Convex mirror experiments [11]

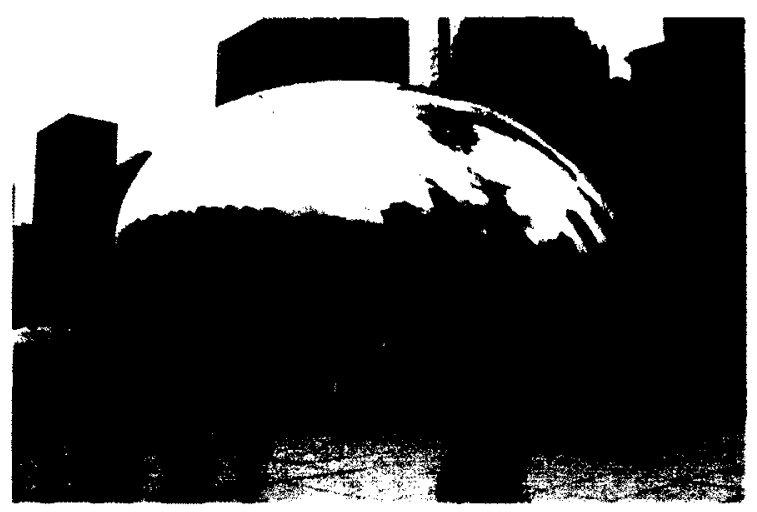

Figure 2: Anish Kapoor's Cloud Gate

\section{Aims and objectives}

The experiment was intended to provide the researcher with a better comprehension of the nature of inclusivity in public spaces. It aimed to recognize and identify circumstances when inclusivity and exclusion take place in this context. Furthermore, it attempted to offer a deeper understanding of the nature of interaction in urban spaces. For this reason, the participants' behaviour was observed when the reflective objects were installed and compared to other people's behaviour when there was no stimulus. The objective was to notice changes in the dynamics of the space. Finally, the investigation endeavoured to observe and interpret the city dwellers' urban experience as pleasurable and enjoyable or not.

\section{Methods}

The research project was reviewed and cleared by the Carleton University Research Ethics Board to protect the rights of the participants. They were observed without the intervention of the researcher. Photographs were taken by the NCC's photographer, according to the organization's ethical practices. Participants' whose facial features were significantly revealed by the pictures were asked to sign a release form. In case of minors, a parent or guardian's consent was required.

\section{Participants}

The researcher chose to observe spontaneous responses to the environment and the objects, rather than preparing people for the experiment. Hence, all people who in some way interacted with the three-dimensional reflective artefacts, either by passing through them, touching or looking at them, were considered participants. When the objects were not present, all the people present in this urban space were also regarded as participants. 


\section{Location}

Located in the core of downtown Ottawa, the Sussex Courtyards owned by the NCC are a common destination for people who appreciate the charming restaurants, cafes and boutiques. The Tin House Courtyard was selected to be the experiment location because of the amount of free ground space. This courtyard attracts many potential participants since it serves as a passage for many pedestrians and can be easily seen by those circulating outside of it.

\section{Duration}

The experiment was conducted from August 24 to 29, 2010. The space was observed with and without the stimulus on alternate days, including the weekend, from 11am to 2pm and from 4:30 to 7:30pm. Variations in the participants' reactions were mapped according to the day of the week and the time of the day they happened.

\section{Data analysis}

As criterion for the observation, the researcher considered participants' actions towards the space and the objects. The courtyard was observed with and without the stimulus. Responses such as approaching, exploring, touching, rearranging the artefacts or playing with them, for instance, were regarded as important data. Also, people's oral reactions to the objects were examined. The observations were documented in notes and photographs. Collected data was organised in an affinity diagram so that recurrent patterns and critical information could be identified. The study progressed in response to the emerging findings in accordance with grounded theory methods [13].

Another method of data collection evolved naturally during the experiment. As participants approached the researcher to ask questions about the objects, informal conversations/interviews arose. The researcher established a close relationship with the local community, listening to their concerns and opinions about the space.

\section{Results}

\section{An interactive activity}

From all the forms of relationship participants established with the objects, the visual and tactile interactions proved to be the most prominent. Looking at the reflections and touching the artefacts were common reactions to the experiment (Figure 3 ). 

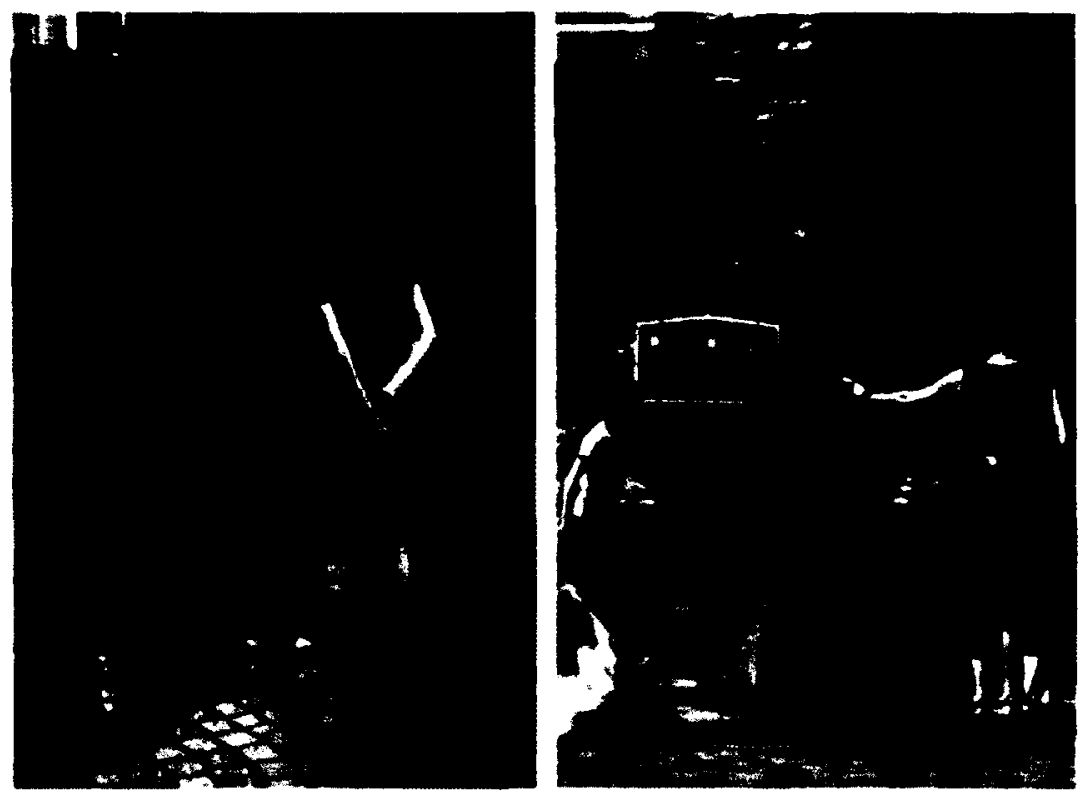

Figure 3: Visual and tactile interactions (Credit: Sarah O'Neill)

The age of the participants strongly influenced the nature of the activities that participants took part in. Whereas children freely interacted with the objects, dancing in front of their reflections, making faces to them or creating games such as hiding behind the artefacts or running around them; adults expressed, in general, reserved responses. They often just took a quick look at the installation and touched the objects.

Subsequently, they would occasionally knock on the artefacts or slightly lift them in an attempt to discover the materials they were made of.

When in groups, however, adults were capable of engaging in more creative activities. They stopped, commented on the reflections, rearranged the artefacts and participated in a more playful experience. A lady, for instance, hid in one of the pyramids and a young man used the smaller one as a hat.

\section{The dynamic of the space}

The courtyard is a common destination for children accompanied by their parents, people walking their dogs, and executives who appreciate spend their lunchtime sitting in the trees' shade. Normally it has two focus points: a fountain and the Tin House façade, a historical metal covered façade that is mounted high on the wall of one of the courtyard buildings. Neither of the two elements invites people to a tactile interaction.

The installation represented a third focus point to the courtyard (Figure 4). The objects, placed in the walkway, were accessible to people and invited them to freely interact. For children, they became a new opportunity to play and develop their creativity by inventing games. Others converted the artefacts into temporary landmarks, photographing them and attributing as much importance to them as to the other two focus points. The pyramids were also featured in some wedding pictures! The local community members, noticing the new elements in the space, expressed views that included the installation's potential to become part of the neighbourhood's identity. 


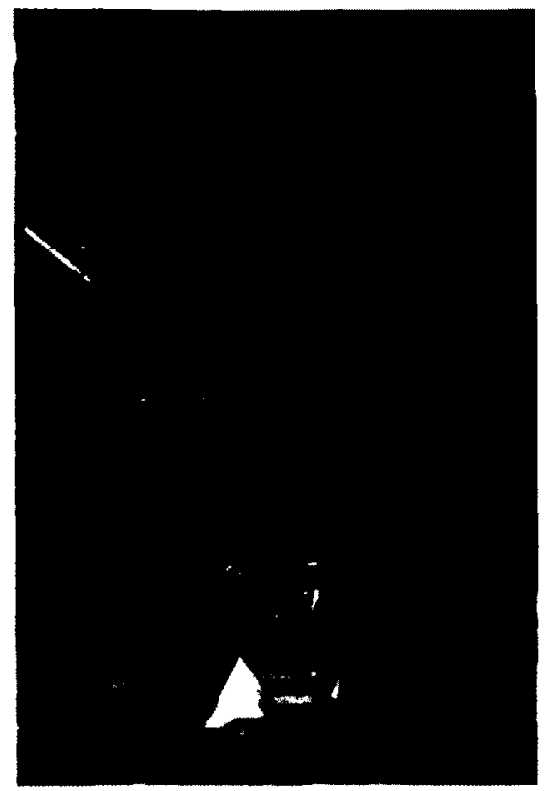

Figure 4: The courtyard's three focus points: Tin House, fountain and the mirrored objects (Credit: Sarah O'Neill)

\section{The urban experience}

The urban experience offered by the experiment seemed to be mostly enjoyable and pleasurable. Many participants captured their unique experiences by taking pictures, which might be an indicator of satisfaction and approval. Furthermore, statements such as "It makes you look skinnier; it's wonderful" and "I'm taller than myself" can be interpreted as manifestations derived from amusing activities.

\section{The triangulation process}

The triangulation process was identified in two different ways. By playing together, children promoted some linkage with their parents. Adults would then engage in conversations about their children and other related topics. The installation seemed to foster connections between strangers as the artefacts offered younger participants more opportunities to create games.

The second and less evident triangulation process occurred between the community members and the researcher. Noticing her presence, people who live or work in the courtyard area approached the researcher to discuss the new elements. One simple question frequently led to longer conversations about their relation to the space.

\section{Discussion}

The ages, capabilities and social status of the participants were diverse. Although the artefacts did not present any childish characteristic, children hugged, kissed, and climbed them as if they were toys. Younger participants frequently involved their parents by creating games and activities. Adults also interacted with the installation. In groups, they seemed to develop more creative relations with the objects. 
The artefacts were accessible to everyone. As an example, a man in a wheelchair stopped to touch and explore the objects. Social position was not an obstacle for the interaction either. Participants from different social backgrounds embraced the urban experience offered by the experiment.

One form of interaction was particularly interesting in this study: the act of touching. In whatever way it happened, touching created a more concrete connection with the environment and the artefacts occupying the space. As previously mentioned in this paper, when people feel attached to the urban space they are more likely to feel a part of it and, consequently, included in it. Future studies in sensory engagement can clarify more aspects of this connection.

In any case, it seemed that all the participants in the experiment shared the sense that they were allowed and even supposed to have a connection with the artefacts. Hence, here lies the opportunity for including more people in the urban space.

This inclusion could result not only from the interaction with the objects in the urban environment but also from their development. Even though the experiment did not represent a co-creation experience, it provided some insights into the possibility of employing this process in such a context. The enthusiastic feedback from the National Capital Commission might be a sign of a position favourable to the development of codesign workshops.

Moreover, the deep interest demonstrated by the public may suggest some willingness to participate. By stating that the installation "ruins the space" or is "dynamic", they were probably expressing a desire to be included in the discussions about the neighbourhood. Is not this sort of judgment already a form of participation?

The study represented a probe into aspects of inclusivity, interaction and co-creation with the purpose of determining whether a deeper research should be undertaken. The results were encouraging and revealed the community's potential to engage in projects to improve the neighbourhood. Further research might propose co-design sessions to build community artefacts out of recycled materials, for instance.

\section{Conclusion}

The concept of inclusivity should be carefully considered by designers. In the urban environment, the exclusion of segments of the population is clear and becomes even more evident when phenomena such as urban alienation and vandalism are observed. The public are not habitually involved in the decisions regarding the urban spaces they utilise, which may lead to a feeling of detachment and estrangement.

Co-creation might contribute to minimise urban alienation. By reducing the gap between designer and user, it enables the development of urban elements that attend to population's needs and respect people's different capabilities. Urban planners and politicians are also invited to participate in the process, providing the other stakeholders with their knowledge about government interests and policies.

Interaction is another factor that may enhance the urban experience and promote social inclusivity. Street characters, physical objects and even views can stimulate linkages between people or between the public and the space. These pleasurable experiences might evoke a sense of connection with the city. 
In the pilot experiment carried out in a courtyard in Ottawa, Canada, the public played an active role, building their own urban experiences in accordance with their wishes and capabilities. The installation was quite inclusive, allowing people to choose if they would interact or not and what activities they would perform. Moreover, it did not hinder anyone from participating. The experiment revealed opportunities for fostering inclusivity in urban spaces. And as stated by a community member, "we need more things like that."

\section{Acknowledgements}

This experiment would not be possible without the National Capital Commission's support. Thanks to Brigitte Beaulne-Syp, Francine Belanger, Helena Achia, Karine Saboui, Lorraine Pierce-Hull, Mathieu Brisson, Sarah O'Neill, Vel Craig, and all the NCC members who participated in this project.

\section{References}

1. lacofano, D., \& Goltsman, S. (n.d.). Inclusive design : moving beyond new urbanism. Retrieved April 21, 2010, from http:/lumwinclusivecitycom/Content/10012/preview.html. 2. King, S., Ferrari, D., Conley, M., \& Latimer, B. (c1989.). Co-design : A process of design participation. New York : Van Nostrand Reinhold

3. Sanders, E. B., \& George, S. (2009). A Social vision for value co-creation in design. Open Source Business Resource, (December), 1-5

4. Keates, S., \& Clarkson, P. J. (2003). Countering design exclusion: An introduction to inclusive design. London; New York: Springer

5. Whyte, W. H. (1980). The social life of small urban spaces. Washington, D.C.: The Conservation Foundation

6. Cassim, J., Coleman, J., Clarkson, J., \& Dong, H. (2007). Why inclusive design?. In R. Coleman, J. Clarkson, H. Dong, \& J. Cassim (Ed.), Design for inclusivity: A Practical guide to accessible, innovative and user-centred design. Hampshire: Gower Publishing Limited; Burlington: Ashgate Publishing Company

7. Choi, S. (2009). Inclusive design as an enabler of product innovation. In Include 2009 Proceedings. London

8. Coleman, R., Topalian, A., Clarkson, J., \& Dong, H. (2007). The Business case. In R. Coleman, J. Clarkson, H. Dong, \& J. Cassim (Ed.), Design for inclusivity: A Practical guide to accessible, innovative and user-centred design. Hampshire: Gower Publishing Limited; Burlington: Ashgate Publishing Company

9. Sanders, E.B.-N, \& Stappers, P. J. (2008). Co-creation and the new landscapes of design. CoDesign, 4(1), 5-18

10. Burns, A. (2000). Emotion and urban experience : Implications for design. Design Issues, 16(3), 67-79

11. Urban experiments. (n.d.). Retrieved May 20, 2010 from http:ll

unw. urbanexperiments.eu/

12. Main, B., \& Hannah, G. G. (2010). Site fumishings : A complete guide to the planning, selection, and use of landscape furniture and amenities. Hoboken, New Jersey: John Wiley \& Sons, Inc 
13. Glaser, B. G., \& Strauss, A. (1967). The Discovery of Grounded Theory: Strategies for Qualitative Research. Chicago: Aldine Transaction 
APPENDIX C

\section{List of interviewees}




\begin{tabular}{ccc}
\hline Position / background & Mumber of participants & Organization \\
\hline Landscape architects & 1 & Consultant companies \\
\hline $\begin{array}{c}\text { Industrial / graphic designers } \\
\text { reconstruction project }\end{array}$ & 2 & Public art jury \\
\hline Business owners representative & 1 & City of Ottawa \\
\hline Artists & 1 & $\begin{array}{c}\text { Preston Street Business } \\
\text { Improvement Association (BIA) }\end{array}$ \\
\hline Public Art Program representatives & 2 & Public art jury / N.A. \\
\hline Community representative & 2 & City of Ottawa \\
\hline Italian community representative & 1 & Dalhousie Community Association \\
\hline Manager, Integrated Street Furniture & 1 & N.A. \\
\hline Program & 1 & City of Ottawa \\
\hline
\end{tabular}




\section{APPENDIX D}

\section{Consent form for interviews}


Canada's Capital University

\section{Consent Form}

\section{PUBLIC PARTICIPATION IN URBAN SPACES}

Date of ethics clearance: August 24, 2010 Expiration: May 31, 2011

\section{PURPOSE}

The research intends to understand what public participation means to the different stakeholders in projects for public spaces. It aims to investigate the role that each agent plays in the process as well as identify specific characteristics of this interdisciplinary collaboration.

\section{TASKS AND DURATION}

You are asked to take part in an interview to clarity aspects of your participation in the project and your relationship with the other stakeholders.

I, voluntarily agree to participate in a research project

conducted by Marla Gabriela Sanches who is doing a Master's of Design thesis supervised by Prof. Lois Frankel, Department of Industrial Design, Carleton University.

\section{QUOTING}

Specific quotes might be used in the thesis reporting upon my approval.

\section{RIGHT TO WITHDRAW}

I may withdraw from participation until May 31, 2011 without prejudice. If I decide to withdraw from the project, any information and data I have provided will be destroyed.

\section{POTENTIAL OF RISK OR DISCOMFORT}

There are no known risks, physical or emotional, to participation in this study.

This project was reviewed and cleared by the Carleton University Research Ethics Board.

If I have any concerns regarding how this study was conducted I may contact the Research Ethics Board chair, Prof. Antonio Gualtieri at 613-520-2517 or ethics@carleton.ca.

Signature of participant

Signature of researcher
Date

Date 
APPENDIX E

Interview scripts 


\section{Interview}

Julie DuPont

Cultural Planner, City of Ottawa

March 15, 2011

1. What projects are you currently working on?

2. What is Open Ottawa? Why did you decide to create such a project

3. Who is involved in Open Ottawa? Decision-makers, academics, public?

4. Who are the sponsors?

5. How does the prototype event happen?

6. What kind of projects are developed in the event? Products, services, events? Examples?

7. Where does the demands for these projects come from?

8. Are the projects discussed implemented?

9. Has any project created last year been implemented? How did people react to it?

10. How does the one percent for art project work? 
Interview

Melissa

Public Art Program Administrator

March 15, 2011

1. What projects of urban rehabilitation/revitalization are you involved in?

2. Where does the demand for the projects come from?

3. Budget. Where does the money come from?

4. Who is responsible for the decisions regarding the projects?

5. Who decides which urban elements will be installed or which artist will develop the artworks that will be featured in the space?

6. Is the public involved in these decisions? How?

7. What was the intention of the projects executed in each one of these streets?
a. Wellington
b. Preston
c. King Edward

8. How did people react to the spaces after the project implementation?
a. Wellington
b. Preston
c. King Edward

9. Did you get any feedback from the public, tenants, neighborhood representatives?

10. How do you measure the success of the space after a rehabilitation project? Do you conduct any postoccupancy evaluation? 


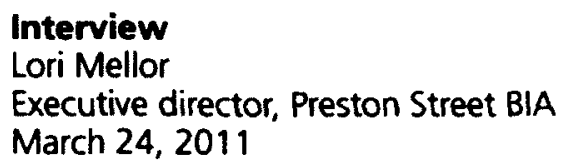

1. What is a BIA? What are the Preston Street BIA responsibilities/activities?

2. Who does the BIA represent?

3. A little bit about Preston Street and Little Italy's history?

4. Do the community of Little Italy have any specific characteristics? What differentiates this neighborhood from the others?

5. Where did the demand for rehabilitating the street come from? Other rehabilitation projects?

6. How were the the decisions regarding the rehabilitation project made? Did the BIA participate in meetings? Was the BIA responsible for approving the project?

7. Who decided which elements should be displayed on the street? (Pieces of street furniture, artwork)

8. Why was the artist $c j$ chosen to develop the sculptures that were installed on the street? Did the BIA participate in the development of the pieces? Did the artist talk to the population and the BIA members?

9. How would you rate the results of the rehabilitation project?

10.How did people react to cj's sculptures?

11.The impact of the project. Feedback? Any system to collect feedback?

12.Other pieces of public art? How is the relationship between the public and the pieces? 
1.Who does the association represent?

2. What are the association responsibilities and activities?

3. What are some of the association accomplishments?

4. How does the community participate in the decisions regarding rehabilitation processes such as the Preston Street project?

5. Who else is involved in the discussion? Government representatives? City councillor?

6. Was the community involved in the choice of the public art pieces which were installed on Preston Street?

7. Was the community involved in the choice of other urban elements?

8. Were you involved in other processes that involved public participation in Ottawa? The Chinatown arch? The Wellington Marbles?

9. On a scale from 0 to 10 , how would you rate the reconstruction project? (being $0=$ very dissatisfied and $10=$ very satisfied) 
1.Why were you invited to participate in the jury?

2. How does the process of choosing the pieces of public art work?

3. What was your role in the decision-making process?

4. Are industrial designers often involved in these process?

5. How do you think industrial designers can help this kind of decision? Could they be involved in other aspects of these projects?

6. Have you participated in any other aspect of Preston Street reconstruction project?

7. Why were some small sculpture chosen as opposed to a smaller number of larger scale pieces?

8. What criteria were observed in the judging process?

9. Did the jury suggest any changes to the pieces? Were you involved in an analysis of the colors, textures, sizes?

10. How satisfied are you with the final artwork choice?

11. How satisfied are you with the overall reconstruction project?

12. How well do you think neighborhoods brand themselves in Ottawa? 
Interview

Ravi Mehta

P. Eng. - Project Manager, City of Ottawa

April 1, 2011

1. What has been your role on the Preston Street rehabilitation project?

2. Why were you designated for this project? Are you responsible for a specific area of the city?

3. What are the other stakeholders in this project? What are their roles? (landscape architect, BIA, community association, city councillor)

4. How are the consultants chosen for each project?

5. Was the community involved in this project? How? Have there been public consultations?

6. Who chose the pieces of street furniture which were installed on the street?

7. Was there any industrial designer involved in the project?

8. Who chose the pieces of public art which were installed on the street?

9. Does the Percent for Art policy require that the pieces of public art be installed at the same place as the construction?

10. How well do you think BIAs work to maintain streets? What do you think of this division of the city by streets?

11. Did you get any feedback on the project?

12. How do you evaluate the results of a project such as this one? 


\section{Interview}

Chantal Gaudet

Landscape architect, Stantec

April 8, 2011

1.What has been your role in the Preston Street rehabilitation project?

2. Who are the other stakeholders in this project? What are their roles? (project manager, BIA, community association, city councillor)

3. How is the relation between consultants and the project manager? Does he approve the projects before the discussions with other stakeholders?

4. How much autonomy did you have in developing the proposals?

5. How was the community involved in this project? Have there been public consultation meetings?

6. Who chose the pieces of street furniture which were installed on the street? How was this decision made?

7. Was there any industrial designer involved in the project?

8. Who chose pieces of public art which were installed on the street?

9. Does the Percent for Art policy require that the pieces of public art be installed at the same place as the construction?

10. How well do you think BIAs work to maintain streets?

11. Did you get any feedback on the project?

12. How do you evaluate the results of a project such as this one?

13. Are you working on the Bambini project? How different is this project from the Postcards from the Piazzas? 
Interview

Pat Durr

Artist, Public Art Jury

April 11, 2011

1. Why were you invited to participate in the jury?

2. What is the difference between public art and the art that is exhibited in galleries?

3. Who can make public art? Just artists? Landscape architects? Industrial designers?

4. Are artists prepared to make public art?

5. What is your opinion about the Percent for Art policy? Does it help artists to divulge their work?

6. How does the process of choosing the pieces of public art work?

7. What was your role in the decision for the artworks?

8. Why were some small sculpture chosen as opposed to a smaller number of larger scale pieces?

9. What criteria were observed in the judging process?

10. Did the jury suggest any changes to the pieces? Were you involved in an analysis of the colors, textures, sizes?

11. How satisfied are you with the final artwork choice?

12. How satisfied are you with the overall reconstruction project?

13. What is your opinion about other pieces of public art that have recently been installed in the city? (Wellington marbles, chairs on Bank) What do you think of this pattern that has been developing of a sequence small pieces along the sidewalks? 
1. How long have you been an artist?

2. How long have you been involved in participatory art projects?

3. Why did you decide to involve the community in the development of public art?

4. What methods do you utilize to develop empathy with the community members (and become a "member of the community")?

5. In what stages of the project does the community participate? (research, creation, execution, etc)

6. Is there anything unique to the Preston Street community?

7. How has your relationship with all the stakeholders in the reconstruction project been? (project manager, landscape architect, BIA, community association, jury) How have they influenced your work?

8. Did you get any feedback from the community after the installation of the sculpture? What was it?

9. Are sidewalks an appropriate location for public art? Why?

10. Why did you decide to have a large number of smaller sculptures as opposed to fewer larger ones?

11. What is the difference between doing art for outdoor public spaces and doing art that is exhibited in galleries and museums?

12. What is your level of satisfaction with the project? What did you enjoy the most? What did you enjoy the least?

13. Did you notice any change in the relationships between the community members after the project?

14. What is the importance of the percent for art policy? Have you worked with other cities which have similar programs?

15. Have you worked with other projects in Ottawa? How do they compare to this one? 


\section{Interview}

Lee Ann Snedden

Integrated Street Furniture Program Coordinator

May 9, 2011

1.How long have you been working at the Sustainability Practice and Neighbourhood Liveability Branch?

2. What is your position?

3. What is your academic background?

4. Why was the Integrated Furniture Program created? Who created it?

5. What are the program's goals?

6. How does this program compare to other cities' street furniture policies? (Vancouver, Toronto, Chicago)

7. Who elaborates the design guidelines for street furniture?

8. Who elaborated the requests for proposals?

9. Who evaluates the submitted proposals?

10. Are designers involved in any stage of the process?

11. Many reconstruction projects are under way and different models of street furniture have been installed in these locations. How does the program intend to promote integration between these pieces and the ones chosen by the ISFP?

12. Why is the project currently on hold? 
Interview

James Acres

Graphic Designer, Public Art Jury

May 10, 2011

1.What is your background (academic and work)?

2. Why were you invited to take part in a jury for public art?

3. Are designers often involved in this process?

4. Can you explain a little bit the Hazeldean Road project? Are the public art pieces elements of a reconstruction or rehabilitation project?

5. Who idealized the aluminum banners?

6. Who were the other members of the jury?

7. How do you think a designer can contribute to this kind of decision?

8. Could designers participate in other stages of the project? Which ones?

9. Did the proposals submitted by the artists meet material's technical requirements?

10. Did the jury suggest any changes to the pieces? Were you involved in an analysis of the colors, textures, sizes?

11. How satisfied are you with the final artwork choice?

12. What is your opinion about the Percent for Art policy and the pieces of public art that have been recently installed in Ottawa's public spaces? 
1. How long have you ived In Ottawa? Do you live in Little Italy?

2. Is there anything unique to the Preston Street community? What?

3. How did you meet cj?

4. cj mentioned that you were very important to the project. How did you help her develop concepts for the sculptures?

5. Did you suggest any changes to the pieces she developed?

6. Did you have any say in the shapes, colors, and sizes of the sculptures?

7. What is your level of satisfaction with the sculptures final results?

8. How did the Italian community react to them?

9. Do the sculptures translate the Italian characteristics that you expected?

10. What is your level of satisfaction with the overall reconstruction project?

11. Did you participate in any of the public consultations regarding this project?

12. Do you see any similarities between Preston Street spaces and the piazzas in Italy? 


\section{APPENDIX F}

Participants' perceptions of the process 


\begin{tabular}{|c|c|c|c|c|c|}
\hline & & Behaviour / attitude & $\begin{array}{l}\text { Number of } \\
\text { participants. }\end{array}$ & $\begin{array}{l}\text { Percentage } \\
\text { of the total }\end{array}$ & Wustrotive quots \\
\hline \multirow{3}{*}{ City of Ottawa } & $\begin{array}{l}\text { General } \\
\text { context }\end{array}$ & $\begin{array}{l}\text { Compared Ottawa to } \\
\text { other cities }\end{array}$ & 2 & $14.3 \%$ & 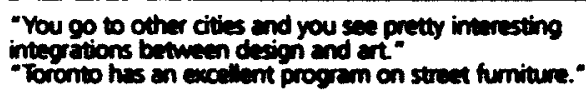 \\
\hline & \multirow{2}{*}{ Neighborhoods } & $\begin{array}{l}\text { Expressed pride for a } \\
\text { neighborthood }\end{array}$ & 2 & $14.3 \%$ & $\begin{array}{l}\text { "My business oumars talke very good are of their } \\
\text { proportis." }\end{array}$ \\
\hline & & $\begin{array}{l}\text { Compared a } \\
\text { neighborhood to } \\
\text { another }\end{array}$ & 2 & $14.3 \%$ & $\begin{array}{l}\text { pluin; it rafucts the } \\
\text { is very consenvtive." }\end{array}$ \\
\hline \multirow{6}{*}{$\begin{array}{l}\text { Ottawa's } \\
\text { strategies }\end{array}$} & \multirow{2}{*}{$\begin{array}{l}\text { Design } \\
\text { strategies }\end{array}$} & $\begin{array}{l}\text { Expressed preference } \\
\text { for manufactured } \\
\text { street furniture }\end{array}$ & 3 & $21.4 \%$ & 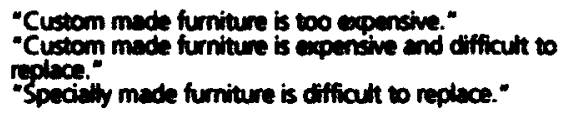 \\
\hline & & $\begin{array}{l}\text { Consider custom } \\
\text { made street furniture } \\
\text { as an option }\end{array}$ & 1 & $7.1 \%$ & "Benches are sommines too big." \\
\hline & \multirow{2}{*}{$\begin{array}{l}\text { Art strategies/ } \\
\text { Percent for Ant } \\
\text { policy }\end{array}$} & $\begin{array}{l}\text { Expressed satisfaction } \\
\text { with the Percent for } \\
\text { Art program }\end{array}$ & 5 & $35.7 \%$ & $\begin{array}{l}\text { "It is a very good poicy." } \\
\text { "I recily lite what has been done. I would like to sea } \\
\text { more. }\end{array}$ \\
\hline & & $\begin{array}{l}\text { Expressed concern } \\
\text { with the Percent for } \\
\text { Aft program }\end{array}$ & 1 & $7.1 \%$ & $\begin{array}{l}\text { "It might be too much [art]." } \\
\text { "Sometimes it is dificult to find space for everything } \\
\text { linfrestucture, art, strect furniture]" }\end{array}$ \\
\hline & \multirow[t]{2}{*}{$\begin{array}{l}\text { Reconstruction } \\
\text { projects }\end{array}$} & $\begin{array}{l}\text { Expressed satisfaction } \\
\text { with the overall } \\
\text { project }\end{array}$ & 5 & $35.7 \%$ & $\begin{array}{l}\text { "I am delighred." } \\
\text { "I am very glad." } \\
\text { "so far it is oood. It has made a cifference in the life of } \\
\text { the street. } \\
\text { "I think it is really good." }\end{array}$ \\
\hline & & $\begin{array}{l}\text { Expressed some } \\
\text { dissatisfaction with } \\
\text { the overall project }\end{array}$ & 1 & $7.1 \%$ & $\begin{array}{l}\text { "It would be nice to hove a piara, a meeting place." } \\
\text { "It is a little bit artifial." }\end{array}$ \\
\hline \multirow{5}{*}{ Interdisciplinarity } & \multirow{4}{*}{ Stakeholders } & $\begin{array}{l}\text { Graphic / industrial } \\
\text { designers identified } \\
\text { by the research (jury } \\
\text { in the public art } \\
\text { competition) }\end{array}$ & 2 & $14.3 \%$ & $\begin{array}{l}\text { "I twe in the neighbohood and had a friend in the } \\
\text { community boand." } \\
\text { "I think I was imited because of my background in } \\
\text { design and technology" } \\
\text { "This competition is offerent than the usual ones." }\end{array}$ \\
\hline & & $\begin{array}{l}\text { Mentioned } \\
\text { interdisciplinary } \\
\text { conflicts }\end{array}$ & 5 & $35.7 \%$ & $\begin{array}{l}\text { "They do not live here. They think car is esential." } \\
\text { "Thardy met with her." } \\
\text { "Nobody asked us." } \\
\text { "You wh not want business cumers to talk to } \\
\text { contractors." }\end{array}$ \\
\hline & & $\begin{array}{l}\text { Professionals crossing } \\
\text { disciplines boundaries }\end{array}$ & 2 & $14.3 \%$ & $\begin{array}{l}\text { Landscape architecture and ant } \\
\text { Ant and street furniture }\end{array}$ \\
\hline & & $\begin{array}{l}\text { Expressed satisfaction } \\
\text { with the group } \\
\text { dynamics }\end{array}$ & 1 & $7.1 \%$ & "This particular group is getting better and better." \\
\hline & $\begin{array}{l}\text { Designers' } \\
\text { possible roles }\end{array}$ & $\begin{array}{l}\text { Envision possible roles } \\
\text { for designers in the } \\
\text { process }\end{array}$ & 3 & $21.4 \%$ & 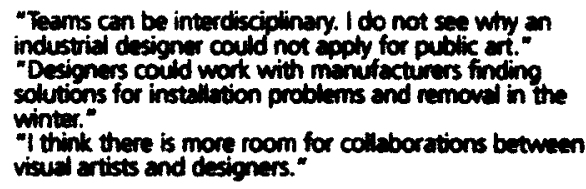 \\
\hline
\end{tabular}




\begin{tabular}{|c|c|c|c|c|c|}
\hline & & Behaviour / attitude & $\begin{array}{l}\text { Number of } \\
\text { participants" }\end{array}$ & $\begin{array}{l}\text { Percentage } \\
\text { of the total }\end{array}$ & Mustrotive quotes \\
\hline \multirow{7}{*}{$\begin{array}{l}\text { Public } \\
\text { participation }\end{array}$} & \multirow{4}{*}{$\begin{array}{l}\text { Control of the } \\
\text { proiect }\end{array}$} & $\begin{array}{l}\text { Expressed } \\
\text { dissatisfaction with } \\
\text { the lack of control }\end{array}$ & 1 & $7.1 \%$ & "We would tite to choose them oursetves." \\
\hline & & $\begin{array}{l}\text { Expressed satisfaction } \\
\text { with relinquishing the } \\
\text { control }\end{array}$ & 1 & $7.1 \%$ & "I do not take ownership of the design." \\
\hline & & $\begin{array}{l}\text { Related the right to } \\
\text { choose with financial } \\
\text { power }\end{array}$ & 2 & $14.3 \%$ & $\begin{array}{l}\text { "They did not ask us bocuse they were pasing for it." } \\
\text { "They are the ons poying for it." } \\
\text { "The BuA wos poying. }\end{array}$ \\
\hline & & $\begin{array}{l}\text { Expressed uncertainty } \\
\text { about the decision } \\
\text { process }\end{array}$ & 1 & $7.1 \%$ & I am now sure where the dedsion is made. $h$ is sort \\
\hline & \multirow{3}{*}{$\begin{array}{l}\text { Participatory } \\
\text { art }\end{array}$} & $\begin{array}{l}\text { Expressed satisfaction } \\
\text { with the process }\end{array}$ & 5 & $35.7 \%$ & $\begin{array}{l}\text { "She talked to people." } \\
\text { "The process is much more important." } \\
\text { "lt was more bout the process then the final result." } \\
\text { "q talked to the comminity." }\end{array}$ \\
\hline & & & & & "It is an amring piece of art." \\
\hline & & $\begin{array}{l}\text { Expressed satisfaction } \\
\text { with the final result }\end{array}$ & 6 & $42.9 \%$ & $\begin{array}{l}\text { "like if, but because I know what it is about." } \\
\text { The thation community is so proud. The reponse has } \\
\text { been so positive." }\end{array}$ \\
\hline
\end{tabular}

* Sessions with 2 experts in other projects in Ottawa took place at public consultation meetings. They were not exactly interviews, and for this reason, they were not computed in the list of interviewees (Appendix C). In these cases, the researcher did not expect to be able to talk to the professionals. Consequently, scripts were not prepared. Also, it was not possible to talk to the interviewees individually and the duration of the conversation was shorter than the interviews. In spite of these being exceptions to the ordinary interview procedures, these dialogues provided the researcher with insights into the research questions. These professionals' behaviours and attitudes towards the projects were therefore mentioned in the data analysis. 
APPENDIX G

Consent form for surveys 


\section{Consent Form}

\section{PUBLIC PARTICIPATION IN URBAN SPACES}

Date of ethics clearance: August 24, 2010 Expiration: May 31, 2011

\section{PURPOSE}

The research intends to understand what public participation means to the different stakeholders in projects for public spaces. It aims to investigate the role that each agent plays in the process as well as identify specific characteristics of this interdisciplinary collaboration.

\section{TASKS AND DURATION}

You are asked to take part in a survey to clarify aspects of the general public relationship with this space and its elements.

$$
\text { I, }
$$
voluntarily agree to participate in a research project

conducted by Maria Gabrlela Sanches who is doing a Master's of Design thesis supervised by Prof. Lois Frankel, Department of Industrial Design, Carleton University.

\section{POTENTIAL OF RISK OR DISCOMFORT}

There are no known risks, physical or emotional, to participation in this study.

\section{ANONIMITY/CONFIDENTIALITY}

My identity will be kept anonymous. No personal information will be gathered.

I have read the above description of this research project and indicate below my consent for the use of this material for research purposes, conferences, academic journals, course research paper, web site/publication and Master's thesis.

This project was reviewed and cleared by the Carleton University Research Ethics Board.

If I have any concerns regarding how this study was conducted I may contact the Research Ethics Board chair, Prof. Antonio Gualtieri at 613-520-2517 or ethics@carleton.ca.

Signature of participant

Signature of researcher

\section{Date}

\section{Date}




\section{Carleton \\ UNIVERSITY}

Canada's Capital University

\section{DEBRIEFING}

Thank you for participating in this study which aims to understand public participation projects and their results to the general public. This survey is part of a Masters thesis research supervised by Prof. Lois Franket, Department of industrial Design, Carleton University.

Your anonymity is assured; no individual will be recognizable.

Your time and efforts are greatly appreciated!

If you have any further questions or comments about this study, you may contact:

Profosecor Lols Frankel

lois_frankel@carleton.ca (613) 520-5675

For any other concerns, contact:

Proteaseor Antonio Guattierl, Chair, Carleton University Research Ethics Board

Carleton University Research Office 20045108 Tory, Carleton University

Ottawa, On K1S 5B6

ethics@carleton.ca (613) 520-2517 
APPENDIX H

Overall likeness score and likeness fingerprint formula 


\section{Overall likeness score}

This overall rating for a building's indoor environment can be determined from the following formula:

$\frac{100 \sum_{j=1}^{m} \sum_{k=1}^{m} i_{j, k} l_{j, k}}{m n i_{\max } l_{\max }}$

where $j$ is the questionnaire number, $k$ is the question number, $i$ is the importance rating $1 \leq \mathrm{i} \leq 7$, $i_{\max }$ is the maximum value of $i(7), l_{\max }$ is the maximum liking rating $(+3), l$ is the linking rating $-3 \leq 1 \leq+3, m$ is the number of completed questionnaires and $n$ is the number of questions in the score (Levermore, 1994: 113). The score is normalized between +100 and -100 , the positive scale increasing with liking and importance and the negative scale showing disliking and unimportance. Zero indicates a neutral position (Levermore, 1994: 113, 114).

\section{Building 'Fingerprint"}

For question $x$, a building fingerprint score is given by

$$
100 \frac{\sum_{j=1}^{m} i_{j, k} I_{j, k}}{m i_{\max } I_{\max }}
$$




\section{APPENDIX I}

Survey 
We would like to know how much or how little you like each aspect of the streetscape and how you evaluate your experience in the space. This is part of a Masters thesis project that intends to examine public participation and the urban experience in public spaces.

\section{Section A:}

Cross the option which best represents your situation:

1. In relation to Preston Street, you are:
a. ( ) a visitor
b. ( ) a resident
c. ( ) a business owner
d. ( ) an employee
e. ( ) other:

2. Number of hours spent per week on Preston Street's public outdoor spaces:
a. () less than 30 minutes
b. () 30 minutes
c. ( ) 1 hour
d. ( 12 hours
e. () more than 2 hours

3. What activities do you perform the most in these spaces?
a. ( ) walking
b. ( ) sitting
c. ( ) shopping
d. ( ) exercising
e. ( ) other:

4. Did you participate in any public consultation regarding this project?
a. $($ ) yes
b. ( ) no

\section{Section B:}

In this section we ask about your likes and dislikes regarding the streetscape and how important you think each factor should be in designing an ideal street. The scale goes from -3 to $3(-3=$ least likable/important, $0=$ neutral, $3=$ most likable/important).

$$
\text { Do you like the... How important is it? }
$$

\begin{tabular}{lllllllllllllllll}
\hline $\begin{array}{l}\text { amount of parking } \\
\text { comments: }\end{array}$ & -3 & -2 & -1 & 0 & 1 & 2 & 3 & -3 & -2 & -1 & 0 & 1 & 2 & 3 \\
\hline $\begin{array}{l}\text { amount of trees } \\
\text { comments: }\end{array}$ & -3 & -2 & -1 & 0 & 1 & 2 & 3 & -3 & -2 & -1 & 0 & 1 & 2 & 3 \\
\hline $\begin{array}{l}\text { sidewalk space } \\
\text { comments: }\end{array}$ & -3 & -2 & -1 & 0 & 1 & 2 & 3 & -3 & -2 & -1 & 0 & 1 & 2 & 3 \\
\hline $\begin{array}{l}\text { benches design } \\
\text { comments: }\end{array}$ & -3 & -2 & -1 & 0 & 1 & 2 & 3 & -3 & -2 & -1 & 0 & 1 & 2 & 3 \\
\hline $\begin{array}{l}\text { litter bins design } \\
\text { comments: }\end{array}$ & -3 & -2 & -1 & 0 & 1 & 2 & 3 & -3 & -2 & -1 & 0 & 1 & 2 & 3 \\
\hline
\end{tabular}




\begin{tabular}{llllllllllllllllll} 
& Do you like the... & How important is it? \\
\hline $\begin{array}{l}\text { street lamps design } \\
\text { comments: }\end{array}$ & -3 & -2 & -1 & 0 & 1 & 2 & 3 & -3 & -2 & -1 & 0 & 1 & 2 & 3 \\
\hline $\begin{array}{l}\text { tree grates design } \\
\text { comments: }\end{array}$ & -3 & -2 & -1 & 0 & 1 & 2 & 3 & & -3 & -2 & -1 & 0 & 1 & 2 & 3 \\
\hline $\begin{array}{l}\text { Little Italy arch } \\
\text { comments: }\end{array}$ & -3 & -2 & -1 & 0 & 1 & 2 & 3 & -3 & -2 & -1 & 0 & 1 & 2 & 3 \\
\hline $\begin{array}{l}\text { sculptures } \\
\text { comments: }\end{array}$ & -3 & -2 & -1 & 0 & 1 & 2 & 3 & -3 & -2 & -1 & 0 & 1 & 2 & 3
\end{tabular}

\section{Section C:}

Finally rate the street on each of the following scales where ' 4 ' is the middle position.

\begin{tabular}{rlllllllll} 
beautiful & 1 & 2 & 3 & 4 & 5 & 6 & 7 & ugly \\
\hline pleasant & 1 & 2 & 3 & 4 & 5 & 6 & 7 & unpleasant \\
\hline unique & 1 & 2 & 3 & 4 & 5 & 6 & 7 & generic \\
\hline pedestrian friendly & 1 & 2 & 3 & 4 & 5 & 6 & 7 & pedestrian unfriendly \\
\hline $\begin{array}{r}\text { favorable to } \\
\text { socialization }\end{array}$ & 1 & 2 & 3 & 4 & 5 & 6 & 7 & $\begin{array}{l}\text { unfavorable to } \\
\text { socialization }\end{array}$ \\
\hline
\end{tabular}

Comments: 
APPENDIX J

List of archival research documents 
- Postcards from the Piazzas by cj fleury backgrounder, issued by the City of Ottawa;

- Preston Street Official Public Art Unveiling: Postcards from the Piazzas by cj fleury FAQ, issued by the City of Ottawa;

- The Wellington Marbles, Marcus Kucey-Jones and Ryan Lotecki, marble, 2010 backgrounder, issued by the City of Ottawa;

- Wellington Street West Official Public Art Unveiling: The Wellington Marbles by Marcus Kucey-Jones and Ryan Lotecki FAQ, issued by the City of Ottawa;

- Ottawa 2020 Arts and Heritage Plan 5-year progress report, April 2010, issued by the City of Ottawa;

- Somerset Street West Reconstruction Comment Sheet, Open House - March 30, 2011, issued by the City of Ottawa;

- Business Improvement Area Handbook 2010, issued by the Province of Ontario;

- City of Ottawa Integrated Street Furniture Policy and Design Guidelines, August 12 2009, issued by the City of Ottawa.

- Urban Design Guidelines for Development along Arterial Mainstreets, issued by the City of Ottawa;

- Urban Design Guidelines for Development along Traditional Mainstreets, issued by the City of Ottawa;

- Urban Design, a Reference Guide to Creating Great Places and Great Spaces, issued by the City of Ottawa. 
APPENDIX K

Comparisons between residents, visitors and employees 
The likeness and importance score was also calculated separately for residents, employees and visitors. The sidewalk space, bench design, and street lamp design are the most liked elements by all the categories. The amount of trees, the design of litter bins and tree grates also received intermediary to low scores. The great discrepancies are related to the the Little Italy arch and the sculptures. The Little Italy arch received a positive score from visitors ( 0.22 points out of 3). However, residents rated it with a -0.12 out of 3 score whilst employees attributed to them a 0 out of 3 score. Sculptures were better praised by employees, who evaluated them with a 0.5 out of 3 score. Residents and visitors did not share the same opinion. They evaluated them with -0.06 and 0.22 out of 3 scores respectively. By comparing the charts below, it is possible to perceive similarities and divergences between the users' likeness scores.

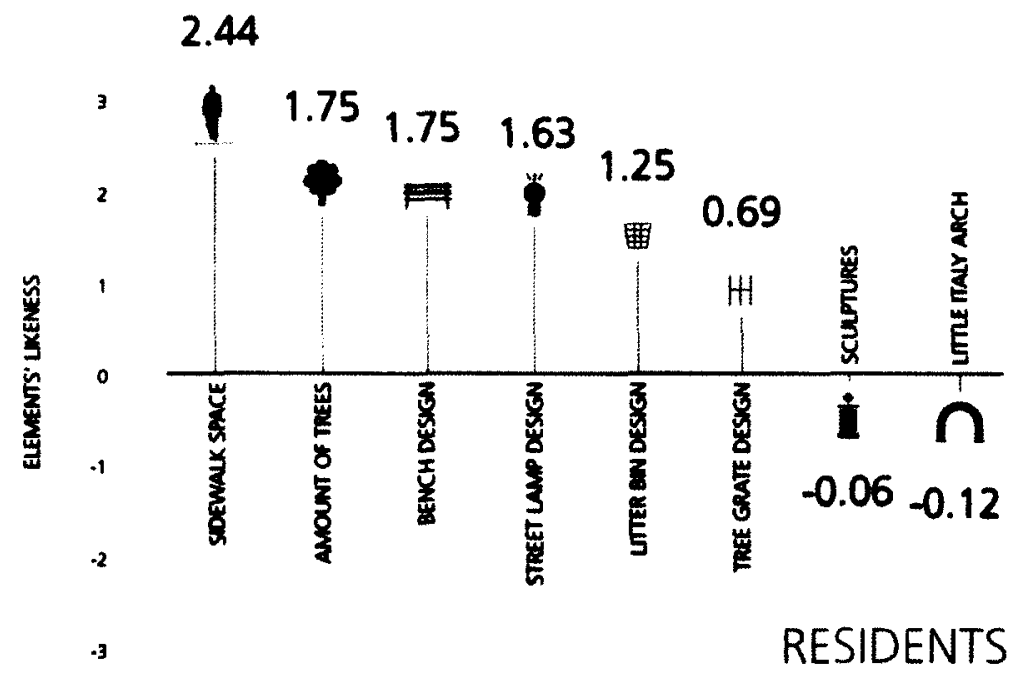

Residents' elements likeness 


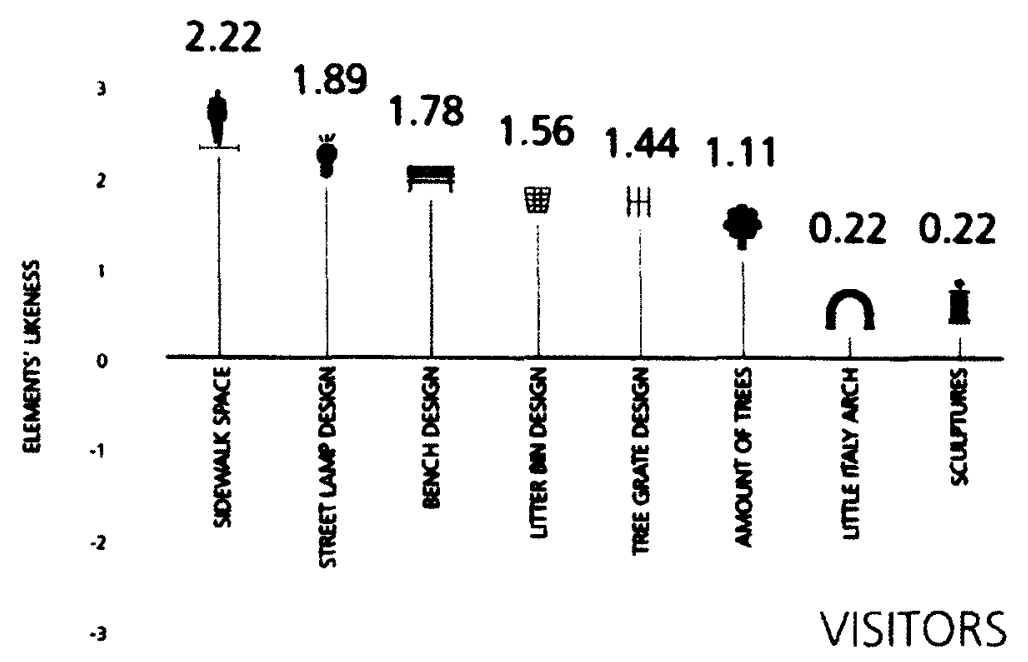

Visitors' elements likeness

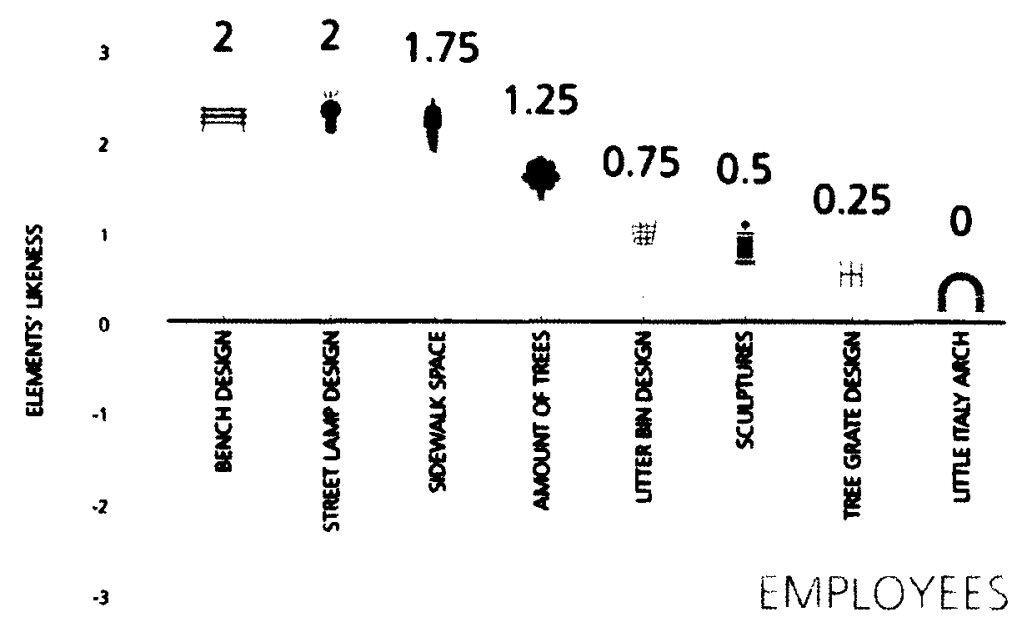

Employees' elements likeness

All elements received positive importance scores from respondents. The aspects considered to be the most important ones were the amount of trees, sidewalk space, and the design of litter bins and street lamps. The design of benches was judged more important to visitors (2.11 out of 3) and employees (2.25 out of 3 ) than to residents (1 out of 3 ). Tree grates received, in general, a low score of importance. Albeit receiving low likeness score, the arch and sculptures are regarded as relevant elements by users. The Little Italy arch received scores of $1.25,1.33$, and 
1.75 out of 3 respectively from residents, visitors, and employees. The sculptures were rated by the same participants with scores of $1.06,1.56$, and 2 out of 3 .

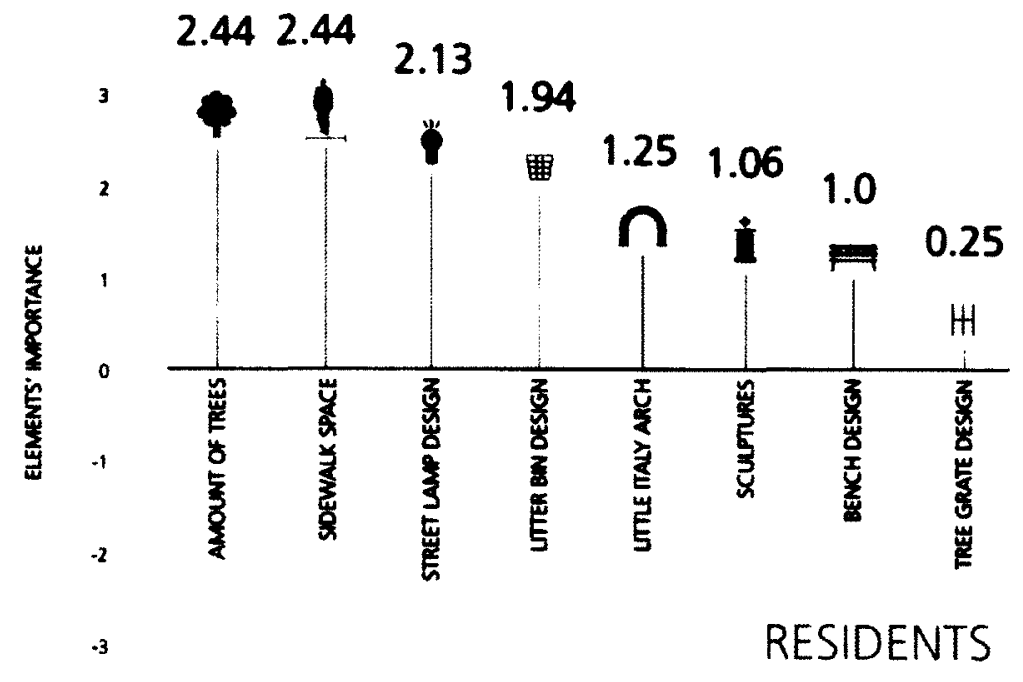

Residents' elements importance

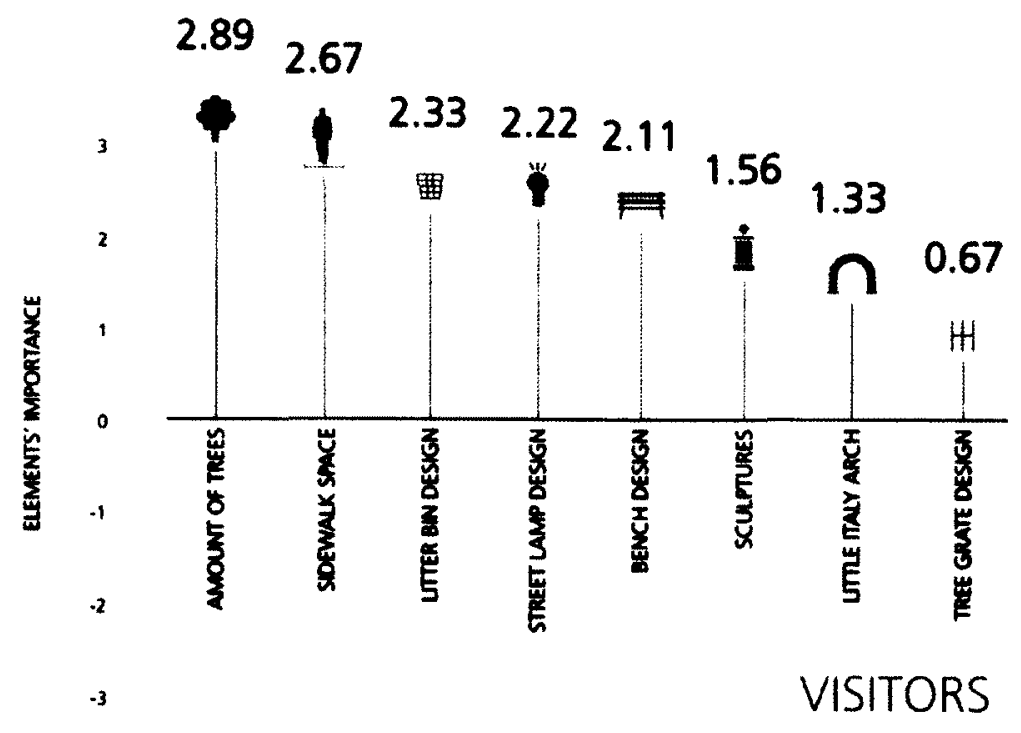

Visitors' elements importance 


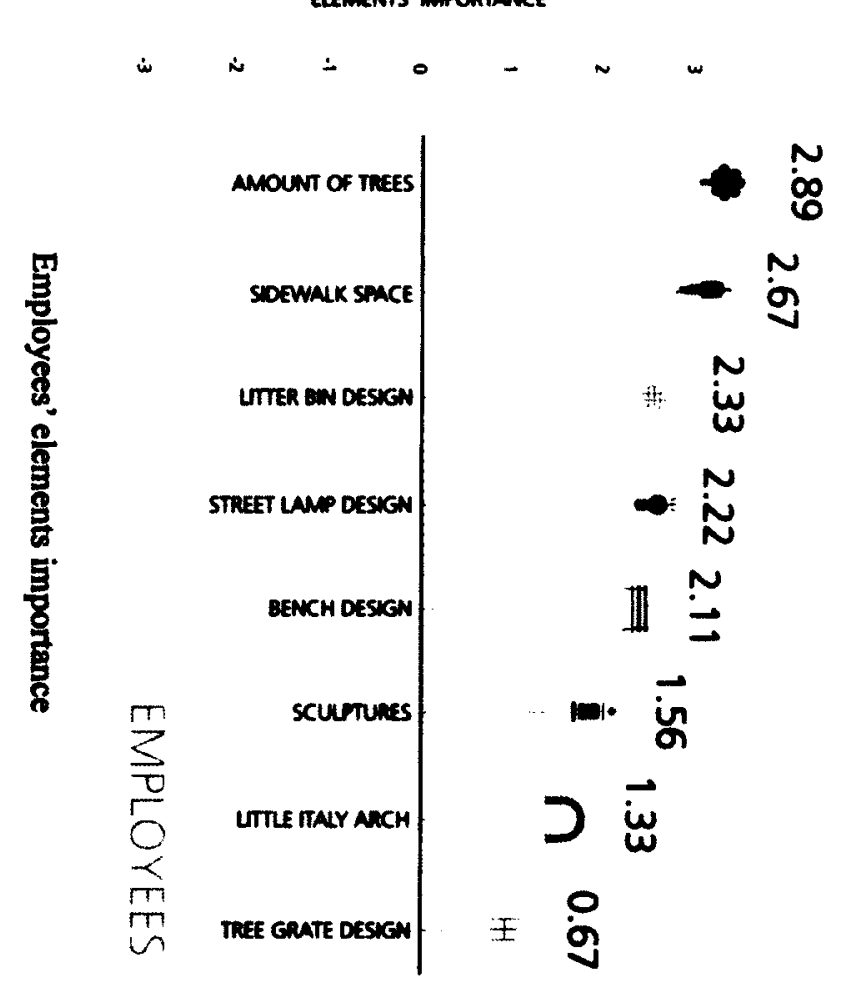

